\title{
LOFT THREE-BEAM DENSITOMETER DATA INTERPRETATION
}

\author{
GORDON D. LASSAHN
}

October 1977

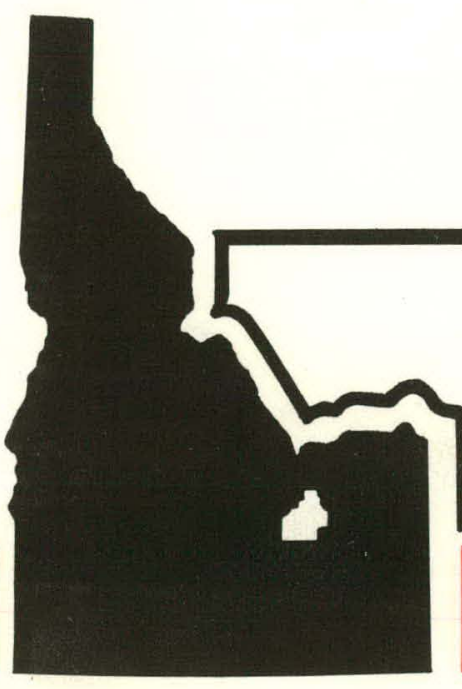

\section{$\prod_{>} E \boldsymbol{E} \Sigma \boldsymbol{G}$ Idaho, Inc.}

IDAHO NATIONAL ENGINEERING LABORATORY

\section{DEPARTMENT OF ENERGY}




\section{DISCLAIMER}

This report was prepared as an account of work sponsored by an agency of the United States Government. Neither the United States Government nor any agency Thereof, nor any of their employees, makes any warranty, express or implied, or assumes any legal liability or responsibility for the accuracy, completeness, or usefulness of any information, apparatus, product, or process disclosed, or represents that its use would not infringe privately owned rights. Reference herein to any specific commercial product, process, or service by trade name, trademark, manufacturer, or otherwise does not necessarily constitute or imply its endorsement, recommendation, or favoring by the United States Government or any agency thereof. The views and opinions of authors expressed herein do not necessarily state or reflect those of the United States Government or any agency thereof. 


\section{DISCLAIMER}

Portions of this document may be illegible in electronic image products. Images are produced from the best available original document. 
Printed in the United States of America

Available from

National Technical Information Service

U.S. Department of Commerce

5285 Port Royal Road

Springfield, Virginia 22161

Price: Printed Copy $\$ 6.00$; Microfiche $\$ 3.00$

"The NRC will make available data tapes and operational computer codes on research programs dealing with postulated loss-of-coolant accidents in light water reactors. Persons requesting this information must reimburse the NRC contractors for their expenses in preparing copies of the data tapes and the operational computer codes. Requests should be submitted to the Research Applications Branch, Office of Nuclear Regulatory Research, Nuclear Regulatory Commission, Washington, D.C. 20555."

\section{NOTICE}

This report was prepared as an account of work sponsored by the United States Government. Neither the the United States nor the Department of Energy, nor the Nuclear Regulatory Commission, nor any of their employees, nor any of their contractors, subcontractors, or their employees, makes any warranty, express or implied, or assumes any legal liability or responsibility for the accuracy, completeness or usefulness of any information, apparatus, product or process disclosed, or represents that its use would not infringe privately owned rights. 
LOFT THREE-BEAM DENSITOMETER DATA INTERPRETATION

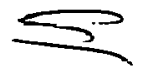

Approved:

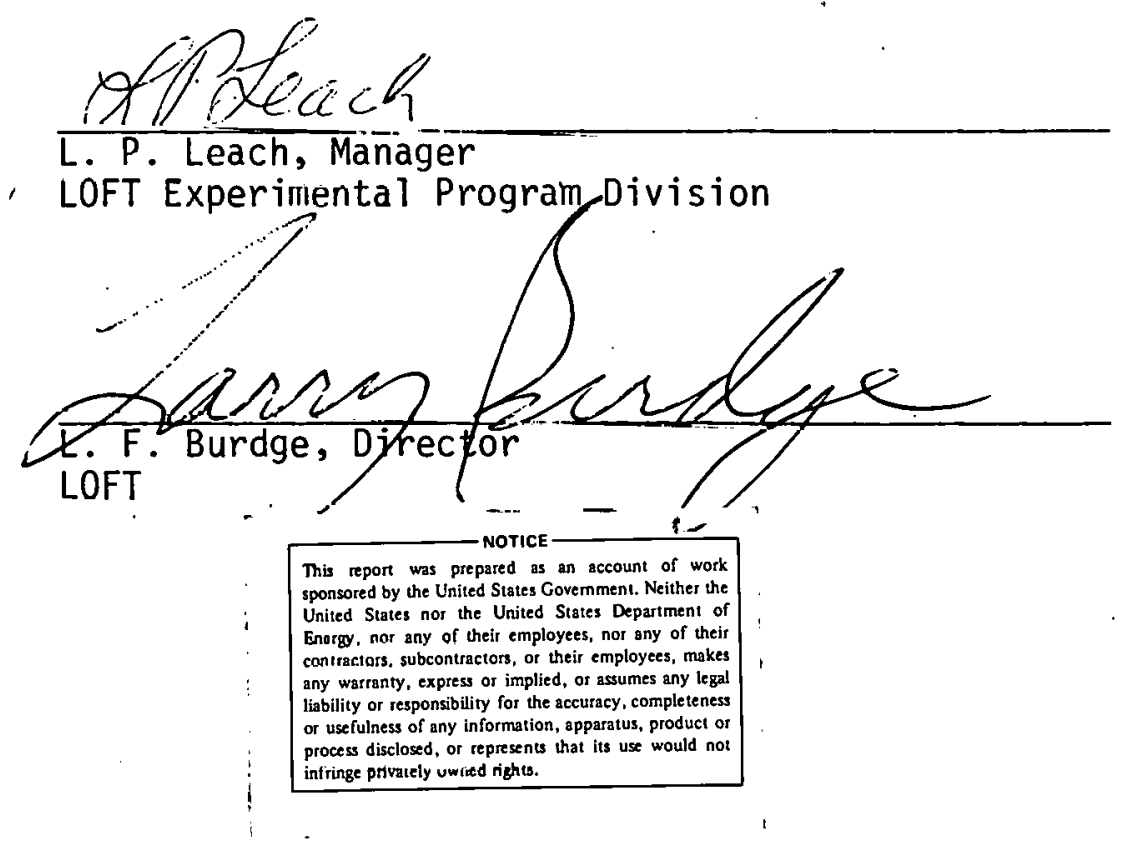

DISTRIBUTION OF THIS DOCUMENT IS UNLIMITED 
Gordon D. Lassahn

EG\&G Idaho, Inc.

October 1977

PREPARED FOR THE

U. S. NUCLEAR REGULATORY COMMISSION

AND

DEPARTMENT OF ENERGY IDAHO OPERATIONS OFFICE

UNDER CONTRACT NO. EY-76-C-07-1570 


\section{ACKNOWLEDGMENTS}

J. L. Miller's very efficient work in rearranging the computer program and running loss-of-fluid test (LOFT) data was indispensable. R. L. Crumley was very cooperative in making available his experimental data for testing purposes. He and others, notably L. D. Goodrich and S. A. Naff, contributed valuable discussion. J. E. Mullaney's programming expertise and his continuing work of finding functional approximations to simplify the program were also essential to this project. 


\title{
ABSTRACT
}

\begin{abstract}
A calculation procedure has been devised for estimating fluid density profiles from three chordal average density measurements in the LOFT densitometer system.
\end{abstract}


A calculation procedure has been devised to fit the best of several density distribution models, or a default model, to chordal average density measurements from the LOFT gamma densitometer to obtain an estimate of the density profile and the average density. The models used are homogeneous, continuous and discontinuous stratified, and continuous and discontinuous annular. The default model is a beam length welghted average for an estimate of the average density. A computer program for applying these calculations to LOFT test data has been written.

This procedure gives average density errors of about $0.02 \mathrm{~g} / \mathrm{cm}^{3}$ for data from wood/plastic simulations of regular, realistic density distributions; $0.06 \mathrm{~g} / \mathrm{cm}^{3}$ for data from wood/plastic simulations of irregular or unrealistic density distributions; and $0.01 \mathrm{~g} / \mathrm{cm}^{3}$ data from analytical simulations of regular, realistic density distributions. This is slightly better than the old data analysis scheme. The new scheme has the advantage of eslillaling quantftatively the density profile. For data from simulated, simple, realistir density distributions, the density profile estimates are generally quite accurate. 


\section{NOMENCLATURE}
A
Pipe cross section area
D
Depth of lower region in Model SD; thickness of annulus in Model $A D$
$D^{\prime}$
Parameter similar to annulus thickness in Model ADPC
$d_{1 i}$ and $d_{2 i}$
$x$ coordinates of the points where the pipe wall
intersects the lower and the upper ends of the ith beam
$\mathbf{F}$
A parameter, related to chordal average densities in annular models
$\overline{\mathbf{F}}$
A parameter related to average densities in annular mode 15
$L_{i}$
Chord length for the ith beam
$\mathbf{R}$
Pipe radius
$r$
Radial coordinate
$\vec{r}$
Position vector
$\mathbf{s}_{\mathbf{i}}$
Perpendicular distance from ith beam to pipe center
$x$
Vertical coordinate; $x=0$ at pipe bottom
y
Horizontal coordinate; $y=0$ at pipe center
$\varepsilon$
Error allowance used in stratification test
$\rho(\vec{r})$
Density distribution from mode]
$\bar{\rho}$
Average density calculated from model
$\hat{\rho}_{i}$
Chordal average density for ith beam calculated from model
$\rho_{\mathbf{i}}$
Measured chordal average density for ith beam
$\rho_{b}$
Density for large negative $x$ in stratified models
$\rho_{t}$
Density for large positive $x$ in stratified models
$\rho_{g}$
Gas density
$P_{\ell}$
Liquid density 


$\begin{array}{ll}\rho_{a} & \text { Annulus density in simple annular models } \\ \rho_{c} & \text { Core density in simple annular models } \\ \rho_{0} & \text { Density at } r=0 \text { in Model ARN } \\ \rho_{1} & \text { Density ar } r=R \text { in Model ARN } \\ \sigma & \text { Root mean square error } \\ \sigma_{\text {hmax }} & \text { Good fit criterion parameter } \\ \sigma_{b / \max } & \text { Acceptable fit criterion parameter }\end{array}$


ACKNOWLEDGMENTS . . . . . . . . . . . . . . . . . . . . .

ABSTRACT. . . . . . . . . . . . . . . . . . . . $i j i$

SUMMARY . . . . . . . . . . . . . . . . . . . . . iv

NOMENCLATURE . . . . . . . . . . . . . . . . . . . . . . v v

I. INTRODUCTION . . . . . . . . . . . . . . . . . . 1

II. STATEMENT OF PROBLEM . . . . . . . . . . . . . . . . . . . 2

III. APPROACH TO PROBLEM SOLUTION . . . . . . . . . . . . . . . . . 4

IV. MODELS. USED. . . . . . . . . . . . . . . . . ... 6

1. Homogeneous Model................. 6

2. Stratified Models................ 8

2.1. Model SFX.................... . 9

2.2. Model SD ..................... 13

3. Annular Models............... 15

3.1. Model ARN . . . . . . . . . . . . . . . 18

3.2. Model ADPC . . . . . . . . . . . . . . . . . 21

4. Default Procedure .. . . . . . . . . . . . 28

V. OVERALL CALCULATION FLOW. . . . . . . . . . . . . . 30

VI. SAMPLE CALCULATIONS ......................... 31

VII. CONTINUING WORK ...................... . . 40

VIII.CONCLUSIONS . . . . . . . . . . . . . . . . 4 41

IX. REFERENCES. . . . . . . . . . . . . . . . . . . . . 42

APPENDIX A: COMPUTER PROGRAM. . . . . . . . . . . . . 43

TABLE

I. ERROR SUMMARY FOR SAMPLE CALCULATIONS . . . . . . . . . . . 39 


\section{FIGURES}

1. Actual densitometer geometry. . ... . . . . . . . . . . 3

2. Simplified densitometer geometry used in models . . . . . . . . 7

3. Continuous stratified distribution function for Model SFX . . 10

4. Calculation flow diagram for Model SFX. . . . . . . . . . . . 14

5. Calculation flow diagram for Model SD . . . . . . . . . 16

6. Density profiles for Model ARN . . . . . . . . . . . . . 19

7. $F_{n}$ versus $n$ for Model ARN. . . . . . . . . . . . . . . 20

8. Calculation flow diagram for Model ARN . . . . . . . . . 22

9. $F_{D}$ versus $R / D$ for Model $A D$. . . . . . . . . . . . . . . . 24

10. Relationships between Models ARN, AD, and ADPC . . . . . . 25

17. Calculation flow diagram for Model ADPC. . . . . . . . . 27

12. Overall calculation flow diagram . . . . . . . . . . . 31

13. Actual and calculated density profiles, stratified symmetry. . 35

14. Actual and calculated density profiles, stratified and near-stratified symmetry . . . . . . . . . . . . . 36

15. Actual and calculated density profiles, annular symmetry . . . 37

16. Actual and calculated density profiles, annular and near-annular symmetry . . . . . . . . . . . . . . . 38 


\section{INTRODUCTION}

The Loss-of-Fluid Test (LOFT) system is a small pressurized water nuclear reactor designed for doing loss-of-coolant experiments; the facility and the experiment program have been described in several reports $[1-3]$. One of the primary goals in these experiments is the verification of analytical models used to analyze power reactors during accidents. In order to do this, measurement of coolant mass and energy flow through the primary coolant system during both the blowdown and the reflood parts of a loss-of-coolant experiment are required. In this connection, it is desirable to know the fluid (coolant) density profile and the density averaged across the pipe cross section at several locations in the primary coolant system. An indication of flow regime will also be useful for verification of some of the more advanced analytical models currently under development. Fluid density measurements are currently made with a three-beam gamma densitometer, which (in principle, at least) gives the average fluid density along each of three chords crossing the pipe. The errors in these chordal average density measurements have been analyzed and are described in a separate report [4], which also gives a more complete description of the densitomet.er than is given here. The problem addressed here is extrapolating from these three chordal average densities to estimate the density profile for the entire pipe cross section. 


\section{STATEMENT OF PROBLEM}

It is desirable during a loss-of-coolant experiment to know the liquid density, $\rho(\vec{r})$, at every point, $\vec{r}$, in certain pipe cross sections, and the average liquid density,

$$
\bar{\rho}=\frac{1}{A} \iint \rho(\vec{r}) \mathrm{dA}
$$

where $A$ is the cross-sectional area of the pipe. Since there are no means to directly measure these liquid densities, a method had to be. devised to estimate the densities using the following known variables:

(1) The three chordal average density readings $\left(\rho_{i}, i=1,2,3\right)$ from the three-beam gamma densitometers.

(2) The liquid density, $\rho_{\ell}$, and the gas density, $\rho_{g}$, determined from temperature and pressure measurements and steam tables.

(3) The densitometer geometry, which is illustrated in Figure 1 for the four installations on the horizontal pipe sections. The same assembly is also installed on one short, vertical pipe section, so that the heams $l i s$ in a horizontal planc. 


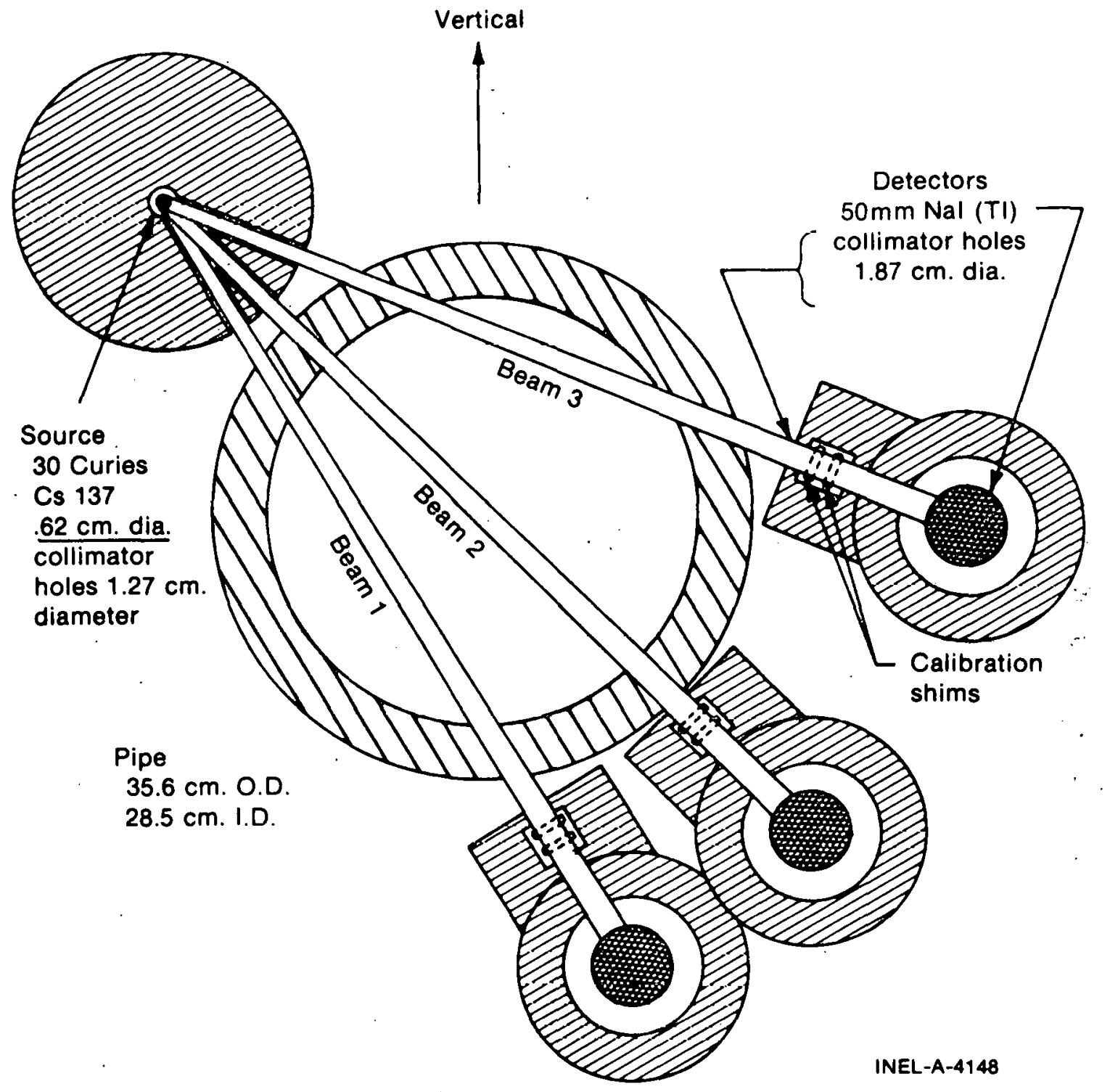

Fig. 1 Actual densitometer geometry. 


\section{APPROACH TO PROBLEM SOLUTION}

The knowledge of the three chordal average densities does not uniquely specify the density at every point in the pipe cross section. The only way to extrapolate from the three chordal averages to the entire pipe is to make some assumption about the general nature of the density profile. That is, one must assume that the density conforms to a model which represents some regular (stable, reproducible, and rather simple) density profile, such as homoqeneous, stratified, or annular. Therefore, the approach used here is to try to fit the chordal average density readings with each of several models and to choose the bestfitting, most plausible model as the best available estimate of the density profile.

Perhaps the most critical and the most subjective part of this analysis procedure is choosing the fluid density profile models and assigning priorities to them. Several criteria are used for selecting models:

(1) The model must be realistic or physically plausible. There must be some mechanism that can produce the density distributions described by the model.

(2) The model should be mathematically tractable. There must be a reasonably simple, programmable process for determining the model parameter values that give the best fit of the model to the data. This usually implies that the model can have no more than three adjustable parameters; in some cases it is impossible to solve for three or even two parameters. The acceptable degree of mathematical complexity in a model usually depends on how valuable the model is according to the first criterion.

(3) Each model should include an indication of how well the model fits the given data (the measured chordal average densities). 
Otherwise, there is no way of choosing which model should be used as the estimate of the density profile. This criterion gives a lower priority to those models which exactly fit any given data.

(4) The models should not overlap. Two (or more) models should not be used which have equal priorities and give equally good fits to the same data, except perhaps for very restricted sets of data which constitute the boundary between sets of data represented by different models. Again, the problem with violating this criterion is deciding which of two different, but equally good, models should be used to represent the data in the overlap region. 
The models used in this work actually represent a simplified form of the densitometer geometry, in which the beam width is assumed to be negligible. The simplified geometry used in the analysis is indicated in Figure 2.

The goodness of fit parameter used in these models is

$$
\sigma-\left[\frac{1}{3} \sum_{i=1}^{3}\left(\rho_{i}-\rho_{i}\right)^{j}\right]^{1 / 2}
$$

where

$$
\begin{aligned}
\rho_{i} & =\text { the measured chordal average density for the } i \text { th beam } \\
\hat{\rho}_{i}= & \text { the chordal average density calculated from the model with the } \\
& \text { parameters optimized. }
\end{aligned}
$$

This quantity $\sigma$ is the root mean square ( $r$ s) difference between the model and the measurements, or the rms error of the model.

\section{HOMOGENEOUS MODEL}

The simplest density profile is, of course, the homogeneous distribution, in which the density is a constant independent of position in the pipe. This is the most natural form to expect. in the ahsence of significant external forces acting on the fluid. Therefore, it seems appropriate to use Model HOMO, in which

$$
\rho(\vec{r})=\bar{\rho}
$$




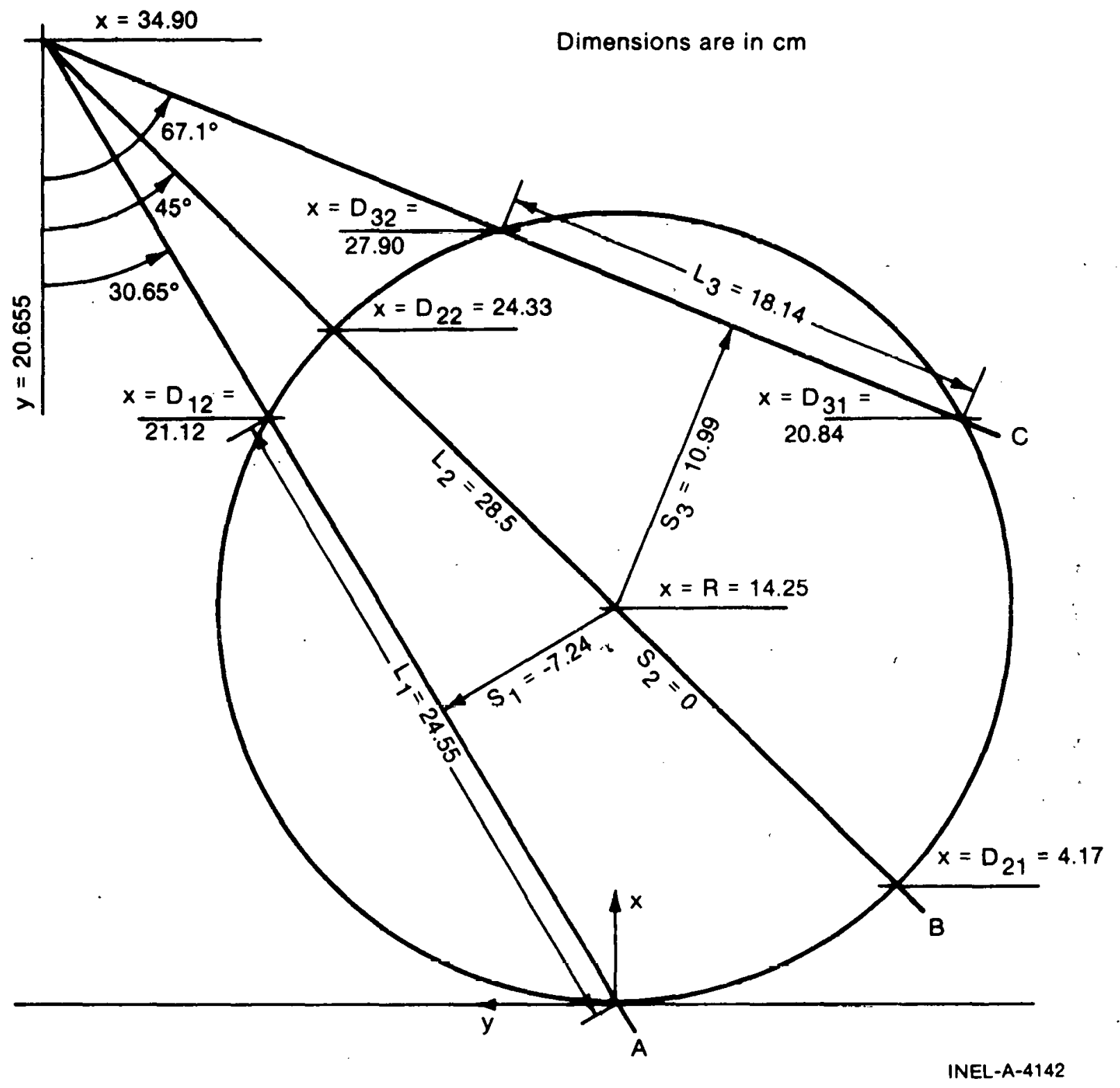

Fig. 2 Simplified densitometer geometry used in models. 
where $\bar{\rho}$, the average density, is the one adjustable parameter in the mode1: The best fit of this model to given data is

$$
\bar{\rho}=\left(\rho_{1}+\rho_{2}+\rho_{3}\right) / 3
$$

and, of course,

$$
\hat{\rho}_{i}=\bar{\rho} \text { for } i=1,2,3 \text { : }
$$

\section{STRATIFIED MODELS}

If the density distribution is influenced primarily by gravity (in a horizontal pipe), some stratified distribution should result. In this discussion, "stratified" is used to describe any density distribution in which the density is a monotonic function of the vertical coordinate $x$ only. From this definition there follows a simple relationship which is useful for determining whether data might represent a stratified distribution:

$$
\hat{\rho}_{1} \geq \hat{\rho}_{2} \geq \hat{\rho}_{3}
$$

for normal stratification, in which the higher density fluid is at the bottom of the pipe: The inequalities are reversed for inverse stratification, which seems to be very unrealistic.

For any stratified model, the calculated chordal average density is the same as the calculated density averaged along the vertical distance spanned by the beam:

$$
\hat{f}=\frac{1}{d_{2 i}-d_{1 i}} \int_{d_{1 j}}^{d_{21}} \rho(\vec{r}) d x
$$


where

$$
\begin{aligned}
d_{2 i} \text { and } d_{1 i}= & \text { the } \times \text { values where the pipe wall intersects the ith } \\
& \text { beam (note figure } 2) \\
\rho(\vec{r}) \quad & \text { the density profile predicted by the model, which } \\
& \text { can be written as a function of } x \text { alone. }
\end{aligned}
$$

Two stratified models considered are SFX and SD.

\subsection{MODEL SFX}

The density distribution, when smoothed over individual bubbles and short time intervals (gamma densitometers automatically effect such smoothing), should be a continuous and smooth function unless the fluid flow velocity is very low. The function (rather arbitrarily) chosen to represent such a distribution is

$$
\rho(\vec{r})=\rho_{\ell}-\frac{\rho_{\ell}-\rho_{g}}{1+\exp (-4 a[x-b])}
$$

where

$$
\begin{aligned}
& a \text { and } b=\text { the two adjustable parameters } \\
& \rho_{g} \text { and } \rho_{\ell}=\text { the gas and liquid densities. }
\end{aligned}
$$

This function is smooth, monotonic, and bounded. Its general form is indicated in Figure 3. Although this function has the potential for representing a very sharp (large a) transition from the $\rho=\rho_{\ell}$ to the $\rho=\rho_{g}$ region, the calculated transition range has always been at least $2 \mathrm{~cm}$ when Model SFX has been applied to simulated data representing a sharp step in the density curve. This is because this particular densitometer cannot distinguish between (that is, it gives the same readings for) the sharp step and the smoother transition from liquid to gas in a stratified distribution. 


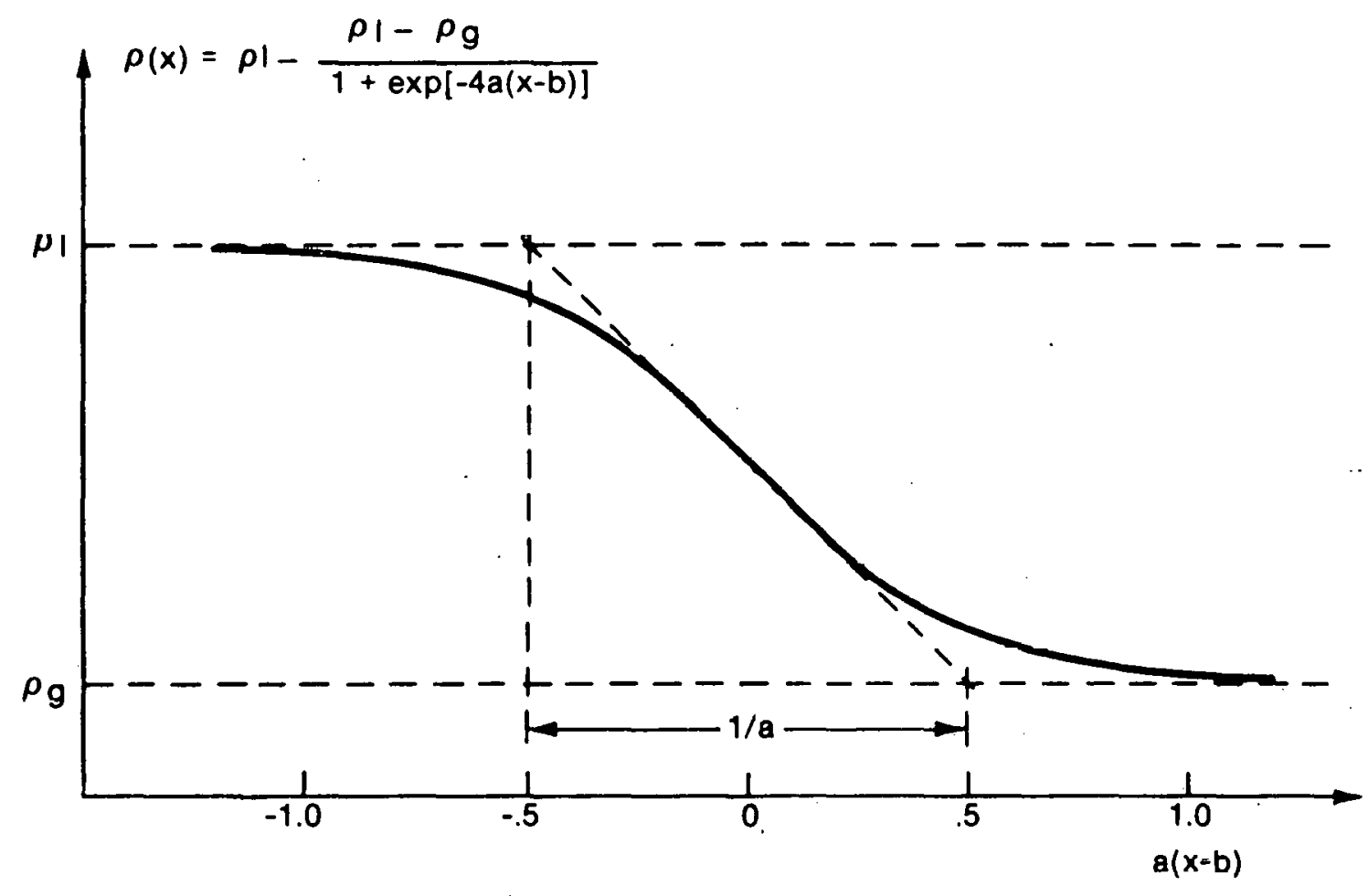

INEL-A-4139

Fig. 3 Continuous stratified distribution function for Model SFX. 
By direct integration, Equations (7) and (8) give

$$
\hat{\rho}_{i}=\rho_{g}+\frac{\rho_{\ell}-\rho_{g}}{4 a\left(d_{2 i}-d_{1 j}\right)} \ln \frac{f_{2 i}}{f_{1 j}}
$$

where

$$
f_{j i}=\frac{1}{1+\exp \left(-4 a\left[d_{j i}-b\right]\right)}
$$

As for all the models, this model is fit to the given data (the chordal average density readings) by adjusting the parameters to minimize the rms error $\sigma$ as defined in Equation (2). For Model SFX, this procedure is a problem of least squares fitting of a function which is not linear in the adjustable parameters.

In applying the non-linear least squares fitting procedure, an initial estimate of the parameter values is needed. For Model SFX, this initial estimate is obtained by first fitting the data with a linear function of $x$ and then matching the functional values and the slopes of the linear function and Equation (8) at $x=R$ (the pipe center). The linear function can be written as

$$
g(x)=\beta+\alpha(x-R)
$$

with $\alpha$ and $\beta$ adjustable. Fitting this linear function is a relatively easy example of a linear least squares fitting procedure. The calculated chordal average densities given by Equation (11) are

$$
\hat{\rho}_{i}=\beta+\alpha\left(1 / 2\left[d_{2 i}+d_{1 j}\right]-R\right) \text {. }
$$


After the values of $\alpha$ and $\beta$ are determined by the linear least squares fitting procedure, the functional values and the derivatives are equated at $x=R$ :

$$
\beta=\rho_{\ell}-\frac{\rho_{\ell}-\rho_{g}}{1+\exp (-4 a[R-b])}
$$

and

$$
\left.\alpha=\frac{-4 a_{0}\left(\rho_{\ell}-\rho_{g}\right)}{\left\{\exp \left(2 a_{0}\left[R-h_{0}\right]\right)+1 / \rho \times p\left(2 a_{u}\left[R-h_{U}\right]\right)\right.}\right\}^{2}
$$

These can be solved for $a_{0}$ and $b_{0}$, the initial estimates of the optimum $a$ and $b$ values:

$$
a_{0}=\frac{-\alpha}{4\left(\rho_{\ell}-\rho_{g}\right)}\left[\sqrt{\frac{\rho_{\ell}-\beta}{\beta-\rho_{g}}}+\sqrt{\frac{\beta-\rho_{g}}{\rho_{\ell}-\beta}}\right]^{2}
$$

and

$$
b_{0}=R+\frac{1}{4 a_{0}} \ln \left[\frac{\beta-\rho_{g}}{\rho_{\ell}-\beta}\right] .
$$

With these initial values, the iteration procedure is bcgun to determine the optimum values of the parameters $a$ and $b$. It is noted that the system of linear equations to be solved in this procedure usualiy becomes indeterminate as the parameter values approach the optimum value, usually after about seven iterations. Therefore, a test. for this indeterminacy should be used as a criterion (nnt the nnly criterion) for stopping the iteration procedure. After the iteration procedure is stopped, a check on the value of $\sigma$ can be used to determine whether the procedure has converged to an acceptable solution; this procedure does not always converge.

If this procedure does converge and give optimum (or near optimum) values for the parameters $a$ and $b$, the average fluid density $\bar{p}$ is calculated by a simple numerical integration. Acceptable accuracy can be obtained by dividing the $x$ range into as few as 15 intervals. 
Figure 4 shows a calculation flow diagram for Model SFX. Some examples of results from this model will be discussed later.

The calculation procedure for this model is rather long. However, this long procedure is felt to be justified because of the great intuitive appeal of this model.

\subsection{MODEL SD}

Because there are certain stratified density distributions that Model SFX can not be expected to describe, and because Model SFX does not always converge properly when it should, a second stratified model, Model SD, is used. This model is described by

$$
\rho(\vec{r})=\left\{\begin{array}{l}
\rho_{b} \text { for } x<D \\
\rho_{t} \text { for } x>D
\end{array}\right.
$$

where $\rho_{b}, \rho_{t}$, and $D$ are adjustable parameters. The calculated chordal average densities are

$$
\hat{\rho}_{i}= \begin{cases}\rho_{t} & \text { for } D<d_{1 i} \\ \frac{D-d_{1 i}}{d_{2 i}-d_{1 i}}\left(\rho_{b}-\rho_{t}\right)+\rho_{t} & \text { for } d_{1 i}<D<d_{2 i} \\ \rho_{b} & \text { for } d_{2 i}<D\end{cases}
$$

It is convenient to divide the total $D$ range $[0,28.5]$ into five smaller ranges:
(1) Range 1:
$0 \leq D \leq 4.17$
(2) Range 2:
$04.17 \leq D \leq 20.98$
(3) Range 3:
$20.98 \leq D \leq 24.33$
(4) Range 4:
$24.33 \leq D \leq 27.90$
(5) Range 5:
$27.90 \leq D \leq 28.50$

In each of these ranges, the $\hat{\rho}_{i}$ are linear functions of $D$.

If $D$ is in Range 5 , the $\hat{\rho}_{j}$ are all equal to $\rho_{b}$ and the density profile is indistinguishable from a homogeneous profile. Therefore, 


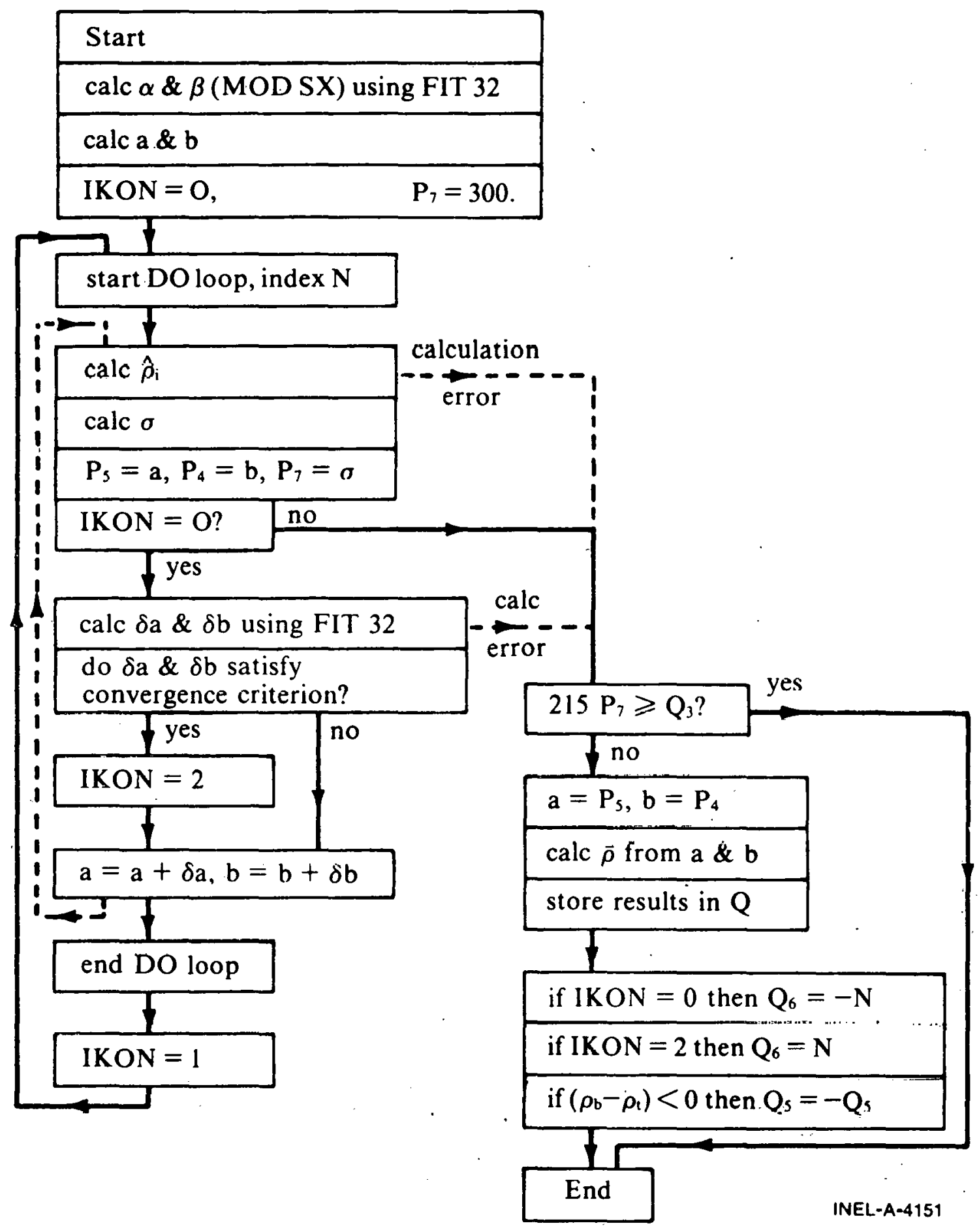

Fig. 4 Calculation flow diagram for Model SFX. 
Range 5 is no longer considered; data that would fall into Range 5 are automatically handled by Model HOMO.

In Ranges 2 and 3, it is possible to solve exactly for all three parameters $D, \rho_{b}$, and $\rho_{t}$ (unless the data are degenerate; the degenerate data are handled by other models or other ranges of Model SD). However, the calculated values of the parameters may not be in the acceptable ranges. The values of $\rho_{b}$ and $\rho_{t}$ should be between $\rho_{g}$ and $\rho_{\ell}$, and the value of $D$ should be within the range represented by the equations used to calculate the parameter values. Therefore, each of these parameter values must be checked to see that it is in the allowable range. If one of the parameter's values is outside the allowable range, the value is reset to the value of the end of the acceptable range closest to the originally calculated value. Then the other parameter values are recalculated to minimize $\sigma$ with the value of the offending parameter held constant. The result of this general procedure is a rather complicated logic flow diagram as indicated in Figure 5.

For $D$ in Range 1 , it is not possible to solve for $D$ and $\rho_{b}$ independently. The procedure used is to set $\rho_{b}$ equal to $\rho_{\ell}$ (or to $\rho_{g}$, if inverse stratified flow is indicated) and then solve for $D$ and $\rho_{t}$. Similarly, in Range $4 \rho_{t}=\rho_{g}$ (or $\rho_{t}=\rho_{\ell}$ ) is used to solve for $D$ and $\rho_{b}$. If certain preliminary logic tests (to be discussed later) are used, the calculated values of the parameters for Ranges 1 and 4 will always be within the acceptable ranges.

\section{ANNULAR MODELS}

If there is a lot of heat transfer between the pipe wall and the two-phase fluid, or if there are other significant interactions, such as adhesion between the fluid and the pipe, the expectation is that the fluid density might depend on the radial coordinate $r$. Unless there is a great deal of turbulence or a long section of pipe upstream from the densitometer, the effects of the pipe-fluid interaction would be 


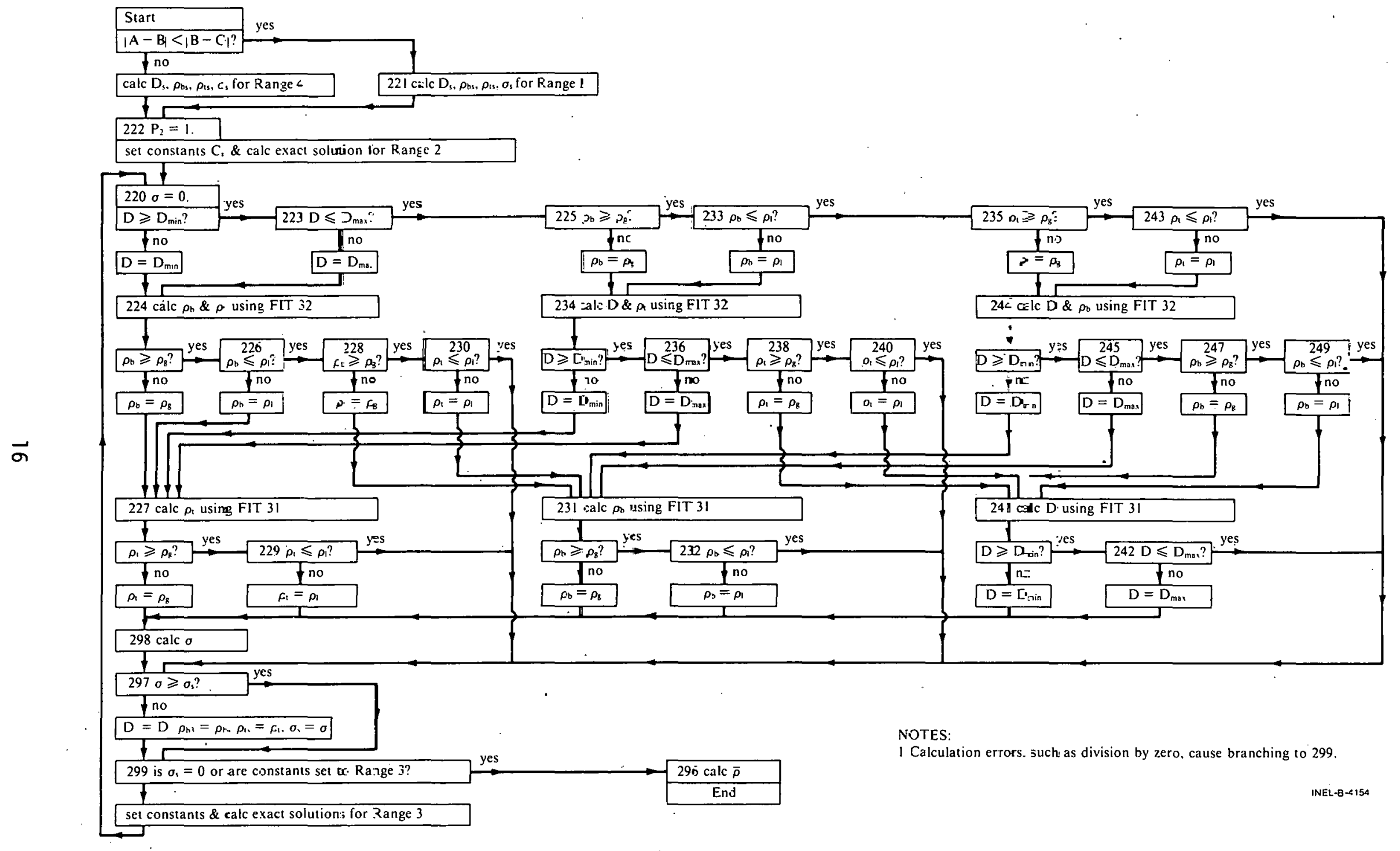

Fig. 5 Calculation flow diagram for Model SD. 
confined to that fluid close to the pipe; that is, the density profile should be nearly flat except for $r \approx R$. This suggests consideration of annular density models with primary attention to thin annulus cases.

In this discussion, an annular density distribution is one in which the density is a monotonic function of $r$ only. This definition implies

$$
\hat{\rho}_{3} \geq \hat{\rho}_{1} \geq \hat{\rho}_{2}
$$

for normal annular distributions (higher densities at the pipe wall), or

$$
\hat{\rho}_{3} \leq \hat{\rho}_{1} \leq \hat{\rho}_{2}
$$

for inverse annular distributions.

For any annular model, the chordal average densities can be written as

$$
\hat{\rho}_{i}=\frac{2}{L_{i}} \int_{S_{i}}^{R} \frac{r \rho(r)}{\sqrt{r^{2}-s_{i}^{2}}} d r
$$

or

$$
\hat{\rho}=\frac{1}{i \sqrt{1-u_{i}^{2}}} \int_{u_{i}}^{l} \frac{w \rho(R w)}{\frac{w^{2}-u_{i}^{2}}{2}} d w
$$

where

$$
\begin{aligned}
\rho(r)= & \begin{array}{l}
\text { the density written as a function of the radial } \\
\text { coordinate } r
\end{array} \\
= & \begin{array}{l}
\text { the perpendicular distance from the beam to the pipe } \\
\text { axis }
\end{array} \\
s_{i}=2 \sqrt{R^{2}-s_{i}^{2}}= & \text { the beam chord length and } \\
u_{i}= & s_{i} / R .
\end{aligned}
$$

Two annular models, Models $A R N$ and $A D P C$, are used. 


\subsection{MODEL ARN}

A fairly simple model which gives smooth density profiles is

$$
\rho(\vec{r})=\rho_{0}+\left(\rho_{1}-\rho_{0}\right)(r / R)^{n}
$$

where $\rho_{0}, \rho_{1}$, and $n$ are adjustable parameters with $n>1$. As Figure 6 indicates, larger values of $n$ give thinner annulus profiles. This model gives

$$
\bar{\rho}=\rho_{0}+2\left(\rho_{1}-\rho_{0}\right) /(n+2)
$$

and

$$
\hat{\rho}_{i}=\rho_{0}+\left(\rho_{1}-\rho_{0}\right) F_{n i}
$$

where

$$
\begin{aligned}
F_{n i}=\frac{2}{L_{i}} \int_{0}^{L_{i} / 2}\left[\frac{1}{R} \sqrt{S_{i}^{2}+L^{2}}\right]^{n} d L & \text { (26) } \\
s_{i}= & \text { the perpendicular distance from the } i \text { th beam to the pipe } \\
& \text { center } \\
L & =\text { a coordinate along the beam } \\
L_{i} & =\text { the length of the } i \text { th beam in the pipe. }
\end{aligned}
$$

This integral can be evaluated numerically or, if $n$ is an even integer, by summing an integrated binomial expansion. For beam $2, S=0$ and $F_{n 2}=1 /(n+1)$. Some valucs of the $F_{n i}$ are graphed in Figure 7 .

It is difficult to fit Equation (23) to given data with all three parameters adjustable, because the equations become indeterminate for large $n$ and a simple functional approximation for $F_{n i}$ for small $n$ has not been found. Therefore, $n$ is not used as an adjustable parameter in the usual sense; the problem is approached in the following manner: For $n>4$, the $\hat{\rho}_{i}$ are close to those arising from a simple annular distribution $\left(\rho=\rho_{0}\right.$ for $r<R-D, \rho=\rho_{1}$ for $\left.r>R-D\right)$ - with $D / R=1 / n$. Model ADPC, to be discussed later, is a composite that 


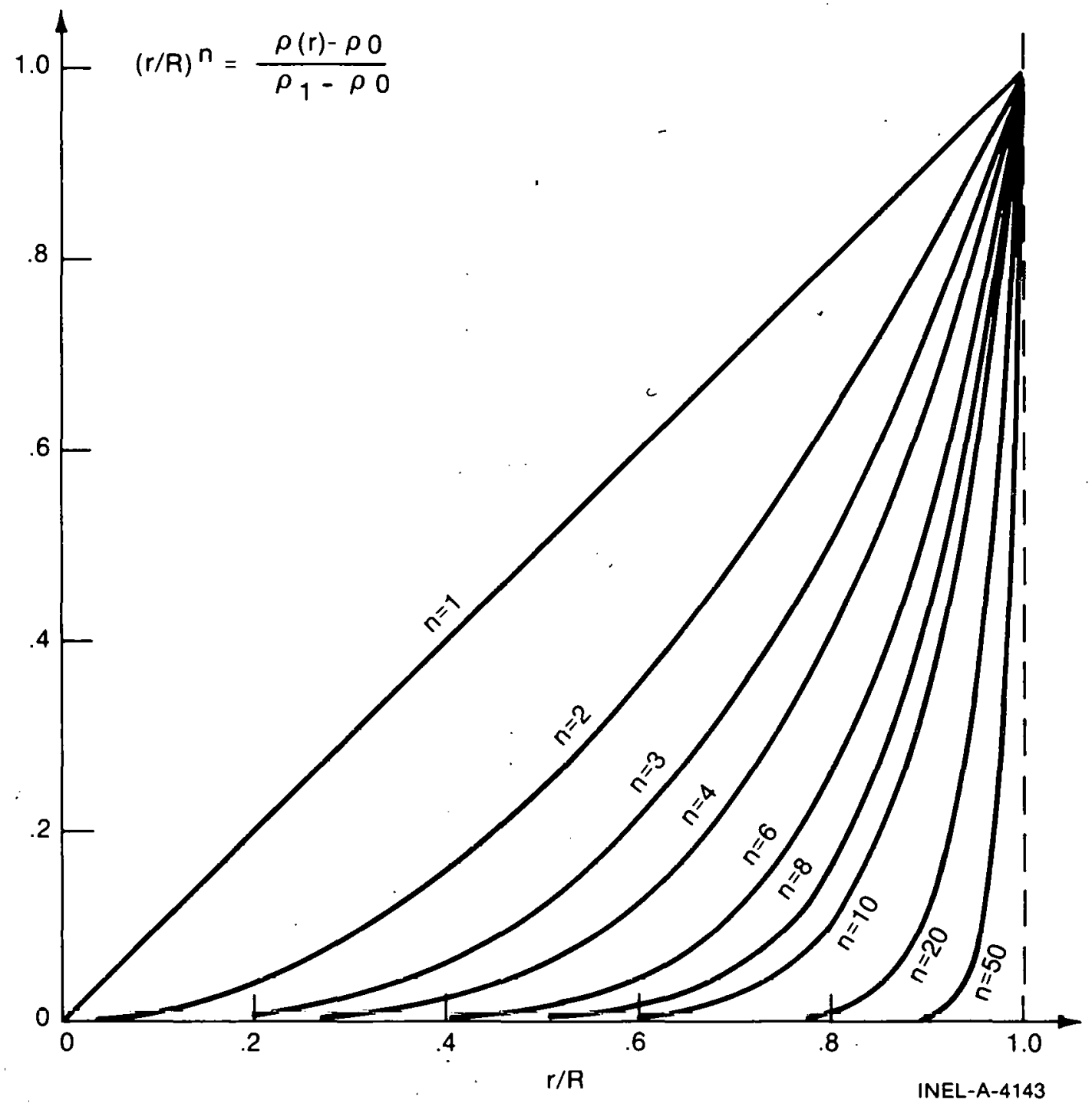

Fig. 6 Density profiles for Model ARN. 


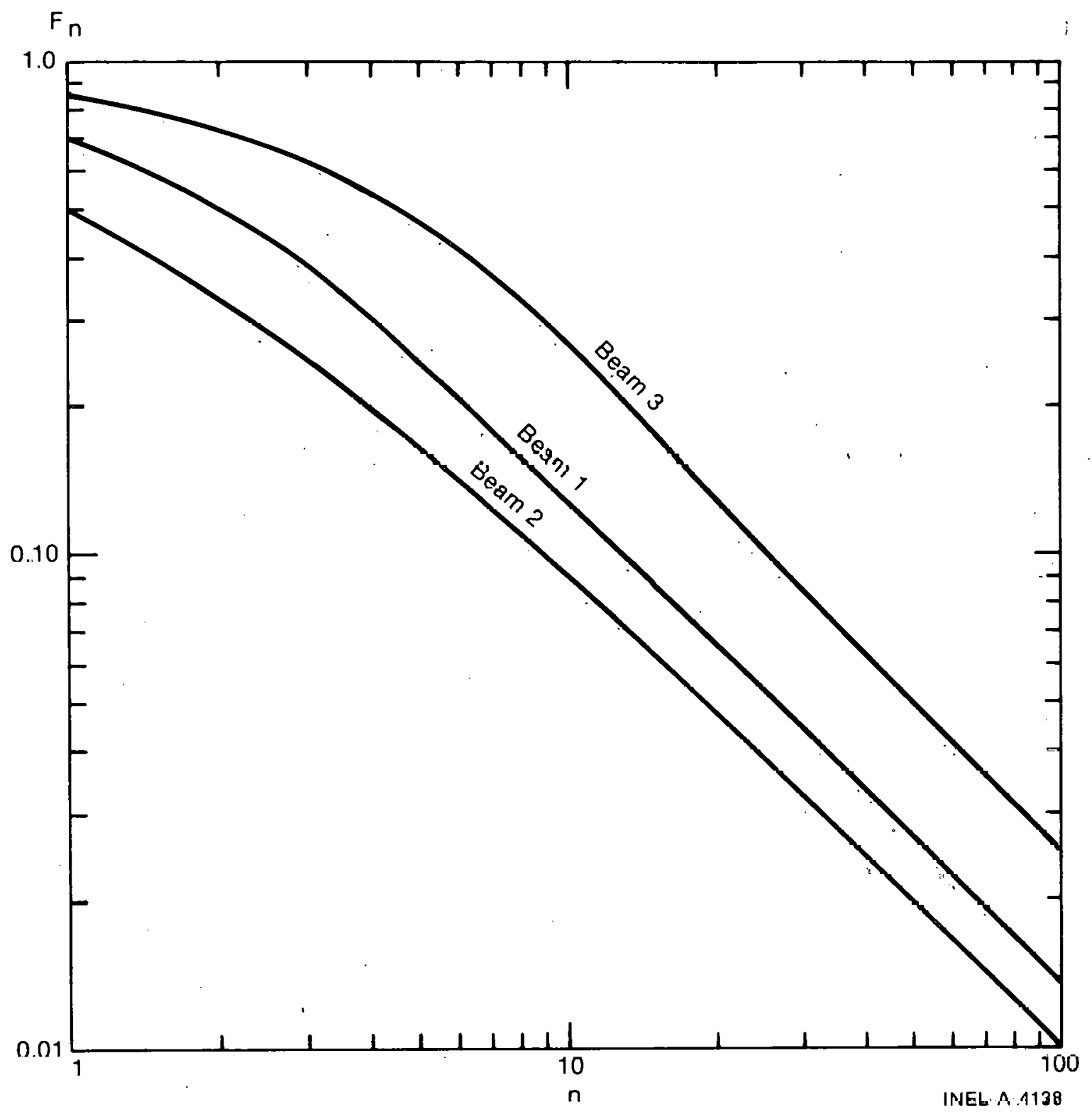

Fig. $7 F_{n}$ versus $n$ for Model ARN. 
handles both Model ARN for $n>4$ and the simple annular distribution for small $D / R$.

For $n<4$, Model ADPC is not adequate. In this range, the values of $\rho_{0}$ and $\rho_{1}$ are optimized for each of several fixed values of $n$. The value of $n$ for which the smallest $\sigma$ value is obtained is taken as the (most nearly) optimum value of $n$. Of course, in many cases this procedure will indicate an optimum $n$ value of 4 when, in fact, the real optimum value is greater than 4. In these cases, the overall program logic (to be discussed later) will automatically use the result of Model ADPC to represent the data.

Thus, Model ARN will give a nearly optimum fit of Equation (23) with $n$ between 1 and 4 . The calculation flow diagram for these calculations is indicated in Figure 8. Note that this includes checks and corrections for values of $\rho_{0}$ and $\rho_{1}$ that are outside the allowable range.

\subsection{MODEL ADPC}

Discontinuous annular models have been commonly discussed, because of their apparent simplicity. One such model is Model ADC, in which .

$$
\rho(\vec{r})=\left\{\begin{array}{l}
\rho_{c} \text { for } r<R-D \\
\rho_{a} \text { for } r>R-D
\end{array}\right.
$$

where $\rho_{c}$ and $D$ are the two adjustable parameters, and $\rho_{a}$ is determined by a preliminary logic test to be either $\rho_{\ell}$ or $\rho_{g}$. This model is surprisingly difficult to use, because of the nonlinearity of the dependence of the $\hat{\rho}_{i}$ on $D$ : 


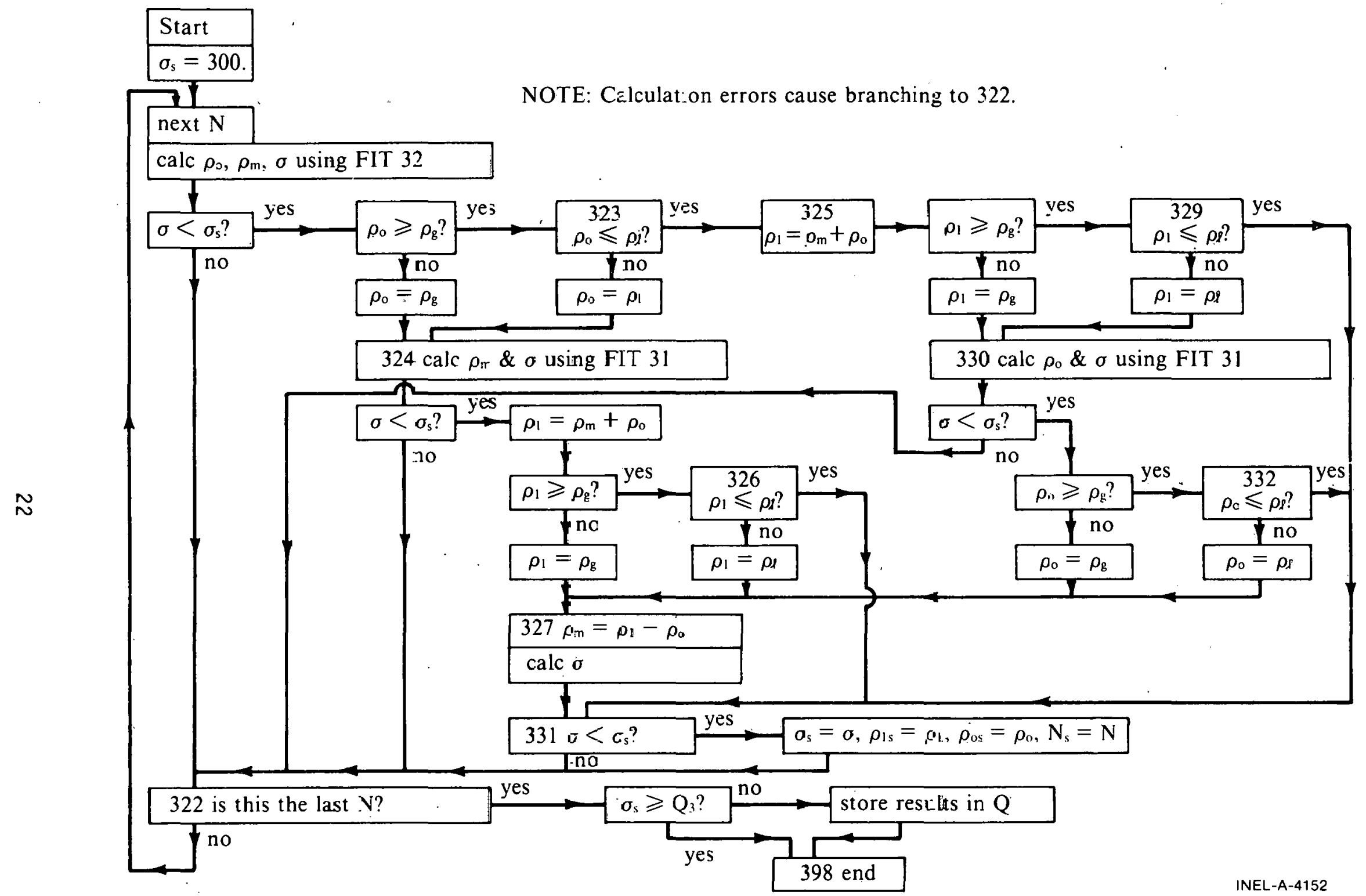

Fig. 8 Calculation flow diagram for Model ARN. 


$$
\hat{\rho}_{i}=\rho_{c}+\left(\rho_{a}-\rho_{c}\right) F_{D i}
$$

where

$$
F_{D i}=\sqrt{1-4 D(2 R-D) / L_{i}^{2}}
$$

Figure 9 shows graphs of $F_{D i}$ versus $R / D$; these were plotted in this manner to illustrate the similarity between $F_{D i}$ and $F_{n i}$ with $n=R / D$ for large $n$ or small D/R. This similarity suggests using an intermediate model to represent both Model ARN for large $n$ and Model ADC for small $D$. Such an intermediate model might best be thought of as an approximation to both Models $A R N$ and $A D C$, or it could be regarded as an entirely separate model which is so close to the other two that there is no reason to use more than one of the three models.

The intermediate model used is Model ADPC, in which $\rho(\vec{r})$ is not specified precisely. It is only said that $\rho=\rho_{\ell}$ (or $\rho=\rho_{g}$ ) for $r$ near: $R, \rho=\rho_{C}$ for small $r$, and the transition between the two regions takes place near $r=R-D^{\prime} . \quad D^{\prime}$ is one of the adjustable parameters of the model, which is intuitively, but not formally, the thickness of a thin annulus (a requirement is $D^{\prime} / R<0.25$ ) and, of course, $\rho_{C}$ is the second parameter of Model ADPC. This model is formally defined by

$$
\hat{\rho}_{i}=\rho_{c}+\left(\rho_{a}-\rho_{c}\right) 4 R D^{\prime} / L_{i}^{2}
$$

and

$$
\bar{\rho}=\rho_{c}+\left(\rho_{a}-\rho_{c}\right)\left[2\left(\frac{D^{\prime}}{R}\right)-4\left(\frac{D^{\prime}}{R}\right)^{2}+8.5\left(\frac{D^{\prime}}{R}\right)^{3}\right] .
$$

Model ADPC gives an estimate of $\bar{\rho}$, but it does not give enough information about $\rho(\vec{r})$ to allow for detailed mass flow rate calculations. For such calculations, it is necessary to revert to some other model, like Models ARN or ADC. Some useful relationships between these two and Model ADPC are indicated in Figure 10. In constructing these relationships, it was assumed that $\rho_{0}$ and $\rho_{1}$ of Model ARN and $\rho_{C}$ and $\rho_{a}$ of Model ADC are equal to $\rho_{c}$ and $\rho_{a}$ of Model ADPC. $n_{e q}$ and $D_{\text {eq }}$ 


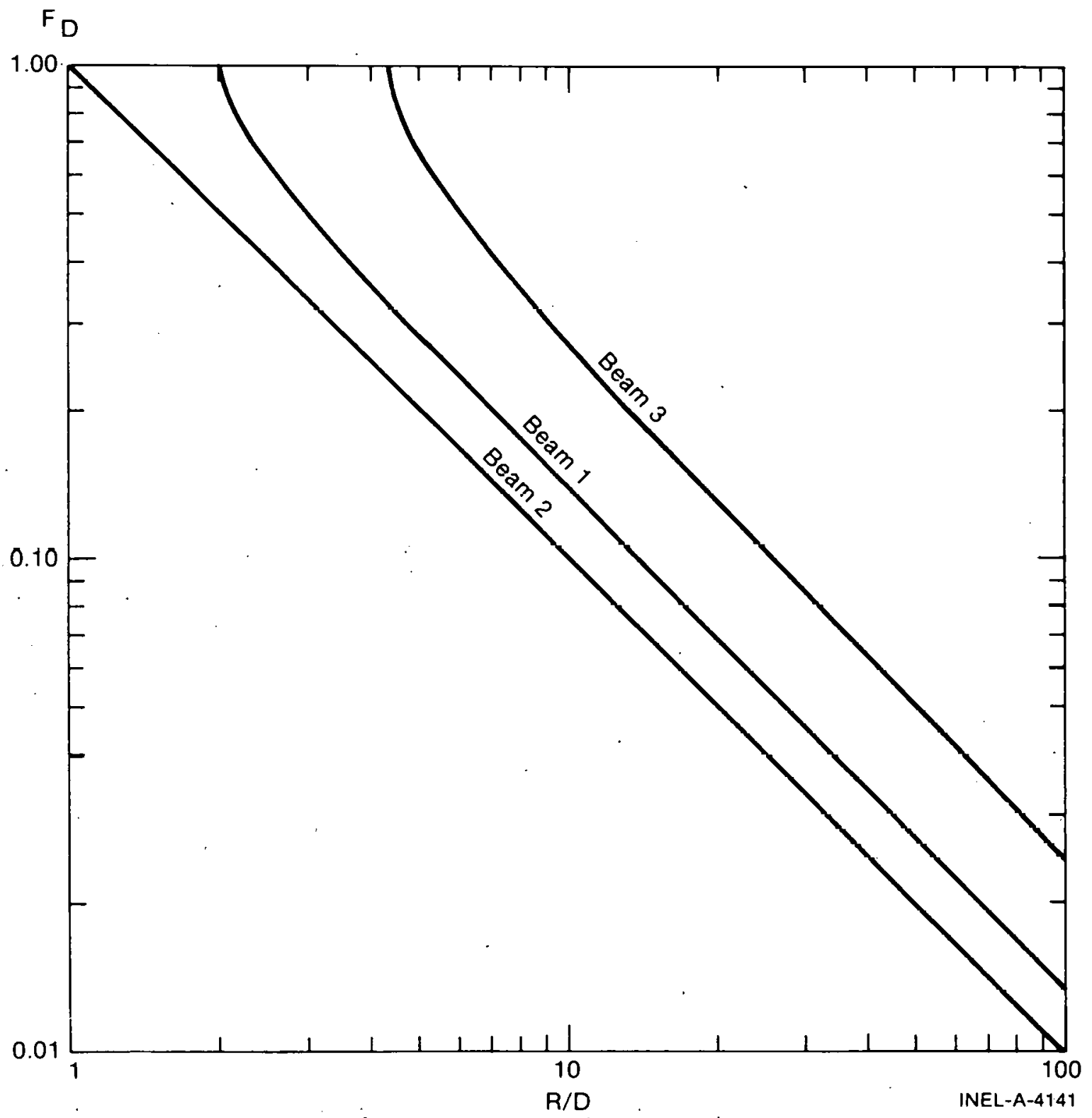

Fig. $9 F_{D}$ versus $R / D$ for Model $A D$.

24 


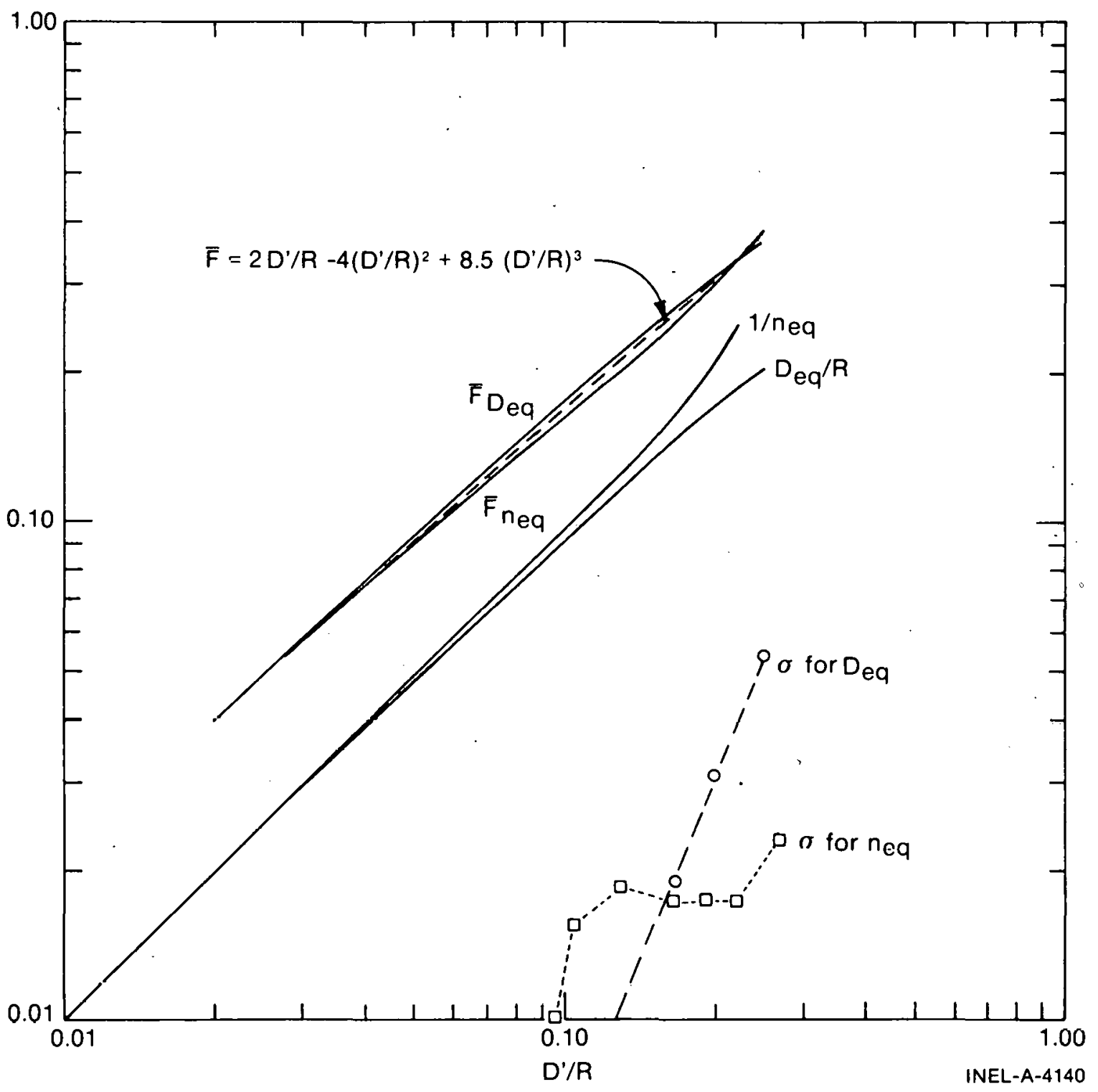

Fig. 10 Relationships between Models ARN, AD, and ADPC. 
are the values of $n$ and $D$ which give the best fits of Models $A R N$ and $A D C$ to data which exactly fit Model ADPC. These values are plotted in the form $1 / n_{\text {eq }}$ and $D e q / R$ versus $D / R$ in Figure. 10; the corresponding values of $\sigma$ are also plotted to indicate the degree of similarity between the models. A third quantity plotted for each model is $F$ defined by

$$
\bar{\rho}=\rho_{c}+\left(\rho_{a}-\rho_{c}\right) \bar{F} \text { or } \bar{\rho}=\rho_{0}+\left(\rho_{1}-\rho_{0}\right) \bar{F} \text {. }
$$

The curve labeled $F_{\text {neq }}$ is the $F$ quantity from Model ARN using the $n_{\text {eq }}$ value: $F_{\text {neq }}=2 /\left(2+n_{e q}\right)$. Similarly, $F_{\text {Deq }}$ is from Model ADC using the Deq value; $F_{\text {Deq }} \Rightarrow(2 \cdot D / R) D / R$. rrom these plots, it is clear that $F$ (and hence the $\rho$ ) for Model ADPC lies generally between those for the other two models, with the difference being not more than about $0.01 \mathrm{~g} / \mathrm{cm}^{3}$. This difference, and also the $\sigma$ values, could probably be reduced by relieving the previously stated conditions on the equality of the density at $r=0$ and $r=R$ between the three models. (This condition is automatically relieved in Model ADPC.)

Thus, if one needs detailed $\rho(\vec{r})$ information, a reasonable procedure is to use Model ARN with $n$ equal to the $n_{e q}$ value obtained from Figure 10, or to use Model $A D C$ with $D$ equal to the $D$ eq value obtained from Figure 10. It would probably be possible to program this conversion or a better representation of Models ARN or ADC based on the Model ADPC result as a first estimate, but this effort does not seem justified at this time because only $\bar{p}$ and the general form of $\rho(\vec{r})$ are required.

Therefore, Model ADPC, as defined by Equations (30) and (31), is used to obtain a $\bar{\rho}$ estimate and a rough estimate of $\rho(\vec{r})$. The logic flow for this calculation is indicated in Figure $1 \%$ 


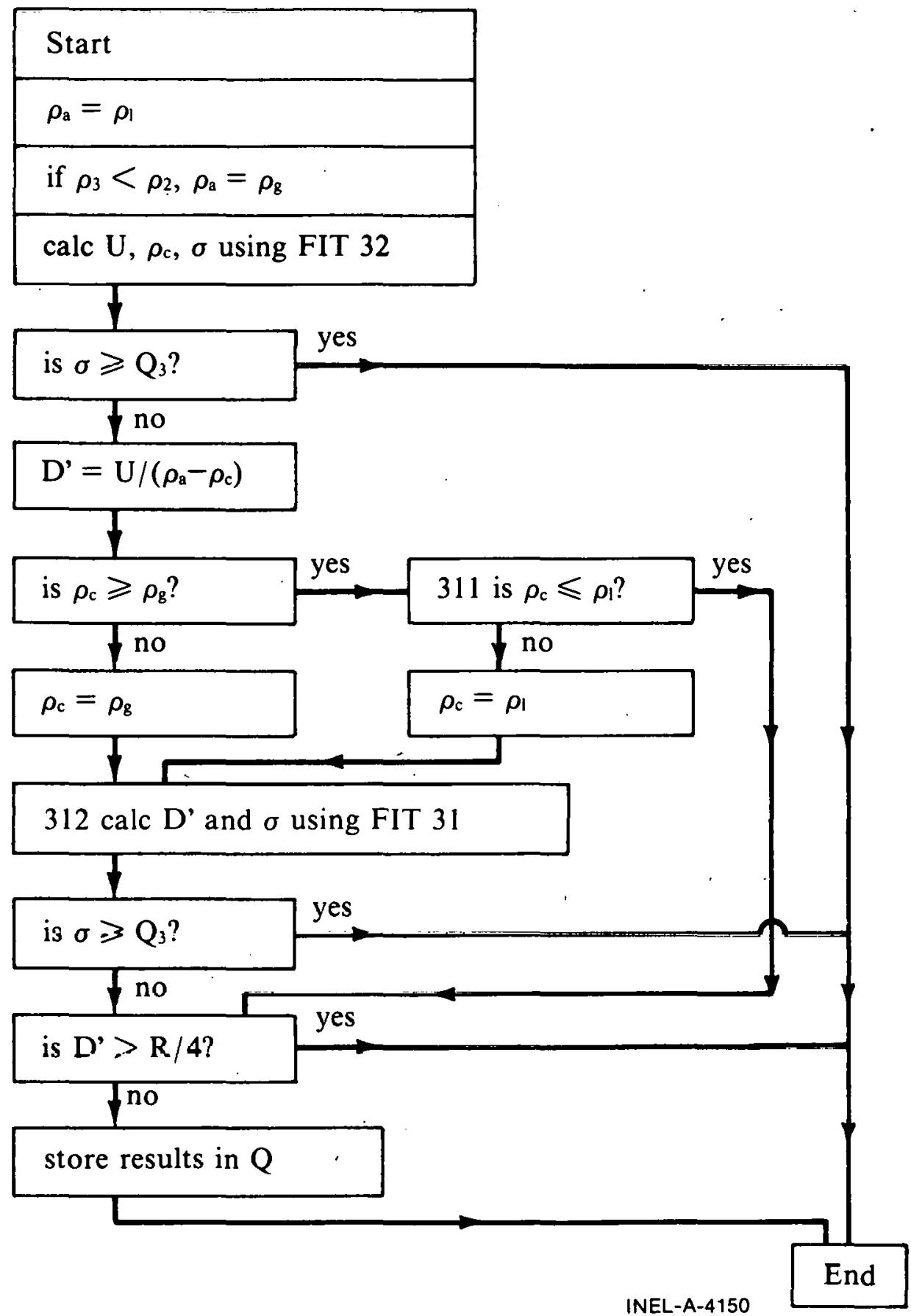

Fig. 11 Calculation flow diagram for Model ADPC. 


\section{DEFAULT PROCEDURE}

All stratified models and all annular models taken together cover only two-thirds of the data space; that is, at least one-third of all the possible data points are not represented by any of the foregoing models. Real data might fall into the unrepresented space either because of random fluctuations in the density profile (due to splashing) or because the density profile is some less common regular distribution that is not represented in the previously discussed models. To handle this otherwise unrepresented data, a default procedure is used which calculates the average density $\bar{\rho}$ as a weighted average of the chordal average density readings $\rho_{j}$ with the weighting factors proportional to the beam lengths. That is, it calculates

$$
\bar{\rho}=0.34485 \rho_{1}+0.40034 \rho_{2}+0.25481 \rho_{3} \text {. }
$$

This default procedure does not give any estimate of the density profile $\rho(\vec{r})$. This procedure will be referred to as "Model $B L$ ", even though it does not represent a density distribution model.

Other default procedures considered included a weighted average with weighting factors proportional to areas or volumes represented by the beams: There is some arbitrariness associated with the decision about what area should be associated with each beam. However, if the pipe cross section is divided into three areas by lines midway between adjacent beams, the resulting areas happen to be approximately proportional to the beam lengths, so that weighting factors proportional to these areas are nearly the same as those used in Equation (33).

Another default procedure that was considered was to fit the data with a function of the form

$$
\rho(\vec{r})=\bar{\rho}+a(x-R)+b y
$$


where $\bar{\rho}, a$, and $b$ are adjustable parameters. This represents an estimate of the average density and the first moments of the density in each of two perpendicular directions. However, there is some risk of attaching too much significance to the results of using this model; the density profile is not expected to resemble Equation (34), and this model should be so interpreted only with considerable caution. Also, this model always gives $\bar{\rho}=\rho_{2}$, which seems intuitively to be not as good an estimate of the actual average density as that obtained from Model BL. In preliminary tests with data representing known, common density distributions, Model $B L$ gave better estimates of the average density than did Equation (34). 


\section{OVERALL CALCULATION FLOW}

This section describes the logic flow of the overall $\rho(\vec{r})$ estimation procedure. A major factor in determining this logic is the partly subjective assignment of relative priorities or preferences for the various models. This and the objective criteria are discussed in the following paragraphs. Figure 12 should be helpful in following this discussion.

Since real data can have some error, it is possible that some of the chordal average density readings may not be between the liquid and gas density values obtained from the temperature and pressure readings. To maintain a more realistic condition and to prevent calculational difficulties, the value of $\rho_{\ell}$ is set in the program to be the greatest of the three $\rho_{j}$ or the liquid density obtained from the temperature and pressure measurements; and a similar procedure is used for $\rho_{g}$. It might be more reasonable to adjust the $\rho_{i}$ values instead of the $\rho_{\ell}$ or $\rho_{g}$ values; this is a rather arbitrary decision.

There are several reasons for trying Model HOMO before the other models. First, the most reasonable a priori guess at the density distribution is a homogeneous distribution. If this model gives a good fit to the data, this model is preferred to the others, even if other models may give a better fit. The "good fit" criterion used here is that $\sigma$ is not.greater than the typical rms noise level in the $\rho_{i}$ readings, which is taken to be about $0.02 \mathrm{~g} / \mathrm{cm}^{3}$ in this work. The second reason for trying Model HOMO first is that data which are very close to exactly homogeneous can cause the other models to diverge. Therefore, Model HOMO first is used to eliminate homogeneous data at the beginning of the procedure. (Near-homogeneous data which cause other models to diverge give Model HOMO $\sigma$ 's much smaller than the $0.02 \mathrm{~g} / \mathrm{cm}^{3}$ good fit criterion.) For these two reasons, if the o from Model HOMO is not greater than $0.02 \mathrm{~g} / \mathrm{cm}^{3}$ (denoted by $\sigma_{\text {HMAX }}$ in the flow chart), the results of Model HOMO are used as the estimate of $\rho(\vec{r})$. 


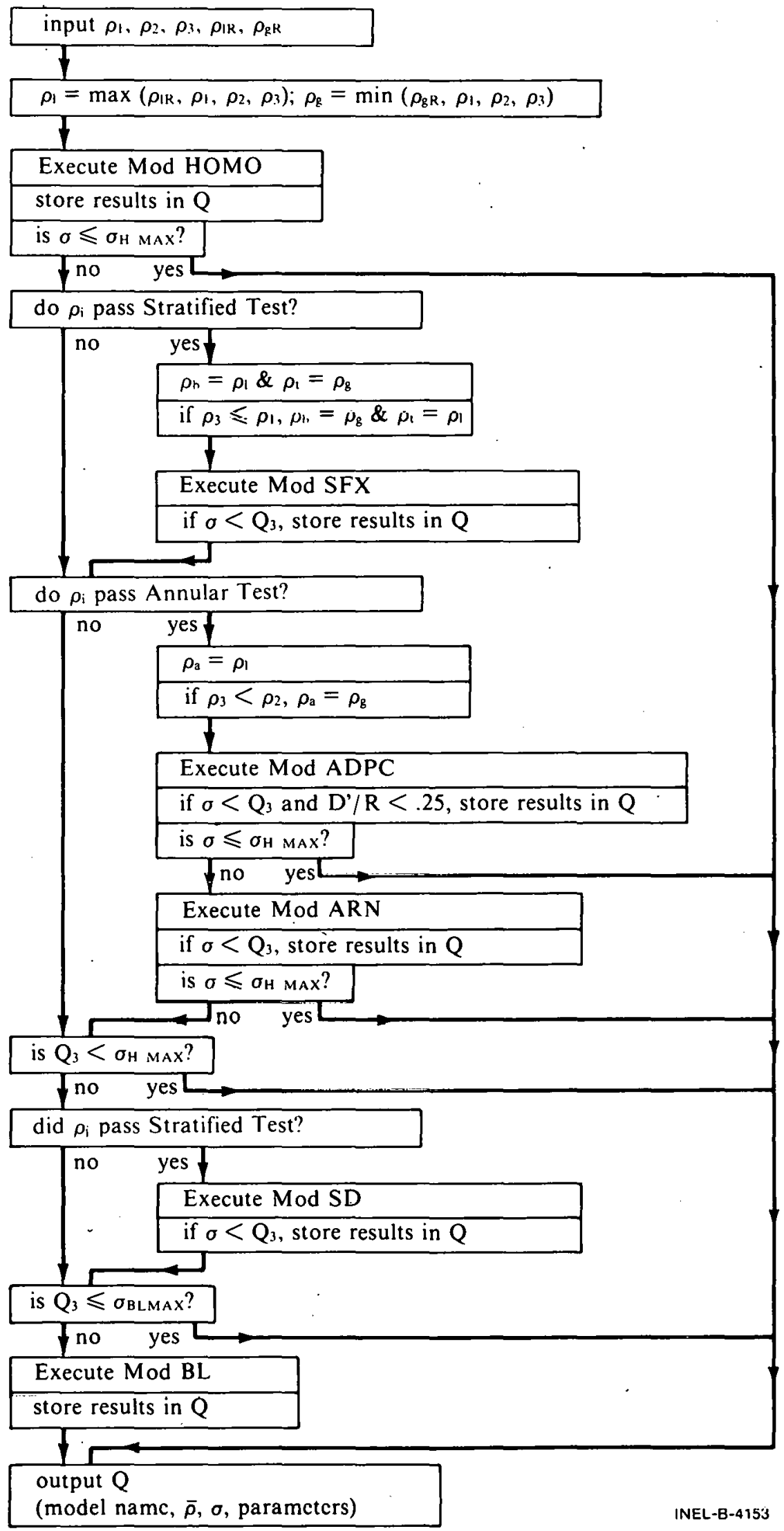

Fig. 12 Overall calculation flow diagram. 
If Model HOMO does not give a good fit, the next assumption is that the density distribution is stratified. This is supported by preliminary. studies of past LOFT data. Therefore, after Model HOMO is tried, a check is performed to see if the data satisfies the stratification criterion. The basic criterion expressed in Equation (6) is not acceptable for use with real data, because it does not allow" for noise or experimental error. The actual criterion used is

and

$$
\begin{aligned}
& \rho_{1}-\rho_{2}>-\varepsilon \\
& \rho_{2}-\rho_{3}>-\varepsilon .
\end{aligned}
$$

where $\varepsilon$ is a positive number" with magnitude comparable to uHAX. The calculations of Ranges 1 and. 4 of Model SD depend on having $\varepsilon<\sigma_{\text {HMAX }} \sqrt{3 / \dot{2}}$ to avold potentlal difflcullies uf pardmeler's being out of range. Therefore the stratification test uses $\varepsilon=1.2 \sigma_{\text {HMAX }}$ in Equation (35). Since both stratified models can handle inverse stratified data as well as normal stratified data, data points that satisfy

and

$$
\rho_{1}-\rho_{2}<\varepsilon
$$

$$
\rho_{2}-\rho_{3}<\varepsilon
$$

are also accepted as stratified data.

The first stratified model to be used is Model SFX, because this model has the previously discussed appeal of giving continuous distributions.

Even if Model SFX gives a good fit, Model ADPC is checked before deciding which model will be used to represent the density distribution. This is because some data will satisfy both the test for stratified data and that for annular data; and these data often fit. Model ADPC." considerably better than Model SFX with significantly different estimates of $\rho(\vec{r})$ and $\bar{\rho}$ resulting. 
While it is desirable to try the annular model before applying the good fit test to the Model SFX results, it is not desirable to apply Model SD before the good fit test on Model SFX. This is because Model SD will almost always give a better fit than Model SFX, but a good fit from Model SFX is preferred over a better fit from Model SD. Thus, after Model SFX is executed, Model SD is not tried until after the good fit test is applied, and the good fit test is not tried until after the Model ADPC is applied. Therefore, Model SD is used after the annular models, instead of in the more natural sequence immediately after Mode 1 SFX.

If none of the models before Model $\mathrm{BL}$ gives a good fit to the data, an "acceptable fit" test is done to determine whether the best fit obtained is usable. The acceptable fit criterion is rather arbitrarily chosen to be $\sigma=0.1 \mathrm{~g} / \mathrm{cm}^{3}$. Preliminary tests show that rms errors larger than this usually indicate that the model does not even give a qualitatively accurate description of the real density distribution or a good $\bar{\rho}$ estimate. Therefore, if the best model gives $\sigma>0.1 \mathrm{~g} / \mathrm{cm}^{3}$, the default calculation Mode $1 B L$ is used. This has been found to give reasonable $\bar{\rho}$ estimates, although it gives no other information about $\rho(\vec{r})$. 


\section{SAMPLE CALCULATIONS}

Appendix A contains a listing of a computer program. suitable for execution of the calculations described earlier in this report, along with a list of important variable names and.output from some. test data:

The first part of the test data represents actual measurements obtained with plastic or wood pieces simulating various fluid density. distributions in the pipe (unreported work by R. L. Crumley). For those tests which represented homogeneous, stratified, or annular distributions, and a few other distributions, graphs of the actual density profiles (dark lines) and the calculated density profiles (light 1ines) are sketched in Figures 13 through 16. The graphs are labeled with the Crumley labels, which also appear in the output listing in Appendix A. In these graphs, the calculated density profiles are labeled with the name of the model that was used to represent the data. In a few cases (such as Test A4), the model used was not of the proper symmetry to allow graphing on the same axes as the actual density profile.

Following the output from the Crumley data is the output from a set of synthetic data, in which the. "measured" chordal average densities. were actually calculated from an assumed density distribution. The computer program generally gave satisfactory results for this test data.

Table I summarizes the errors in the calculated average density. values for the old analysis scheme and for the new scheme presented in this report. The new scheme is slightly better for the regular density distributions, while the old scheme is silghtly better for irreguldr distributions; however, the differences are smaller than the measurement error for a single chordal average density. Thus, neither method has a significant advantage in the accuracy of the average density calculation. (a)though the old method has a considerable advantage in computer time and cost). The advantage of the new method is that it gives quantitative estimates of the density distributions. 

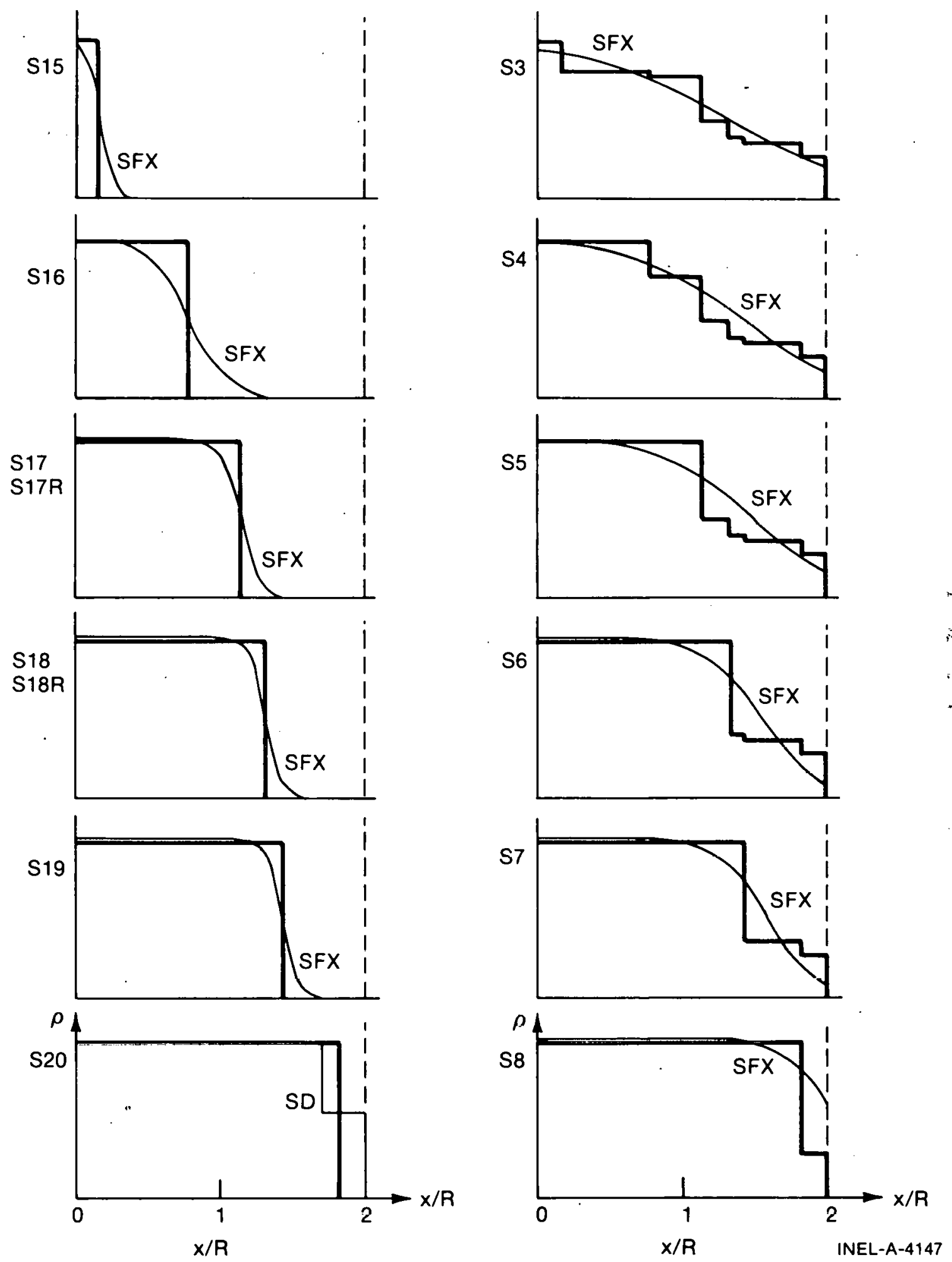

Fig. 13 Actual and calculated density profiles, stratified symmetry. 

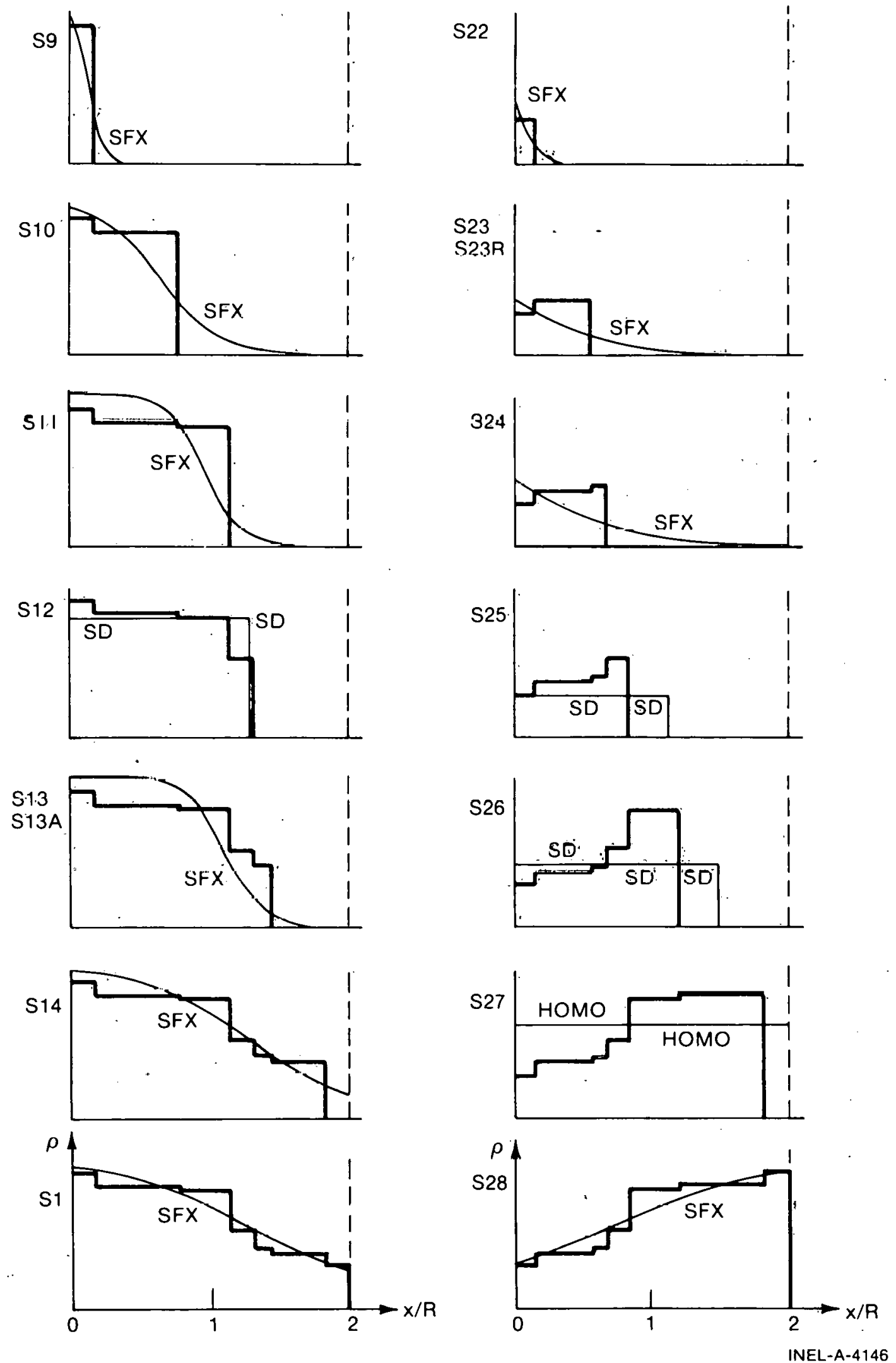

Fig. 14 Actual and calculated density profiles, stratified and near-stratified symmetry. 

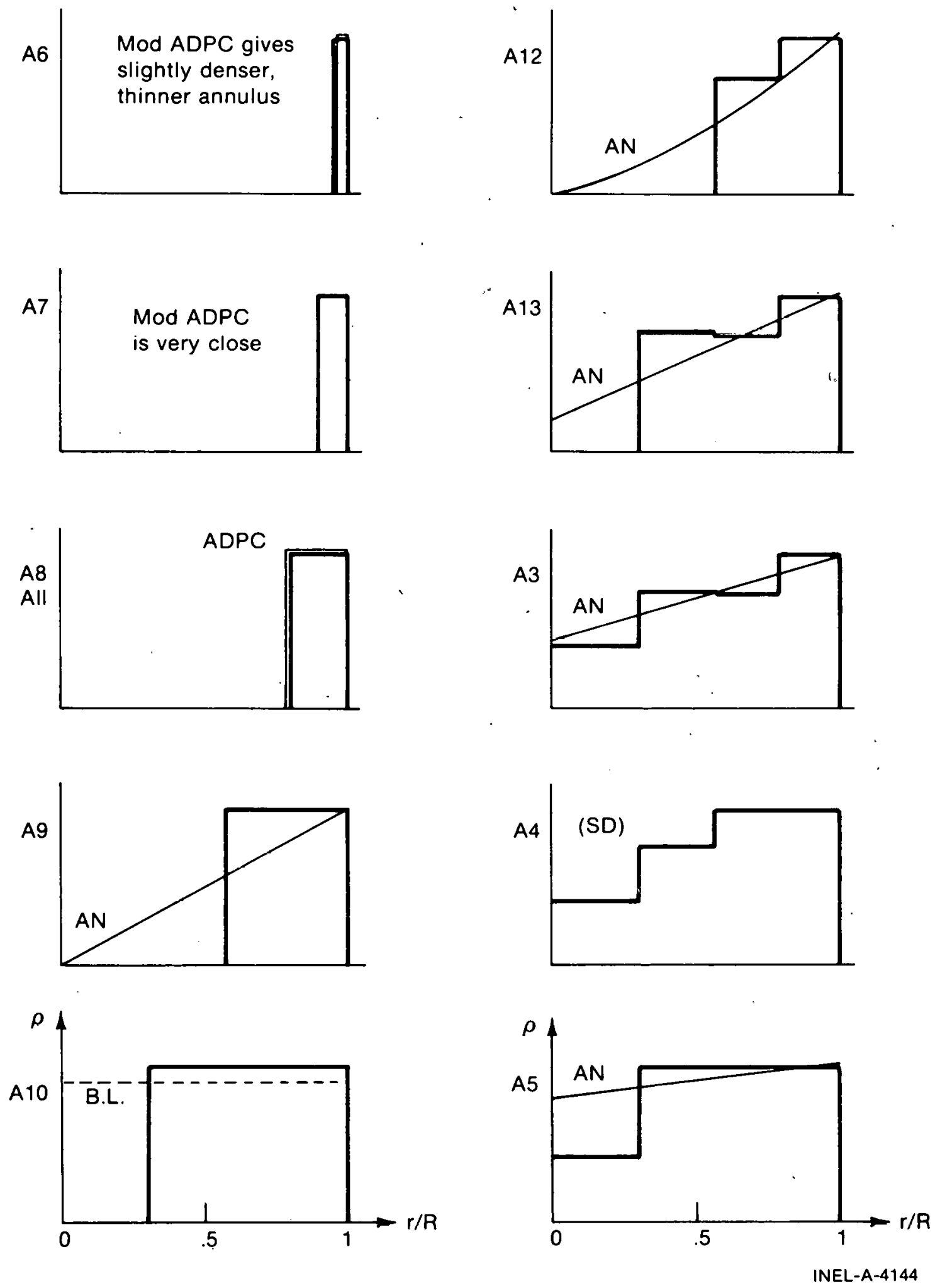

Fig. 15 Actual and calculated density profiles, annular symmetry. 

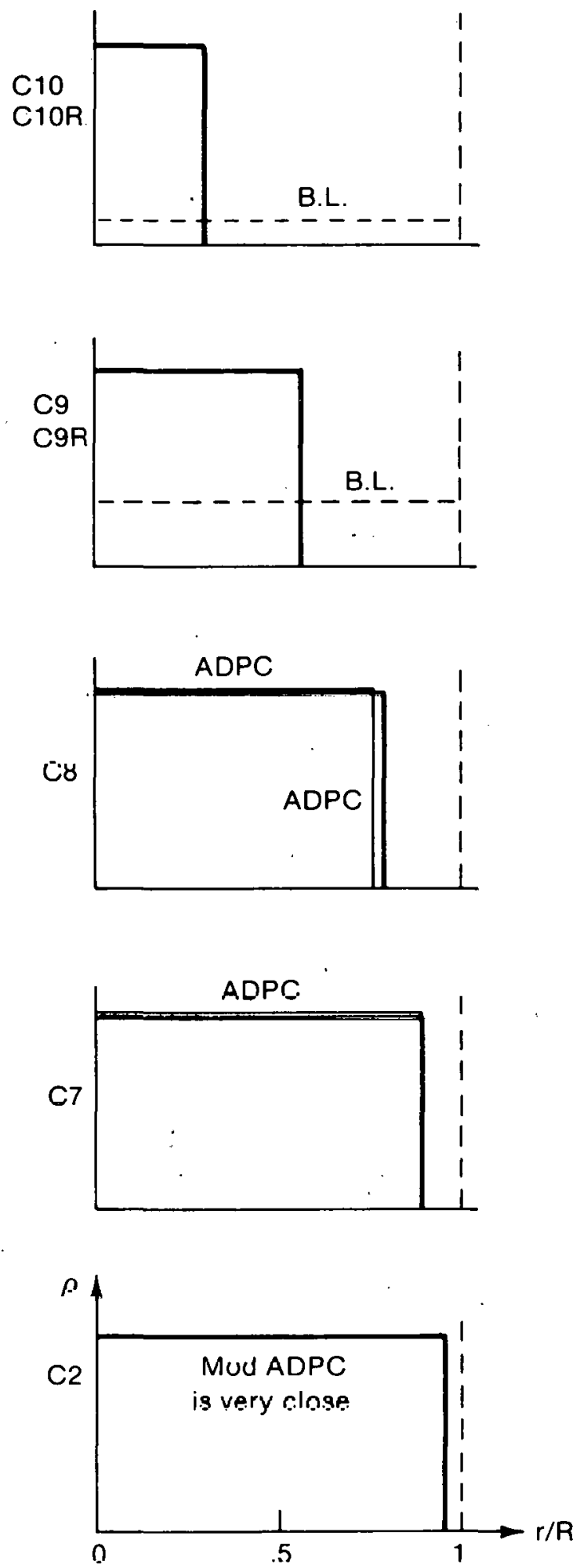
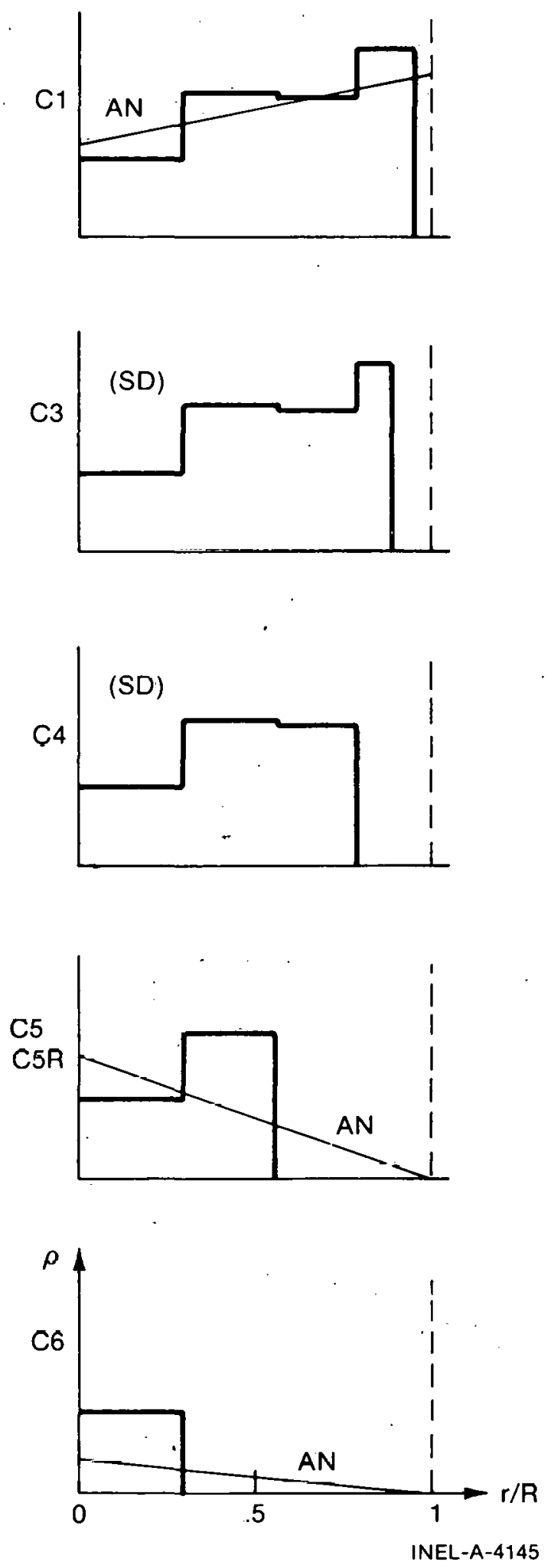

Fig. 16 Actual and calculated density profiles, annular and near-annular symmetry. 
$\underline{\text { TABLE I }}$

ERROR SUMMARY FOR SAMPLE CALCULATIONS

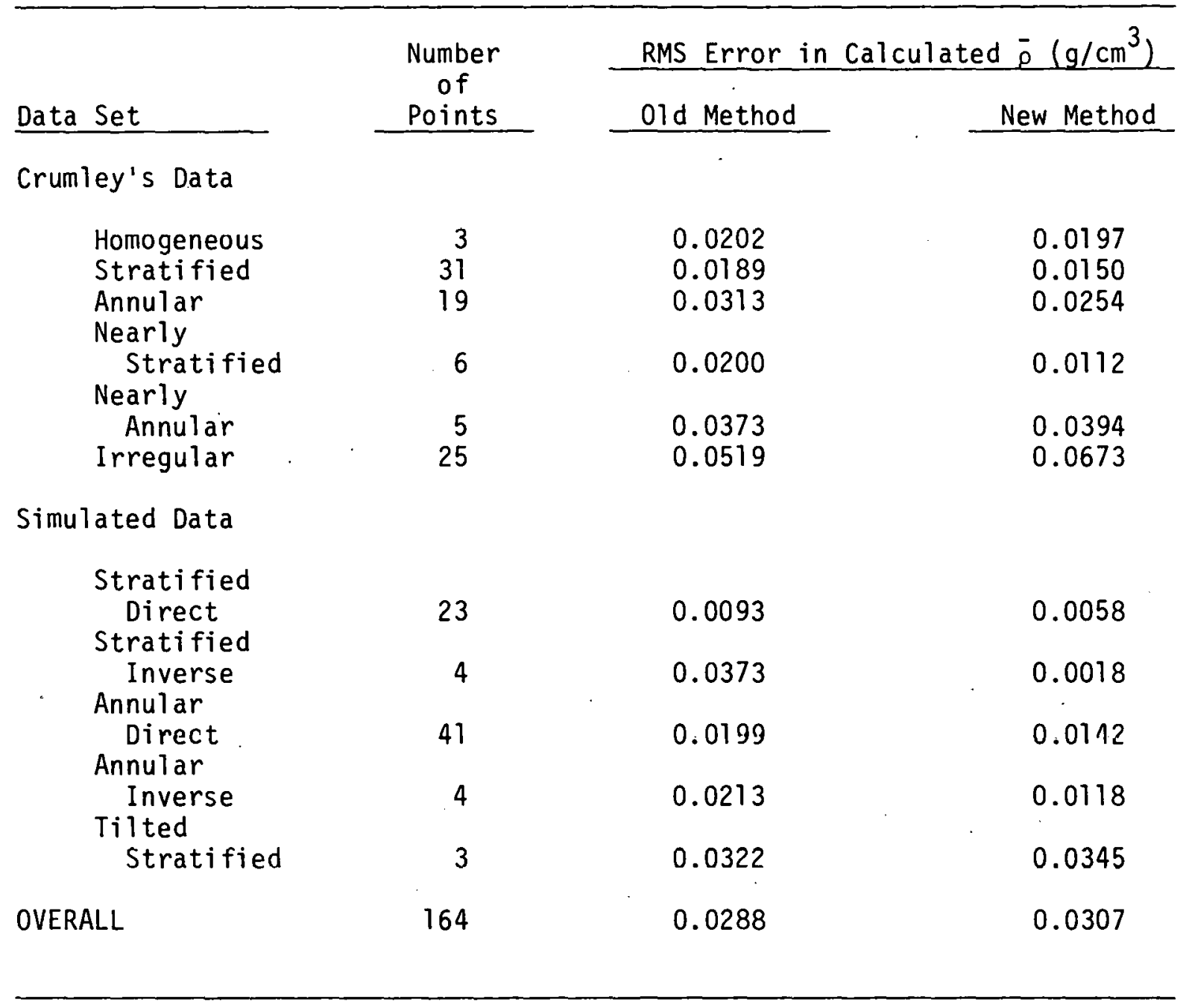

This sample run of 164 test points required 25 system seconds, including 9 central processor seconds, on a CYBER 173 computer. (cost about fifty cents under the local billing system).

Real LOFT data have been studied with more general prototype versions of this calculational procedure. Most of the data can be fit very well with stratified models. In a few cases, an annular model gave a better fit. However, because of the rarity and irregularity of these cases, they probably represent irregular fluctuations in the density profile rather than a well defined, stable annular density profile. 


\section{CONTINUING WORK}

It would be desirable to use a much shorter computer program to implement the analysis scheme described in this report. One possible approach would be to use a three-dimensional array for the average density and similar tables for each of the model parameters, with "reduced" chordal average densities

$$
\rho_{i}^{\prime}=\frac{\rho_{i}-\rho_{g}}{\rho_{\ell}-\rho_{g}}
$$

as the indexes to locate the proper point in each array, perhaps with interpolation between the points in the lable. However, first indications are that a table that could give reasonable accuracy would be quite large, so that the computer time - memory space trade off would not be justified.

Another possible approach is to find simple functions of the three chordal average densities to represent lhe average density and the parameter values for each model. However, initial attempts along these lines have not been successfiit?

Work is continuing on both of these possible techniques for shortening the computer program. 
VIII. CONCLUSIONS

The calculation procedure discussed here represents the best method thus far determined for calculating the fluid density profile in the pipe. Although there is the possibility of large errors in the density profile estimate, the probability of occurrence of these large errors is expected to be small. This calculation procedure should be very useful for obtaining either qualitative or quantitative density profile estimates. 


\section{REFERENCES}

1. H. C. Robinson, LOFT Systems and Test Description (Loss-of-Coolant Experiments Using a Core Simulator), TREE-NUREG-1019 (November 1976).

2. J. K. Jacoby, LOFT Experiment Operating Specification, LOFT Nonnuclear Experiment Series LI-1 EOS Vol. 1 Rev. 1 with Appendix A (August 1974).

3. H. L. Coplen, L..J. Ybarrando, "Loss-of-Fluid Test Integral Test Facility and Program", Nuclear Safety, 15, 6 (November December 1974).

4. G. D. Lassahn, Measurement Uncertainty Analysis: LOFT Three-Beam Gamma Densitometer System, TREE-NUREG-1143 (to be published). 


\section{ERRATA}

Errata to TREE-NUREG-1111, "LOFT Three-Beam Densitometer Data Interpretation, October 1977, G. D. Lassahn.

On Page 42, the fourth reference is incorrectly typed. Change title to LOFT Three Beam Densitometer Data Interpretation and number TREE-NUREG-1089, Volume XVI (to be published). 
APPENDIX A

COMPUTER PROGRAM 


\section{APPENDIX A}

This appendix contains a listing of the subroutine DPRøF2 which does the calculations for the data analysis scheme described in the report, along with a list of some of the primary variable names and the meanings, brief descriptions of the secondary subroutines FIT3I and FIT32, and a listing of the output from a sample run. 

$A, B, C$
$\rho_{j}$; measured chordal average densities
$D G, D L$
$\rho_{g}, \rho \ell ;$ gas and liquid densities
$\mathrm{S}$
$\sigma$; rms error
SHMAX
$\sigma_{\text {HMAX }}$ good fit criterion
SBLMAX
$\sigma_{\text {BLMAX }}$; acceptable fit criterion
Q1
name of best model tried
Q2
$\bar{\rho}$, calculated average density, from best model tried
Q3
Q4, Q5, Q6
$\sigma$, rms error, from best model tried
values of parameters from best model tried

\section{Stratified Models}

DB, DT

$\rho_{b}, \rho_{t}$; density for large negative $x($ or $x=0)$, and for large positive $x$ (or $x=2 R$ )

ERRS

$\varepsilon_{1}$; error allowance for determining stratified distributions

Mode 1 SFX

$A C, B C, C C$

$\hat{\rho}_{j}$; calculated chordal average densities

PA, PB

$a, b$; adjustable parameters

NSFX maximum allowed number of iterations

NSFX2 number of intervals used in numerical integration to get $\vec{\rho}$

Model SU.

D

D; distance from pipe bottom to interfares hotwon two fluid density regions

U

$u=D\left(\rho_{b}-\rho_{t}\right)$ 
Annular Models

Model ADPC

D D'; adjustable parameter similar to annulus thickness

$D C, D A$ $\rho_{c}, \rho_{a} ;$ core and annulus densities

Model ARN

NAN

number of values of $n$

CAN

values of $n$ and coefficients Fni

DO, DI, DM $\rho_{0}, \rho_{1}, \rho_{1}-\rho_{0}$; densities at $r=0$ and at $r=R$, and the difference

SECONDARY SUBROUTINES

$\operatorname{FIT32}\left(a_{1}, a_{2}, a_{3}, b_{1}, b_{2}, b_{3}, c_{1}, c_{2}, c_{3}, U, v, a, y_{1}, y_{2}, y_{3}\right)$

Calculates the values of $U$ and $V$ that give the best fit (minimum rms error $\sigma$ ) to the equations

$$
\begin{aligned}
& a_{1} u+b_{1} v+c_{1} \approx y_{1} \\
& a_{2} u+b_{2} v+c_{2} \approx y_{2} \\
& a_{3} u+b_{3} v+c_{3} \approx y_{3} .
\end{aligned}
$$

$\sigma$ is the rms error in the least squares fit. If the solution is undefined or non-existent, the values returned are

$$
\begin{aligned}
& \sigma=-9, \\
& U=V=0 .
\end{aligned}
$$

FIT31 is similar to FIT32, except that the second variable $V$ and the related coefficients are missing. 
MODEL PARAMETERS

\begin{tabular}{|c|c|c|c|}
\hline Model Name (Q1) & Q4 & Q5 & Q6 \\
\hline HOMO & & . & \\
\hline SFX & $b$ & a & Not used \\
\hline SD & D & $\rho_{t}$ & $\rho_{b}$ \\
\hline ARN & $\rho_{0}$ & $\rho_{1}$ & $n$ \\
\hline$A D P C$ & $D^{\prime}$ & $\rho_{c}$ & $\rho_{a}$ \\
\hline$B L$ & & & \\
\hline
\end{tabular}


Four lines of output are printed for each test point:

Line 1: input data. Label, A, B, C, $\rho_{\ell}, \rho_{g}$, "correct" $\bar{\rho}, Q 4, Q 5$, Q6. For the Crumley data, the label includes the test name and an indication of the symmetry of the density distribution ( $H=$ homogeneous, $I A=$ inverse annular, $C=$ curved $),$ if the test name does not indicate the symmetry. For the simulated data, the label just indicates the "actual" symmetry.

Line 2: calculated quantities. The symmetry designation for the old analysis scheme, and the model name, $\sigma, Q 4, Q 5$, and Q6 calculated by the new scheme.

Line 3: calculated $\bar{\rho}$ values, as calculated by the old scheme, by Model HOMO, by Model BL, and by the new analysis scheme.

Line 4: errors in calculated - $\bar{\rho}$ values; calculated $\bar{\rho}$ minus "actual" $\bar{\rho}$ for the old scheme, Model HOMO, Model BL, and the new scheme.

The sketches indicate the density distributions for some of the irregular test points. 


\section{PROGRAM LEACH (I NPUT, TAPES = INPUT, OUTPUT, TAPEG =OUTPUT)}

REAL P(12)

DATA P/12* $\neq 1$

NPT $=0$

$D L P=0$.

$D G P=0$.

10 READ $(5,31) A, B, C, D L R, O G R, L A B 1, L A B 2, R H O C,(P(I), I=1,8)$

31 FORMAT $(5(1 X, F 5,3), 2 A 4, F 7,5,8 A 4)$

IF (OLR.LT.O.) STOP

IF (NLR.FQ.O.) GO TO ? I

$D L P=O L R$

$D G P=O G R$

$21 N P T=N P T+1$

IF (1.EQ.MOD(NPT,6) WRITE $(6,1)$

1 FORMAT $(\neq 1 \neq / /)$

CALL DPROF2 (A,B,C,DLP,DGP,Q1,Q2,Q3,Q4, Q5, Q6)

AVHOMO $=(A+B+C) / 3$.

$A \vee B L=.34485 * A+.40034 * B+.25481 * C$

$A V O L D=A V B L$

IF (A.GT•B •AND・B•GT•C) AVOLD $=.437 * A+.417 * B+.146 * C$

$R=\neq H \neq$

$X M A X=A M A X 1(C / A, C / B, A / B)$

$X M I N=A M I N 1(C / A, C / B, A / B)$

IF (XMAX.LE.1.02 .AND. XMIN.GE.0.98) GO T0 39

$R= \pm A \pm$

If $(C \bullet G T \bullet B) \quad G 0$ TO 39

$R=\neq S \neq$

IF $(A \bullet G T \bullet C)$ GO TO 39

$R=\neq I \neq$

IF $(A . L T \cdot B) \quad$ GO TO 39

$R=\neq D \neq$

39 $E 1=Q 2-R H O C$

E2 $=A$ AHOMO $-R H O C$

$E 3=A V B L-R H O C$

$E 4=A$ Q $L D=R H O C$

$E 5=Q 2-A V O L D$

URITE $(6,41) L A B 1, L A B 2, A, B, C, D L P, D G P, R H O C, \quad(P(I), I=1,8)$,

$1 R, Q 1, Q 3, Q 4, Q 5, Q 6, A V O L D, A V H O M O, A V B L, Q 2, E 4, E 2, E 3, E 1$

41 FORMAT $(/ / 1 X, 2 A 4,2 X, 5 F 6,3, F 8,5,8 A 4 / 13 X, A 1,22 X, A 4,3 X, F 5,4$,

$11 X, 3 F 9.4 / 9 X, 4(2 x, F 6.4) / 9 X, 4(2 x, F 6.4))$

GO TO 10

END 
SUBROUTINE DPROF2 ( $A, B, C, O L P, D G P, 01, Q 2, Q 3, Q 4, Q 5,06)$

REAL CAN $(4,11)$

DATA NAN, CAN/11,.69456,.5,.8515,1.,.50542,.33333,.72986,2. $1, .38446, .25, .62984,3 \ldots, .30437, .2, .54729,4 ., .5891, .4, .78768,1.5$ $2, .43848, .28571, .67743,2.5, .34049, .22222, .58661,3.5$

$3, .67143, .47619, .83822,1.1, .62834, .43478, .81245,1.3$

$4, .55333, .37 u 37, .76386,1.7, .47687, .3125, .70827,2.2$

FSFXI $(X, A, B)=1 \cdot((1 \cdot+\operatorname{EXP}(-4 \cdot \star A \star(X-B)))$

SHMAX $=.02$

ERRS $=1.2$ * SHMAX

SBLMAX $=\bullet 1$

NSFX $=15$

NSF $\times 2=15$

$21 D L=A M A X 1 \quad(A, B, C, D L P)$

$D G=A M I N 1 \quad(A, B, C, D G P)$

$D D=D L-D G$

$A P=(A-D G) / D D$

$B P=(B-D S) / D D$

$C P=(C-D G) / D D$

KODS $=0$

C MOO HOMO

$Q 1=\neq H O M O \#$

$Q 2=(A+B+C) / 3$

$Q 3=.57735 * S Q R T((A-Q 2) * 2+(B-Q 2) * 2+(C-Q 2) * * 2)$

Q4 $=0$.

$Q 5=0$.

$06=0$.

IF (Q3.LE.SHMAX) 60 TO 400

C STRATIFIED, GENERAL IZED

200 IF $((((A-B) \cdot G T \bullet-E R R S)$ AND $\bullet((B-C) \bullet G T \bullet-E R R S))$

$1 \cdot O R \cdot(((A-B) \cdot L T \cdot E R R S)$. AND $((B-C) \cdot L T \cdot E R R S)))$ GO TO 201 GO TO 300

$201 D T=D G$

$D B=D L$

IF (C .LE A A) GO TO 205

$D T=D L$

$D B=D G$

$205 \quad D E=D B-D T$

$K O D S=1$

C MOD SFX

CALL FIT32 (1, 1, 1, 1, $3,-3,69,0,10,12,0,, 0,0,0, P 3, P 4, S, A, B, C)$

IF (S.LT.O.) GO TO 219

$P 7=300$.

$I K O N=0$

$Z=S Q R T((D B-P 3) /(P 3-D T))$

$P A=-P 4 \star .25 / D E *(Z+1 \cdot / Z) \star \star 2$

$P B=14 \cdot 25-A L O G(Z) * \cdot 5 / P A$

$204 D 0211 \mathrm{~N}=1$, NSFX

$T 1=4 \cdot * P A \star P B$

$T 2=4 \cdot * P A \star(P B-27 \bullet 9)$

IF (ABS(T1).GT.6756.OR.ABS(T2).GT.675.) GOTO 215

$F 1=F S F \times 1(0,0, P A, P B)$

$F 2=F S F \times 1(21,12, P A, P B)$ 


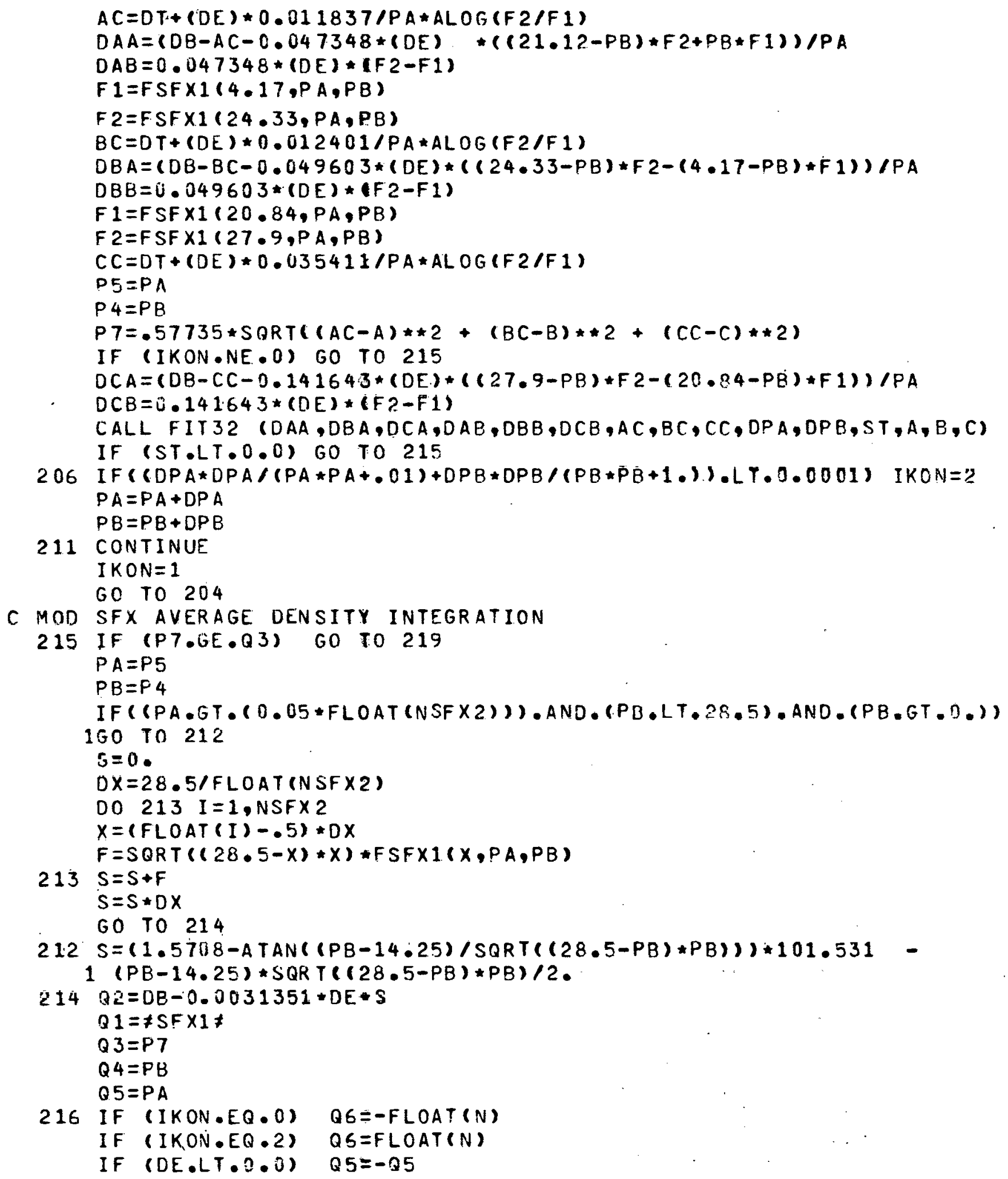


219 CONTINUE

C ANNULAR, GENERALIZED

300 IF ( ( ( (C-A) .GT. -.02) .AND. ((A-B) .GT. -.02)) .OR.

$1(((C-A) \cdot L T \cdot \bullet 02) \cdot A N D \cdot((A-B) \cdot L T \cdot \bullet \cap 2))) G 0$ TO 302 GO TO 202

C MOO ADP DISCONTINUOUS ANNULAR, LINEAR APPROXIMATION

$C$ $302 D A=D L$ WITH CORRECTED AVERAGE DENSITY CALC.

IF $(C \cdot L T \cdot B) \quad D A=D G$

CALL FIT32 (.074574,.070175,.173220,1,.1,1.,0.,0.,0.,

$1 U, D C, S, A, B, C)$

IF $((S \cdot L T \cdot 0.) \cdot O R \cdot(S \cdot G E \bullet Q 3))$ GO TO 399

IF $(A B S(D C-D A) \cdot L T \cdot 0.001)$ GO TO 399

$D=U /(D A-O C)$

IF $(D C, G E \cdot D G) \quad G O$ TO 311

$D C=D G$

GO TO 312

311 IF (DC.LE.DL) GO TO 313

$D C=D L$

312 IF (DA.EQ.DC) GO TO 399

$(1=.094574 *(D A-D C)$

$C 2=.070175 *(D A-D C)$

$C 3=.173223 *(D A-D C)$

$C A L L F I T 31(C 1, C 2, C 3, D C, D C, D C, D, S, A, B, C)$

IF $((S \cdot L T \cdot 0.) \cdot O R \cdot(S \cdot G E \cdot Q 3))$ GO TO 399

$313 x=0 / 14 \cdot 25$

IF $\left(X . G_{2} T \ldots 25\right)$ GO TO 399

$F=x \star(2 \cdot-x \star(4 \cdot-x \star 8 \cdot 5))$

$Q 1=\neq A D P C \neq$.

$Q 2=D C+(D A-D C) \star F$

$Q 3=5$

Q4 $=0$

$Q 5=D C$

$Q .5=D A$

IF (Q3.LE.SHMAX) GO TO 400

399 CONTINUE

C MOO AN FOR FIXED DISCRETE SMALL $N$

321 CONTINUE

$S S=300$.

DO $322 N=1$, NAN

CALL FIT32 (CAN $(1, N), C A N(2, N), C A N(3, N), 1,1,1,1,0,0,0,0,0 M, D 0, S$,

$1 A, B, C)$

IF $((S \cdot L T \cdot O \cdot) \cdot O R \cdot(S \bullet G E \bullet S S))$ GO TO 322

IF (DO.UE.DG) GO TO 323

$D O=0 G$

GO TO 324

323 IF (DQ,LE,DL) GO TO 325

$D O=D L$

324 CALL FIT31 (CAN $(1, N), C A N(2, N), C A N(3, N), D O, D O, D O, D M, S, A, B, C)$

IF $((S \bullet L T \bullet O),. O R \bullet(S \bullet G E \bullet S S))$,SO TO 322

$D 1=D M+D 0$

IF (D1•GE•DG) GO TO 326

$01=D G$

GO TO 327 


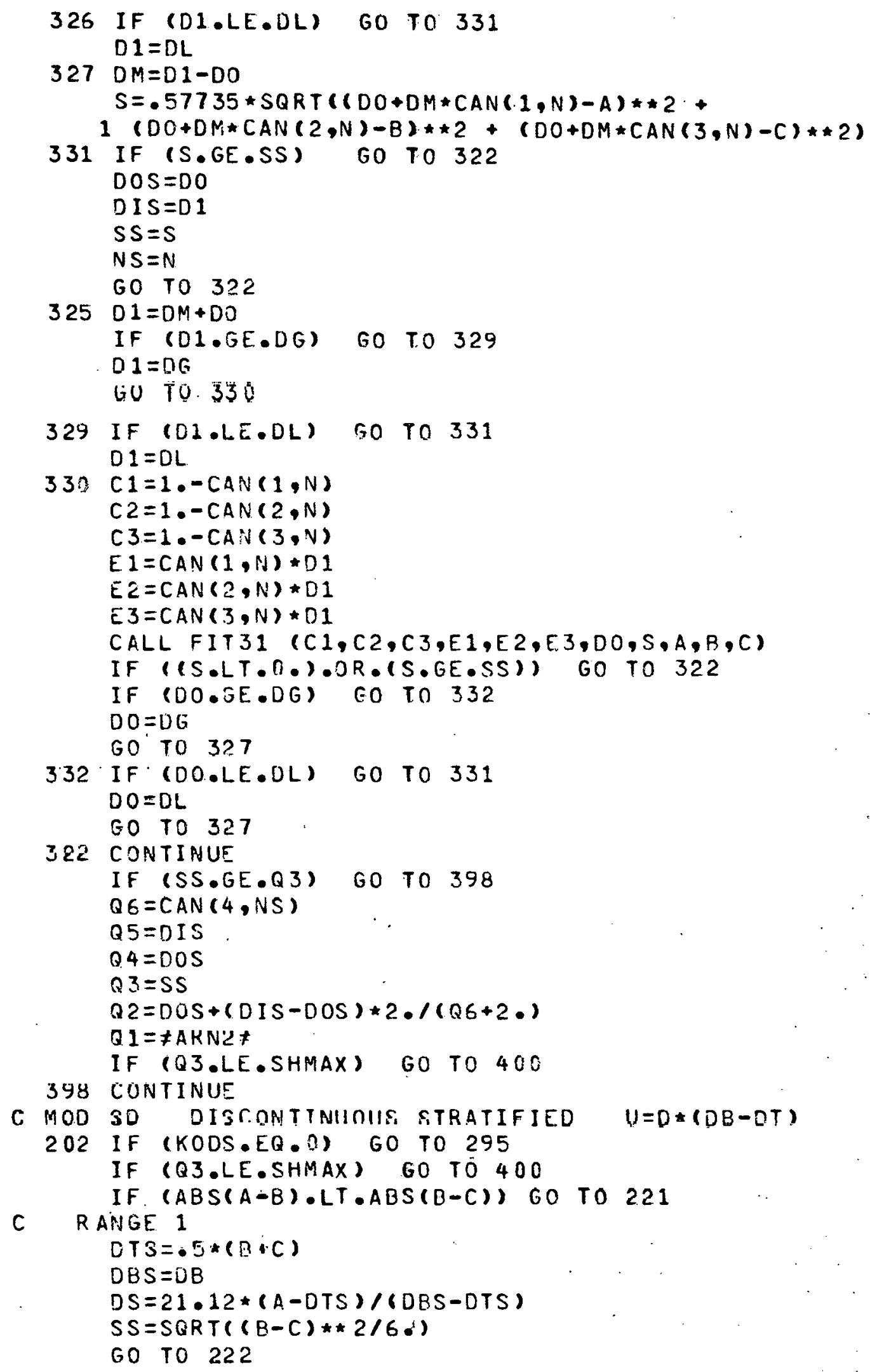




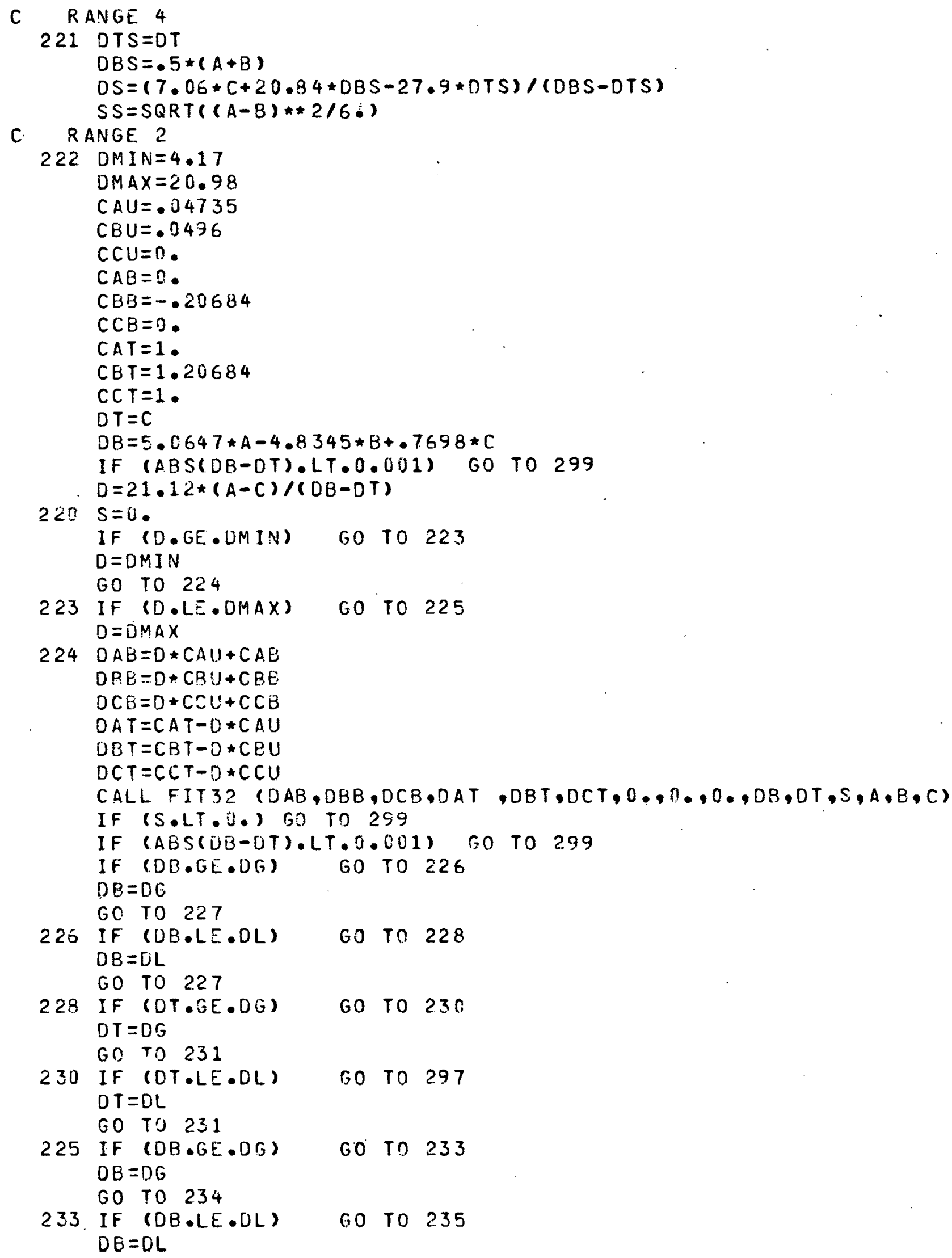




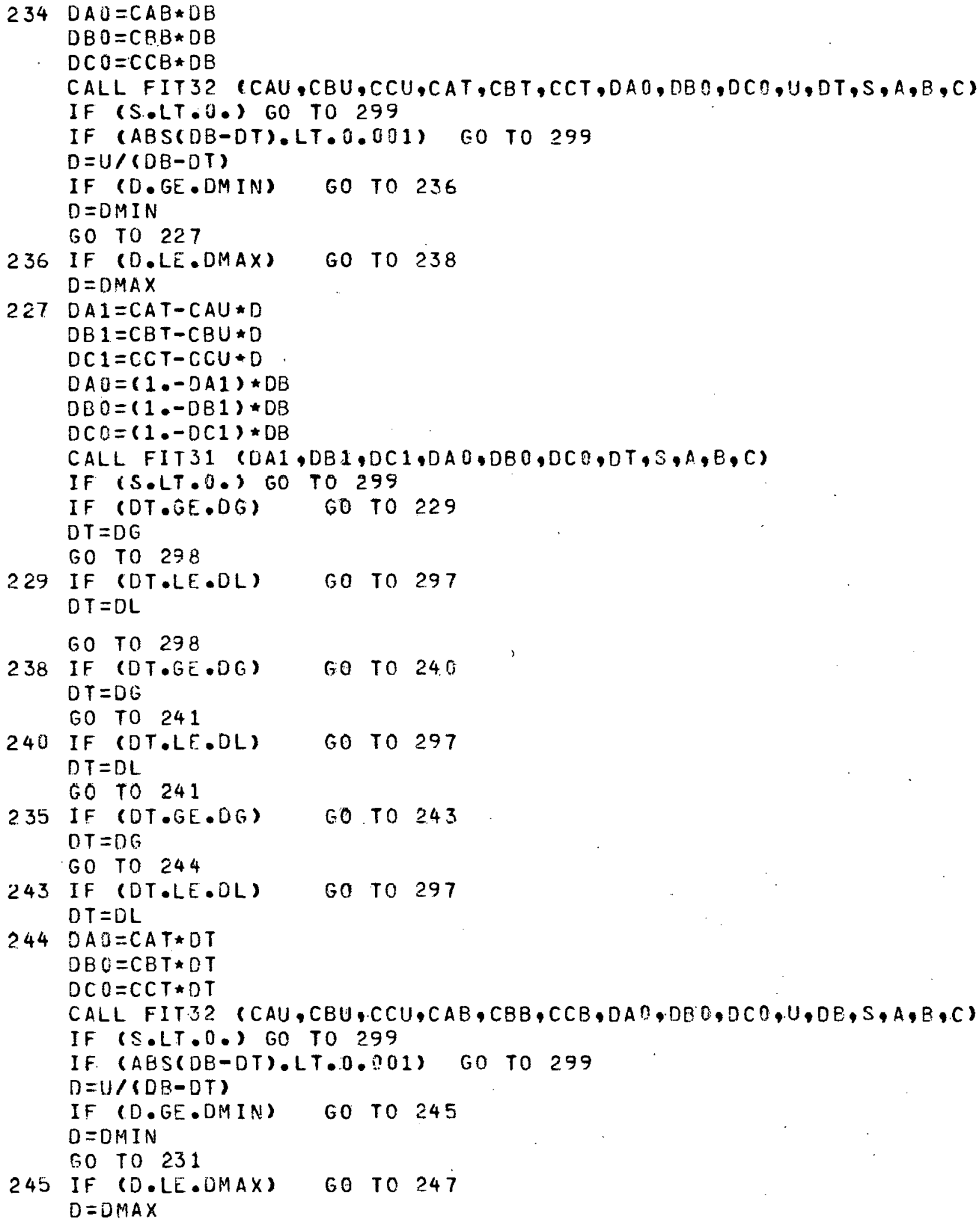




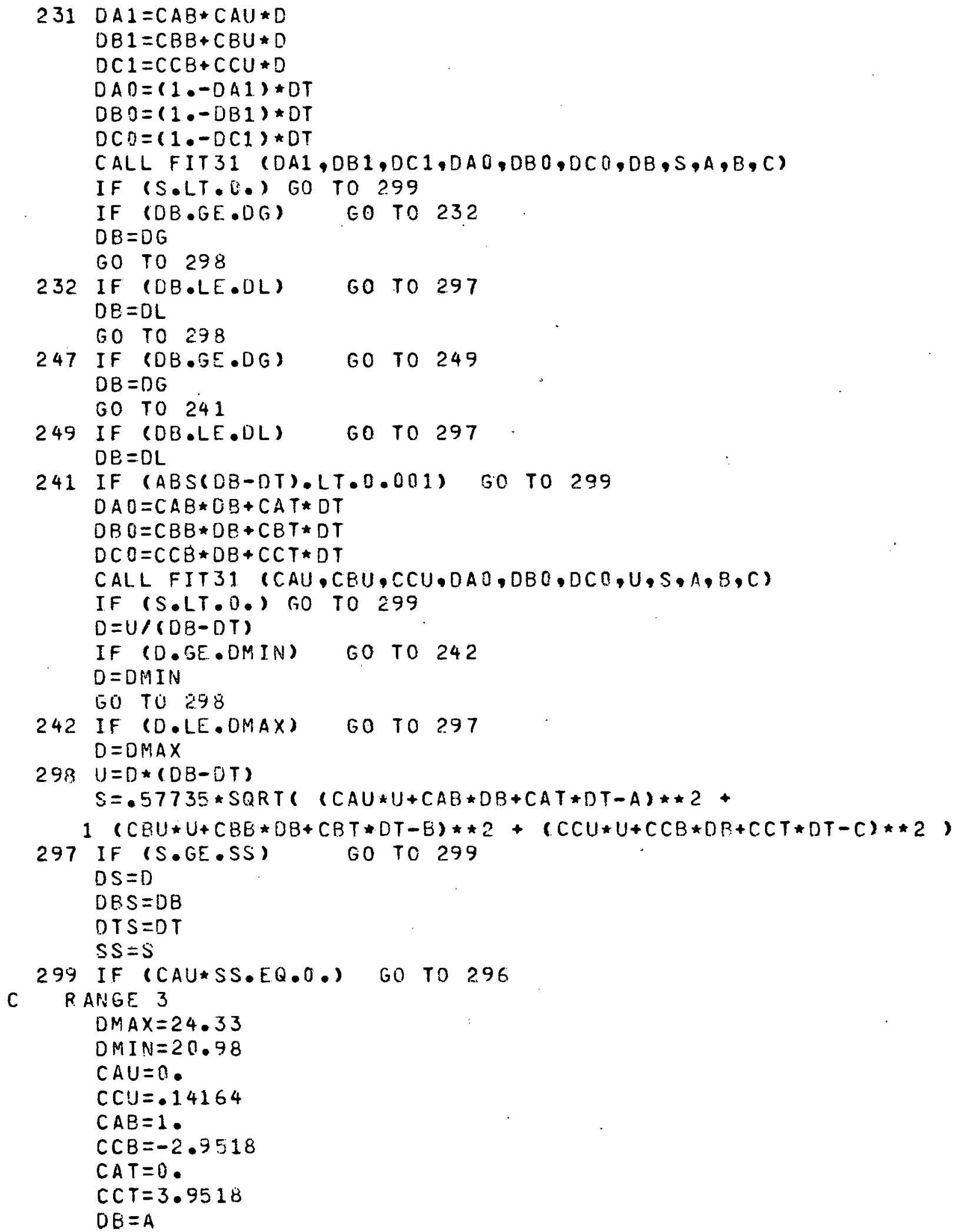




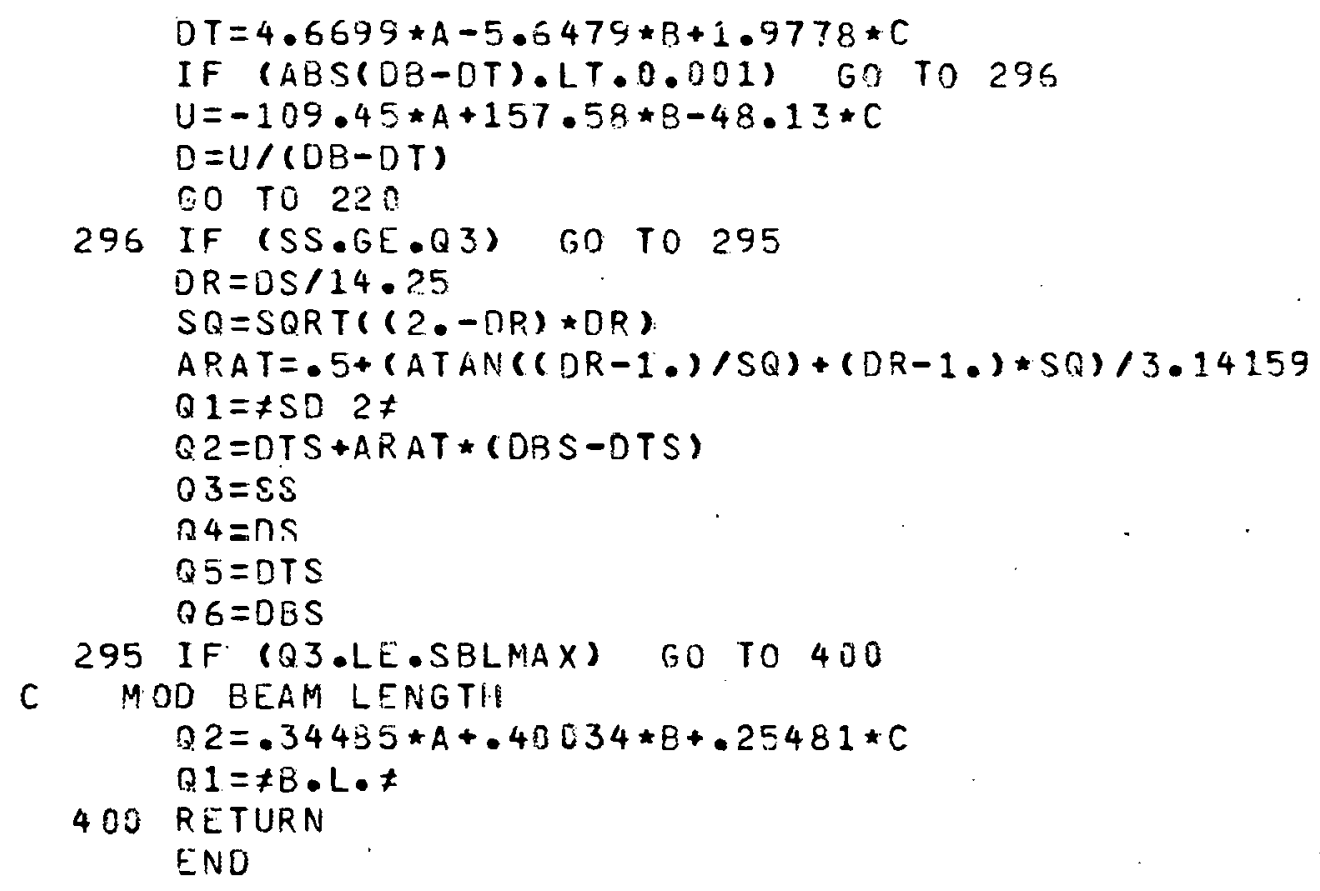




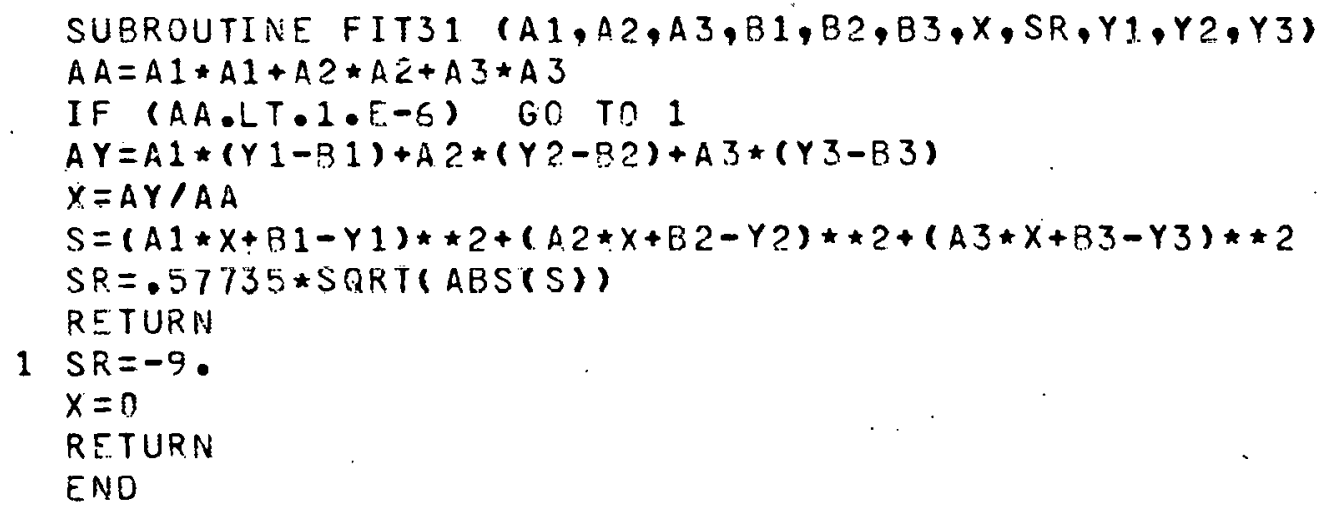




\section{CR.JMLEY DATA}

$\begin{array}{lllllllll}S & 2 H & 1.123 & 1.123 & 1.119 & 1.123 & .001 & 1.10763\end{array}$

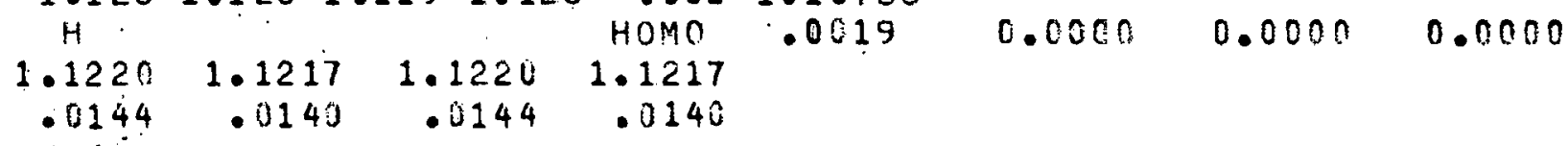

A $2 \mathrm{H} \quad 1.1231 .1231 .1121 .123 \quad .001 \quad 1.09577$

\begin{tabular}{|c|c|c|c|c|}
\hline $\begin{array}{c}H \\
1.1232 \\
.0244\end{array}$ & $\begin{array}{r}1.1193 \\
.0236\end{array}$ & $\begin{array}{r}1 . .202 \\
.0244\end{array}$ & $\begin{array}{l}\text { HOMO } \\
\text { D. } 1193 \\
.0235\end{array}$ & .0052 \\
\hline
\end{tabular}

S $35 \mathrm{H} \quad 1.128 \quad 1.1291 .127 \quad 1.123 \quad .001 \quad 1.10763$

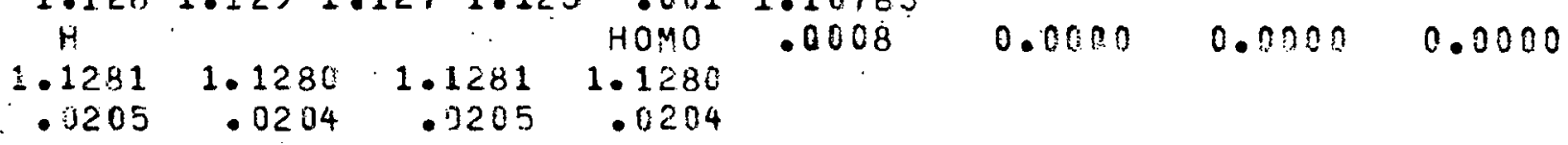

g

$S 15 \quad .136 \quad .094 \quad 00611.123 \quad .001 \quad .04726$

$\begin{array}{llllllll}.136 & .004 & .061 & 1.123 & .001 & .04726 & & \\ S & & & S F \times 1 & .0300 & 2.5265 & .3760 & 11.0000 \\ .0612 & .0470 & .0488 & .0507 & .000 & & & \\ .0140 & -.0003 & .0015 & .0034 & & & & \end{array}$

S 29

\begin{tabular}{|c|c|c|c|c|c|c|c|}
\hline $\begin{array}{l}.135 \\
s \\
.0608 \\
.0135\end{array}$ & $\begin{array}{r}.004 \\
.0467 \\
-.07077\end{array}$ & $\begin{array}{r}.0011 .123 \\
.0484 \\
.0011\end{array}$ & $\begin{array}{l}.001 \\
\text { SF } \times 1 \\
.0502 \\
.0029\end{array}$ & $\begin{array}{l}.04733 \\
.0000\end{array}$ & 2.5036 & .3728 & 11.0000 \\
\hline
\end{tabular}

S 30

$\begin{array}{llllllll}.432 & .236 & .061 & 1.123 & .001 & .26221 & & \\ S & & & S F \times 1 & .0005 & 8.0713 & .1159 & 7.0000 \\ .2873 & .2230 & .2437 & .2737 & & & & \\ .0251 & -.0352 & -.0185 & .0115 & & & & \end{array}$


S 31

$\begin{array}{lccccccc}.514 & .320 & .001 & 1.123 & .001 & .33416 & & \\ \$ & & .0021 & 9.6641 & .1068 & 6.0000 \\ .3582 & .2783 & .3056 & .3454 & & & & \\ .0240 & -.0558 & -.0285 & .0113 & & & \end{array}$

S 16

\begin{tabular}{|c|c|c|}
\hline $\begin{array}{l}.600 \\
S\end{array}$ & .407 & .0011 .123 \\
\hline 4321 & .3360 & .3701 \\
\hline
\end{tabular}

\section{.40655}

$.0255 \quad-.0706 \quad-.0364 \quad .0136$

S 32

$\begin{array}{llllllll}.647 & .455 & .001 & 1.123 & .001 & .45452 & & \\ S & & & S F \times 1 & .0034 & 12.2427 & .1388 & 7.0000 \\ .4726 & .0677 & .4055 & .4616 & & & & \\ .0181 & -.0869 & -.0490 & .0071 & & & & \end{array}$

as

\begin{tabular}{|c|c|c|c|c|c|c|c|c|c|}
\hline$s$ & 17 & $\begin{array}{l}.856 \\
.6553 \\
.6522\end{array}$ & $\begin{array}{r}.674 \\
.5103 \\
-.1428\end{array}$ & $\begin{array}{r}.0011 .123 \\
.5653 \\
-.0878\end{array}$ & $\begin{array}{l}.001 \\
S F \times 1 \\
.6550 \\
.0919\end{array}$ & $\begin{array}{l}.65311 \\
.0437\end{array}$ & 16.1848 & .2624 & 9.0000 \\
\hline$S$ & $17 R$ & $\begin{array}{l}.851 \\
.6518 \\
. .6013\end{array}$ & $\begin{array}{r}.671 \\
.5077 \\
-.1454\end{array}$ & $\begin{array}{r}.0011 .123 \\
.5624 \\
-.0508\end{array}$ & $\begin{array}{c}.001 \\
S F \times 1 \\
.6513 \\
-.0018\end{array}$ & $\begin{array}{l}.65311 \\
.0045\end{array}$ & 16.1124 & .2495 & 9.3030 \\
\hline & 33 & $\begin{array}{l}.907 \\
.9 \\
. .7002 \\
.0009\end{array}$ & $\begin{array}{r}.728 \\
.5457 \\
. .1554\end{array}$ & $\begin{array}{r}.0021 .123 \\
.6047 \\
-.0963\end{array}$ & $\begin{array}{l}.001 \\
S F \times 1 \\
.7025 \\
.0015\end{array}$ & $\begin{array}{l}.70108 \\
.0038\end{array}$ & 17.1524 & .2822 & 8.0000 \\
\hline
\end{tabular}


న

S 13

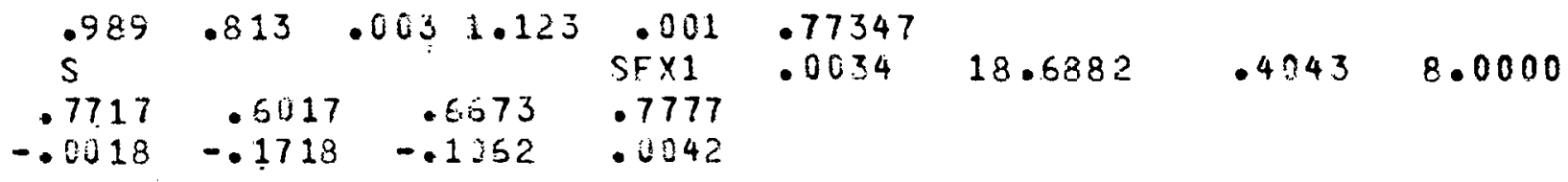

S $18 R$

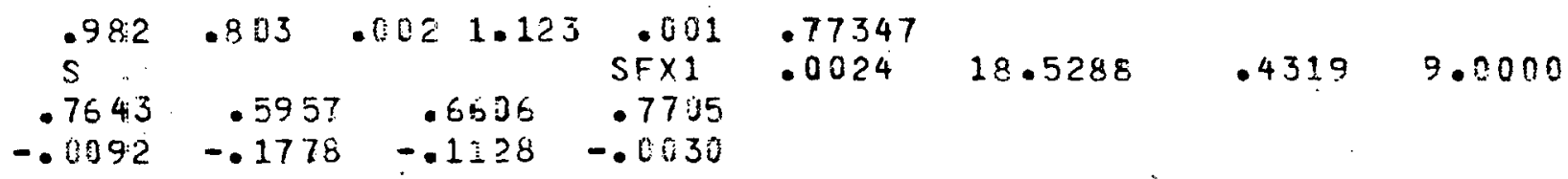

\$ 19

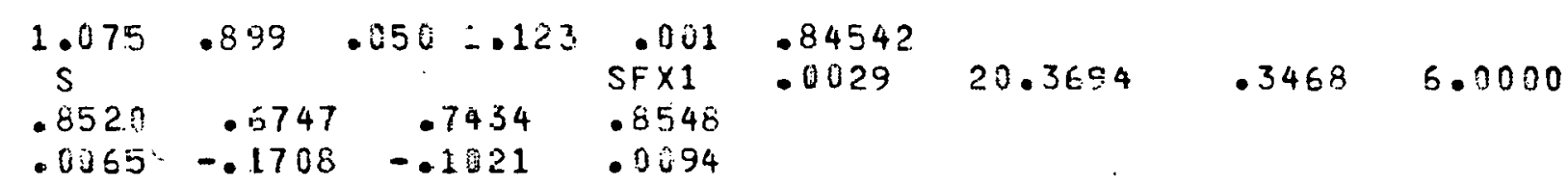

520

$1.123 \quad 1.123 \quad .8501 .123 \quad .001 \quad 1.06030$

$\begin{array}{cccccccc}S & & & 502 & .0000 & 24.1316 & .6052 & 1.1280 \\ 1.0853 & 1.0337 & 1.0552 & 1.0774 & & & & \end{array}$

S 34

$1.1231 .128 \quad .8331 .123 \quad .0011 .06037$

S SFX1 .0010 26.1925 .5168-11.0000

$\begin{array}{rrrr}1.0587 & 1.0370 & 1.0584 & 1.0811 \\ -.0019 & -.0234 & -.0019 & .0207\end{array}$

S 3

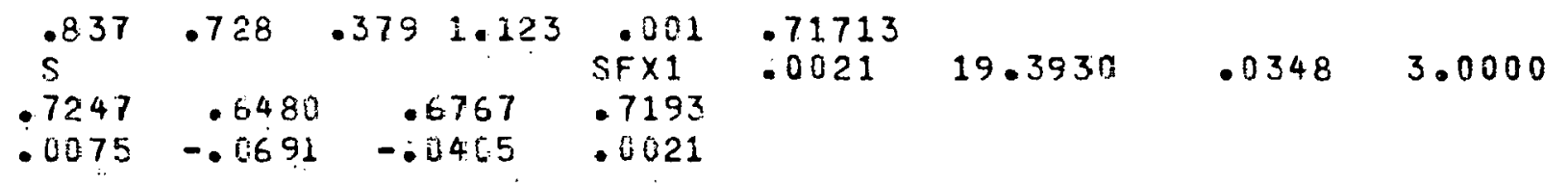




\begin{tabular}{|c|c|c|c|c|c|c|c|c|c|c|}
\hline & $S$ & 4 & $\begin{array}{l}.917 \\
.9 \\
.7899 \\
.0047\end{array}$ & $\begin{array}{r}.804 \\
.6967 \\
-.0885\end{array}$ & $\begin{array}{c}.3691 .123 \\
.7321 \\
-.0531\end{array}$ & $\begin{array}{c}.001 \\
\text { SFX1 } \\
.7849 \\
-.0003\end{array}$ & $\begin{array}{l}.78518 \\
.0009\end{array}$ & 20.4451 & .0474 & 3.0000 \\
\hline & $S$ & 5 & $\begin{array}{l}.975 \\
.8 \\
.8392 \\
.0015\end{array}$ & $\begin{array}{r}.857 \\
.7380 \\
-.0997\end{array}$ & $\begin{array}{c}.3821 .123 \\
.7767 \\
-.0611\end{array}$ & $\begin{array}{l}.001 \\
S F \times 1 \\
.8345 \\
-.0033\end{array}$ & $\begin{array}{l}.83773 \\
.0041\end{array}$ & 21.3145 & .0576 & 4.0000 \\
\hline & $S$ & 6 & $\begin{array}{l}1.058 \\
.5 \\
.9044 \\
.0072\end{array}$ & $\begin{array}{r}.933 \\
.7847 \\
-.1125\end{array}$ & $\begin{array}{c}.3631 .123 \\
.8309 \\
-.0663\end{array}$ & $\begin{array}{l}.001 \\
S F \times 1 \\
.8992 \\
.0020\end{array}$ & $\begin{array}{l}.89717 \\
.0090\end{array}$ & 22.0738 & .0921 & 5.0000 \\
\hline & $S$ & 7 & $\begin{array}{c}1.089 \\
S \\
.9386 \\
-.0006\end{array}$ & $\begin{array}{r}.966 \\
.8217 \\
.01175\end{array}$ & $\begin{array}{r}.4101 .123 \\
.8567 \\
-.0724\end{array}$ & $\begin{array}{r}.001 \\
S F \times 1 \\
.9317 \\
-.0074\end{array}$ & $\begin{array}{l}.93913 \\
.0133\end{array}$ & 22.7830 & .1038 & 5.0030 \\
\hline & $S$ & 8 & $\begin{array}{l}1.132 \\
5 \\
1.1039 \\
.0190\end{array}$ & $\begin{array}{l}1.116 \\
1.0777 \\
-.0072\end{array}$ & $\begin{array}{c}.9851 .123 \\
1.0881 \\
.0033\end{array}$ & $\begin{array}{r}.001 \\
\text { SFX1 } \\
1.1001 \\
.0153\end{array}$ & $\begin{array}{c}1.08486 \\
.0023\end{array}$ & 29.4789 & .1057 & 7.0000 \\
\hline & $S$ & 9 & $\begin{array}{l}.116 \\
.0517 \\
.0091\end{array}$ & $\begin{array}{r}.002 \\
.0397 \\
-.0329\end{array}$ & $\begin{array}{c}.0011 .123 \\
.0411 \\
-.0015\end{array}$ & $\begin{array}{r}.001 \\
\text { SFX1 } \\
.0403 \\
-00023\end{array}$ & $\begin{array}{l}.04260 \\
.0004\end{array}$ & 2.1513 & .3930 & -14.0000 \\
\hline
\end{tabular}


S 10

\begin{tabular}{|c|c|c|c|}
\hline$i_{S}^{490}$ & .328 & .0311 .123 & $S F \times 1$ \\
\hline $\begin{array}{l}.3545 \\
.0207\end{array}$ & $\begin{array}{r}.2757 \\
-.0582\end{array}$ & $\begin{array}{r}.3053 \\
-.035\end{array}$ & $\begin{array}{l}.3440 \\
.0101\end{array}$ \\
\hline
\end{tabular}

.33384

$\begin{array}{llll}.0086 & 9.4223 \quad .0824 & 5.0000\end{array}$

$.0207 \quad-.0582 \quad-.0305 \quad .0101$

S 11

$\begin{array}{llllllll}.709 & .549 & .031 & 1.123 & .001 & .52785 & & \\ S & .0 & & S F \times 1 & .0149 & 13.6990 & .1344 & 7.0000 \\ .5389 & .0197 & .4645 & .5323 & & & & \\ .0112 & -.01082 & -.0633 & .0044 & & & & \end{array}$

S 12

$\begin{array}{lccccccc}.756 & .622 & .0013 .123 & .001 & .58877 & & & \\ S & & & 502 & .0000 & 18.5227 & .0010 & .8733 \\ .5943 & .4630 & .5134 & .6011 & & & \\ .0055 & -.01258 & -.0753 & .0123 & & & \end{array}$

क्ष

$\$ 13$

\begin{tabular}{|c|c|c|c|}
\hline$\underbrace{.813}_{s}$ & $.6 \in 3$ & .0191 .123 & $\begin{array}{l}.001 \\
S F \times 1\end{array}$ \\
\hline $\begin{array}{l}.6345 \\
.0162\end{array}$ & $\begin{array}{r}.4983 \\
-.1200\end{array}$ & $\begin{array}{r}.5536 \\
-.0677\end{array}$ & $\begin{array}{r}.6321 \\
.0138\end{array}$ \\
\hline
\end{tabular}

.61829

$\begin{array}{llll}.0152 & 15.7634 & .1253 & 6.0000\end{array}$

$.0162-.1200-.0677 \quad .0138$

S $13 A$

$\begin{array}{lccccccc}.008 & .657 & .021 & 1.123 & .001 & .61829 & & \\ S & & & \text { SFX1 } & .0146 & 15.6686 & .1216 & 6.0000 \\ .6301 & .4953 & .5470 & .6273 & & & & \\ .0116 & -.01230 & -.0713 & .0090 & & & & \end{array}$

S 14

$\begin{array}{cccccccc}.840 & .750 & .294 & 1.123 & .001 & .64893 & & \\ S & & & S F \times 1 & .0135 & 18.5879 & .0457 & 3.0000 \\ .7228 & .6280 & .6648 & .7177 & & & & \\ .0738 & -.0209 & .0159 & .0687 & & & & \end{array}$


$\mathrm{s}$

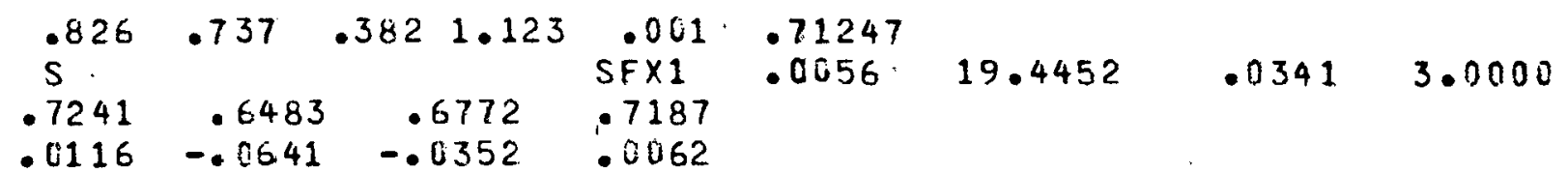

S 22

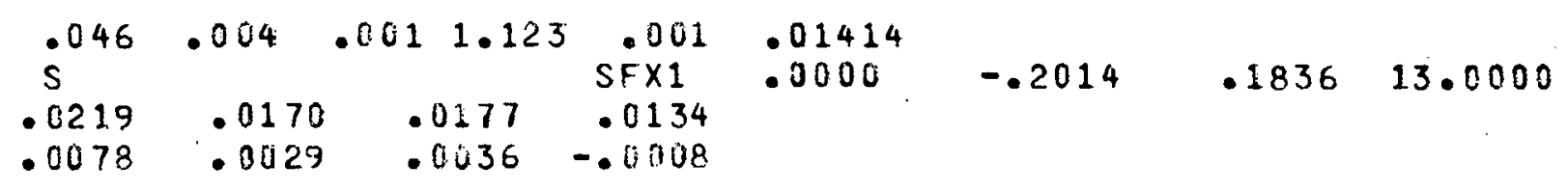

S $22 A$

\begin{tabular}{|c|c|c|c|c|c|c|c|}
\hline $\begin{array}{l}.067 \\
.0311 \\
.0365\end{array}$ & $\begin{array}{l}.004 \\
.0240 \\
.0006\end{array}$ & $\begin{array}{c}.0011 .123 \\
.0250 \\
.0004\end{array}$ & $\begin{array}{c}.001 \\
S F \times 1 \\
.0214 \\
-.0932\end{array}$ & $\begin{array}{l}.02456 \\
.0000\end{array}$ & .7926 & .2229 & 12.0000 \\
\hline
\end{tabular}

요

S. 23

\begin{tabular}{|c|c|c|c|c|c|c|c|}
\hline $\begin{array}{l}.135 \\
.0925 \\
.0017\end{array}$ & $\begin{array}{r}.080 \\
.0720 \\
.0222\end{array}$ & $\begin{array}{r}.0011 .123 \\
.0788 \\
-.0153\end{array}$ & $\begin{array}{r}.001 \\
\text { SFX1 } \\
.0848 \\
-.0094\end{array}$ & $\begin{array}{l}.09418 \\
.0056\end{array}$ & -2.4206 & .0458 & 6.0000 \\
\hline
\end{tabular}

S $23 R$

\begin{tabular}{|c|c|c|c|c|c|c|c|}
\hline$\dot{s}^{133}$ & .000 & .0011 .123 & $\begin{array}{l}.001 \\
S F \times 1\end{array}$ & $\begin{array}{l}.09418 \\
.0058\end{array}$ & -2.6630 & .0459 & 5.0000 \\
\hline $\begin{array}{r}.0916 \\
.0026\end{array}$ & $\begin{array}{r}.0713 \\
-00228\end{array}$ & $\begin{array}{r}.0781 \\
-.0160\end{array}$ & $\begin{array}{r}.0839 \\
-.0103\end{array}$ & & & & \\
\hline
\end{tabular}

S 24

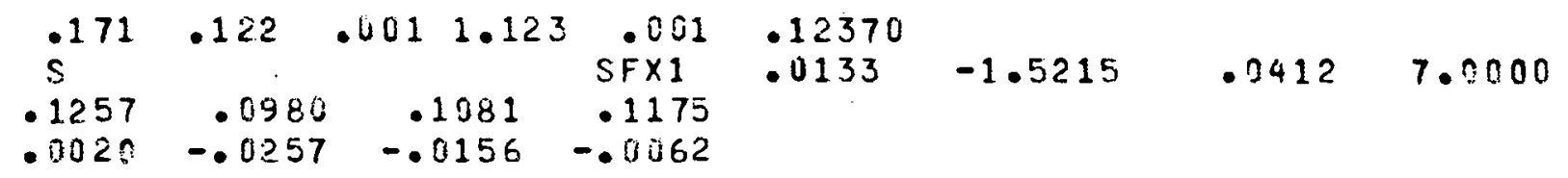


S 25

$\begin{array}{cccccccc}.227 & .177 & .001 & 1.123 & .001 & .18462 & & \\ S & & & .002 & .0000 & 16.2489 & .0010 & .2948 \\ .1732 & .1350 & .1494 & .1740 & & & & \\ -.0115 & -.04496 & -.0352 & -.0106 & & & \end{array}$

S 26

$\begin{array}{cccccccc}.435 & .357 & .061 & 1.123 & .001 & .37863 & & \\ S & & & S 02 & .0139 & 20.9800 & .0039 & .4534 \\ .3358 & .2777 & .3092 & .3585 & & & & \\ -.0228 & -.010 & -.0694 & -.0201 & & & \end{array}$

S 27

$\begin{array}{llllllll}.507 & .716 & .691 & 1.123 & .001 & .66987 & & \\ I & & & .040 & .0466 & 0.0000 & 0.0000 & 0.0000 \\ .6720 & .6713 & .6720 & .5713 & & & & \\ .0322 & .0015 & .0022 & .0015 & & & & \end{array}$

용

S 28

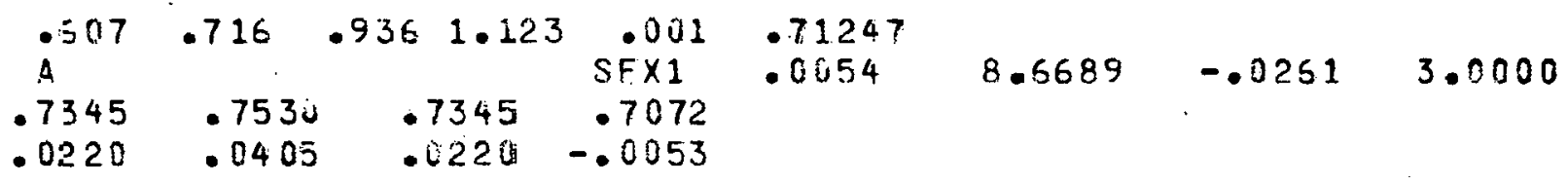

A 5

$\begin{array}{cccccccc}.073 & .053 & .123 & 1.123 & .001 & .09849 & & \\ A & & & \text { A0PC } & .0015 & .5995 & .0077 & 1.1230 \\ .0777 & .0830 & .0777 & .0943 & & & & \\ -.0208 & -.0155 & -.0208 & -.0042 & & & & \end{array}$

A 7

$\begin{array}{rrrrrrrr}.175 & .126 & .309 & 1.123 & .001 & .22886 & & \\ A & & & \text { AOPC } & .0026 & 1.05730 & .0053 & 1.1230 \\ .1895 & .2033 & .1895 & .2103 & & & & \\ -.0393 & -.0255 & -.0393 & -.0185 & & & \end{array}$




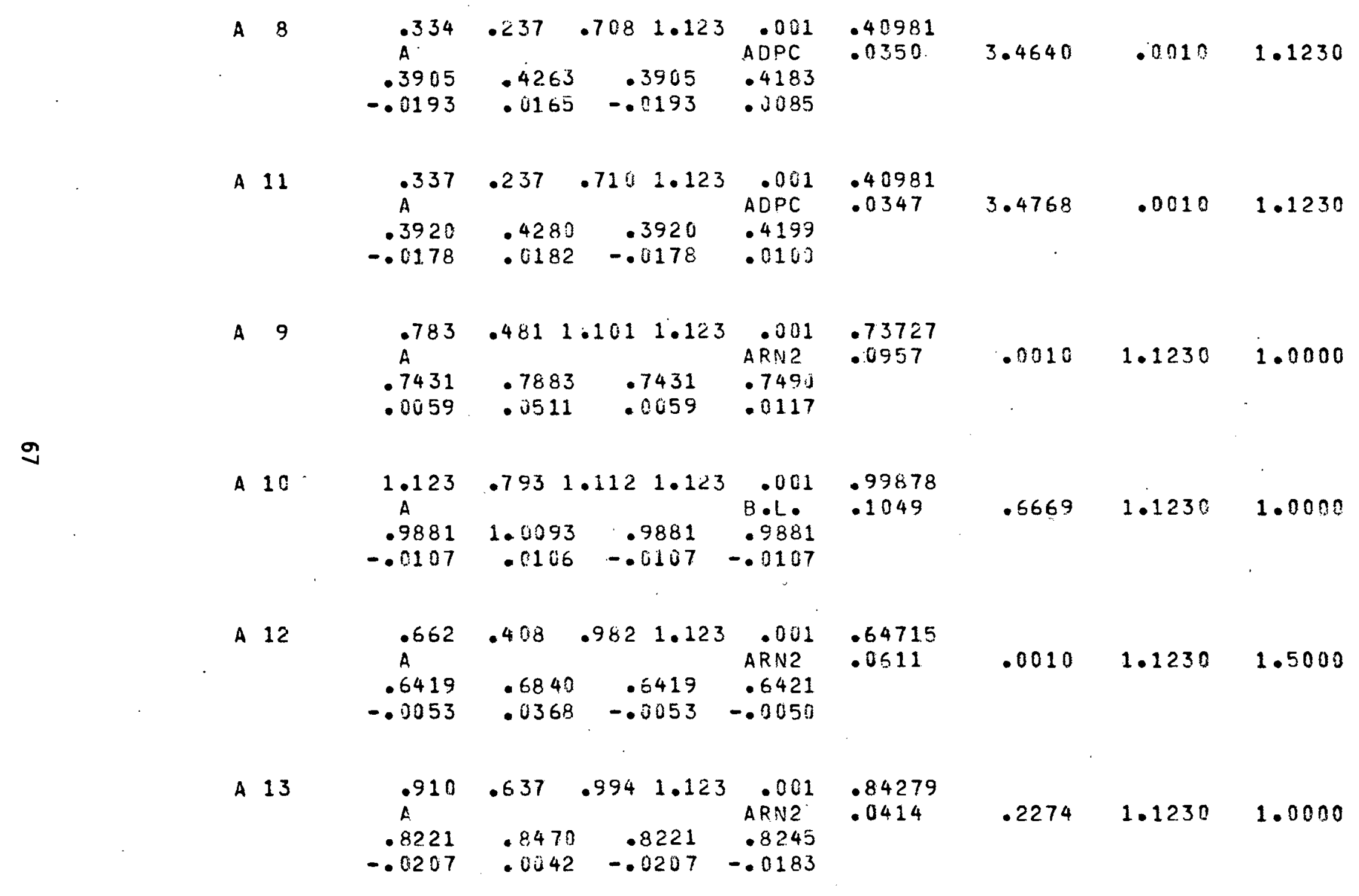




\begin{tabular}{|c|c|c|c|c|c|c|c|}
\hline .914 & .787 & .9941 .123 & $\begin{array}{l}.001 \\
\text { ARN2 }\end{array}$ & $\begin{array}{l}.88319 \\
.0058\end{array}$ & .4950 & 1.0864 & 1.0000 \\
\hline $\begin{array}{r}.8835 \\
.0034\end{array}$ & $\begin{array}{r}.8983 \\
.0151\end{array}$ & $\begin{array}{r}.5835 \\
.0004\end{array}$ & $\begin{array}{l}.8893 \\
.0061\end{array}$ & & & & \\
\hline
\end{tabular}

A 4

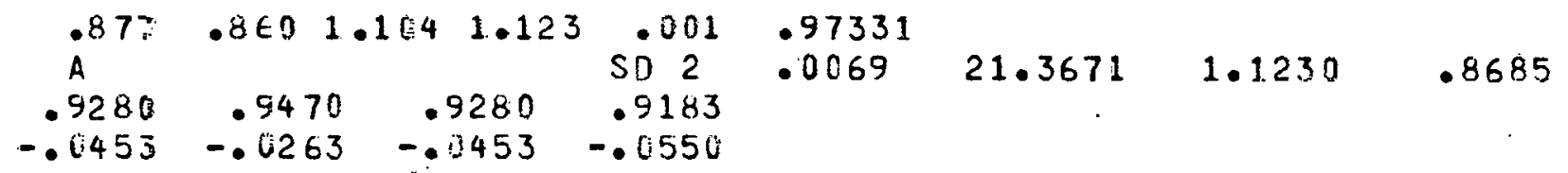

A 5

$\begin{array}{cccccccc}1.122 & .945 & 1.112 & 1.123 & .001 & 1.03918 & & \\ A & 0.012 & .0557 & .8749 & 1.1230 & 1.0000 \\ 1.0485 & 1.0600 & 1.0489 & 1.0403 & & & & \\ .0099 & .0208 & .0098 & .0011 & & & \end{array}$

\section{10 IA}

.001
1351

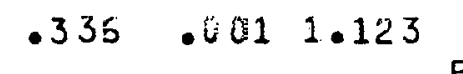

1351
.0381

$$
.1127
$$

.001 B.L.

.1351

.09699

$.4595 \quad .0010 \quad 1.0000$

C IORIA

$\begin{array}{llllllll}.003 & .336 & .001 & 1.123 & .011 & .03699 & & \\ S & & & 0.0 .0 & .1078 & .4611 & .0010 & 1.0000 \\ .1358 & .1133 & .1358 & .1358 & .078 & & & \\ .0388 & .0163 & .0388 & .0383 & & & \end{array}$

C 9 IA

$\begin{array}{lccccccc}.326 & .645 & .007 & 1.123 & .001 & .35850 & & \\ S & & & 0.0 .10 & .1049 & 1.1230 & .0010 & 1.0000 \\ .3724 & .3260 & .3724 & .3724 & & & & \\ .0139 & -.0325 & .0139 & .0139 & & & \end{array}$


웅

\begin{tabular}{|c|c|c|c|c|c|c|c|c|c|}
\hline C & 9R I A & $\begin{array}{l}.329 \\
.3 \\
.3735 \\
.0150\end{array}$ & $\begin{array}{r}.645 \\
. .3270 \\
-.0315\end{array}$ & $\begin{array}{c}.0071 .123 \\
.3735 \\
.0150\end{array}$ & $\begin{array}{l}.001 \\
\text { B.L. } \\
.3735 \\
.0150\end{array}$ & $\begin{array}{l}.35850 \\
.1047\end{array}$ & 1.1230 & .0010 & 1.0000 \\
\hline C & 8 I A & $\begin{array}{l}.786 \\
. \\
.7356 \\
.0497\end{array}$ & $\begin{array}{r}.888 \\
.7007 \\
.0147\end{array}$ & $\begin{array}{c}.428 i .123 \\
.7356 \\
.0497\end{array}$ & $\begin{array}{l}.001 \\
A D P C \\
.7101 \\
.0242\end{array}$ & $\begin{array}{l}.68596 \\
.0303\end{array}$ & 3.4280 & $1.123 n$ & .0010 \\
\hline$C$ & 7 I A & $\begin{array}{l}.950 \\
.9348 \\
.0679\end{array}$ & $\begin{array}{r}.998 \\
.9210 \\
.0541\end{array}$ & $\begin{array}{c}.8151 .123 \\
.9348 \\
.0679\end{array}$ & $\begin{array}{l}.001 \\
A D P C \\
.9140 \\
.0471\end{array}$ & $\begin{array}{l}.86691 \\
.0021\end{array}$ & 1.5749 & 1.1194 & .0010 \\
\hline
\end{tabular}

\begin{tabular}{|c|c|c|c|c|c|c|c|c|c|}
\hline C & 2 IA & $\begin{array}{c}1.049 \\
S \\
1.0453 \\
.0480\end{array}$ & $\begin{array}{r}1.0591 \\
1.0403 \\
.0431\end{array}$ & $\begin{array}{c}.0031 .123 \\
1.0453 \\
.0480\end{array}$ & $\begin{array}{c}.001 \\
\text { AOPC } \\
1.0294 \\
.0321\end{array}$ & $\begin{array}{l}.99728 \\
.0020\end{array}$ & .5648 & 1.1110 & .0010 \\
\hline C & 1 & $\begin{array}{l}.848 \\
.8 \\
.8104 \\
.0257\end{array}$ & $\begin{array}{r}.737 \\
.8204 \\
.0353\end{array}$ & $\begin{array}{c}.8751 .123 \\
.8104 \\
.0257\end{array}$ & $\begin{array}{l}.001 \\
\text { ARN2 } \\
.8139 \\
.0292\end{array}$ & $\begin{array}{l}.78470 \\
.0163\end{array}$ & .5475 & .9471 & 1.0000 \\
\hline C & 3 & $\begin{array}{l}.748 \\
.7 \\
.7816 \\
.0473\end{array}$ & $\begin{array}{r}.571 \\
.7020 \\
.0477\end{array}$ & $\begin{array}{c}.6871 .123 \\
.7016 \\
.0473\end{array}$ & $\begin{array}{l}.001 \\
\text { SD } 2 \\
.7107 \\
.0564\end{array}$ & $\begin{array}{l}.65433 \\
.0265\end{array}$ & 4.1700 & .6790 & 1.0285 \\
\hline
\end{tabular}




\begin{tabular}{|c|c|c|c|c|c|c|c|c|c|c|}
\hline C & 4 & I A & $\begin{array}{l}.589 \\
5 \\
.5371 \\
.0637\end{array}$ & $\begin{array}{l}.565 \\
.4853 \\
.4120\end{array}$ & $\begin{array}{c}.3021 .123 \\
.5063 \\
.0329\end{array}$ & $\begin{array}{c}.001 \\
s 52 \\
.5337 \\
.0603\end{array}$ & $\begin{array}{l}.47338 \\
.0000\end{array}$ & 23.2102 & .1568 & .5890 \\
\hline C & 5 & I A & $\begin{array}{l}.245 \\
s \\
.2400 \\
.0040\end{array}$ & $\begin{array}{r}.384 \\
.2120 \\
-.0240\end{array}$ & $\begin{array}{c}.00 ? 1.123 \\
.2400 \\
.0040\end{array}$ & $\begin{array}{l}.001 \\
\text { ARN2 } \\
.2445 \\
.0085\end{array}$ & $\begin{array}{l}.23604 \\
.0512\end{array}$ & .7316 & .0010 & 1.0000 \\
\hline C & & R I A & $\begin{array}{c}.238 \\
.2360 \\
-.0001\end{array}$ & $\begin{array}{l}.386 \\
.2083 \\
-.0277\end{array}$ & $\begin{array}{c}.00 i 1.123 \\
.2360 \\
-.0001\end{array}$ & $\begin{array}{r}.001 \\
\text { ARN2 } \\
.2408 \\
.0047\end{array}$ & $\begin{array}{l}.23604 \\
.0601\end{array}$ & .7203 & .0010 & 1.0000 \\
\hline$c$ & 6 & I A & $\begin{array}{l}.005 \\
.0616 \\
.0212\end{array}$ & $\begin{array}{c}.149 \\
.0517 \\
.0113\end{array}$ & $\begin{array}{c}.0011 .123 \\
.0616 \\
.0212\end{array}$ & $\begin{array}{r}.001 \\
\text { ARN2 } \\
.0695 \\
.0292\end{array}$ & $\begin{array}{l}.04040 \\
.0463\end{array}$ & .2069 & .0010 & 1.0000 \\
\hline C & $=37$ & I A & $\begin{array}{l}.250 \\
5 \\
.3134 \\
.0208\end{array}$ & $\begin{array}{r}.565 \\
.2730 \\
-.0196\end{array}$ & $\begin{array}{r}.0041 .12 \Xi \\
.3134 \\
.3208\end{array}$ & $\begin{array}{l}.001 \\
B . L \\
.3134 \\
.0208\end{array}$ & $\begin{array}{l}.29253 \\
.1089\end{array}$ & 1.1230 & .0010 & 1.0000 \\
\hline $\mathbf{S}$ & 21 & C & $\begin{array}{r}.133 \\
5 \\
.0770 \\
-.3039\end{array}$ & $\begin{array}{r}.045 \\
.0557 \\
-.0213\end{array}$ & $\begin{array}{r}.0011 .123 \\
.0641 \\
-.0169\end{array}$ & $\begin{array}{l}.001 \\
\text { SFX1 } \\
.0680 \\
.0129\end{array}$ & $\begin{array}{l}.09092 \\
.0002\end{array}$ & .9704 & .0884 & 7.0000 \\
\hline
\end{tabular}




\begin{tabular}{|c|c|c|c|c|c|c|c|c|c|c|}
\hline C & 36 & $\begin{array}{c}.085 \\
.0071 \\
-.0139\end{array}$ & $\begin{array}{r}.093 \\
.0600 \\
-.0209\end{array}$ & $\begin{array}{c}.0021 .123 \\
0.0671 \\
-.0139\end{array}$ & $\begin{array}{l}.001 \\
\text { SF } \times 1 \\
.0677 \\
-.0132\end{array}$ & $\begin{array}{l}.08092 \\
.0198\end{array}$ & $-12 \cdot 2454$ & .0277 & 5.0000 & \\
\hline C & 35 & $\begin{array}{c}.112 \\
.0499 \\
-.0310\end{array}$ & $\begin{array}{r}.002 \\
.0383 \\
-.0426\end{array}$ & $\begin{array}{c}.0011 .123 \\
3 \quad .0397 \\
6 \quad-.0412\end{array}$ & $\begin{array}{c}.001 \\
S F \times 1 \\
.0382 \\
-.0427\end{array}$ & $\begin{array}{l}.08092 \\
.0002\end{array}$ & 2.0704 & .3976 & 0.0000 & \\
\hline C & 33 & $\begin{aligned} & .486 \\
. & 35.35 \\
-. & 6812\end{aligned}$ & $\begin{array}{r}.269 \\
.3407 \\
-.1041\end{array}$ & $\begin{array}{c}.267 \quad 1.123 \\
7 \quad .3433 \\
1 \quad-.1014\end{array}$ & $\begin{array}{c}.031 \\
\text { SD2 } \\
.3802 \\
-.0645\end{array}$ & $\begin{array}{l}.44473 \\
.0008\end{array}$ & 5.3850 & .2680 & $1.123 n$ & \\
\hline C & 11 & $\begin{array}{l}.002 \\
.1168 \\
.0199\end{array}$ & $\begin{array}{l}.095 \\
.1517 \\
. \quad 547\end{array}$ & $\begin{array}{c}.448 \quad 1.123 \\
.1168 \\
.0199\end{array}$ & $\begin{array}{c}.001 \\
S F \times 1 \\
.0830 \\
-.0139\end{array}$ & $\begin{array}{l}.09699 \\
.0006\end{array}$ & 25.0880 & -.5682 & 10.0000 & \\
\hline$c$ & $11 R$ & $\begin{array}{l}.003 \\
.1159 \\
.0189\end{array}$ & $\begin{array}{l}.005 \\
.1503 \\
.0533\end{array}$ & $\begin{array}{c}.443 \quad 1.123 \\
.1159 \\
.0189\end{array}$ & $\begin{array}{c}.001 \\
S F \times 1 \\
.0820 \\
-.0150\end{array}$ & $\begin{array}{l}.09699 \\
.0011\end{array}$ & 25.1197 & -.5538 & 11.0000 & $\begin{array}{l}\text { Repeat } \\
\text { of } \\
\text { above }\end{array}$ \\
\hline
\end{tabular}




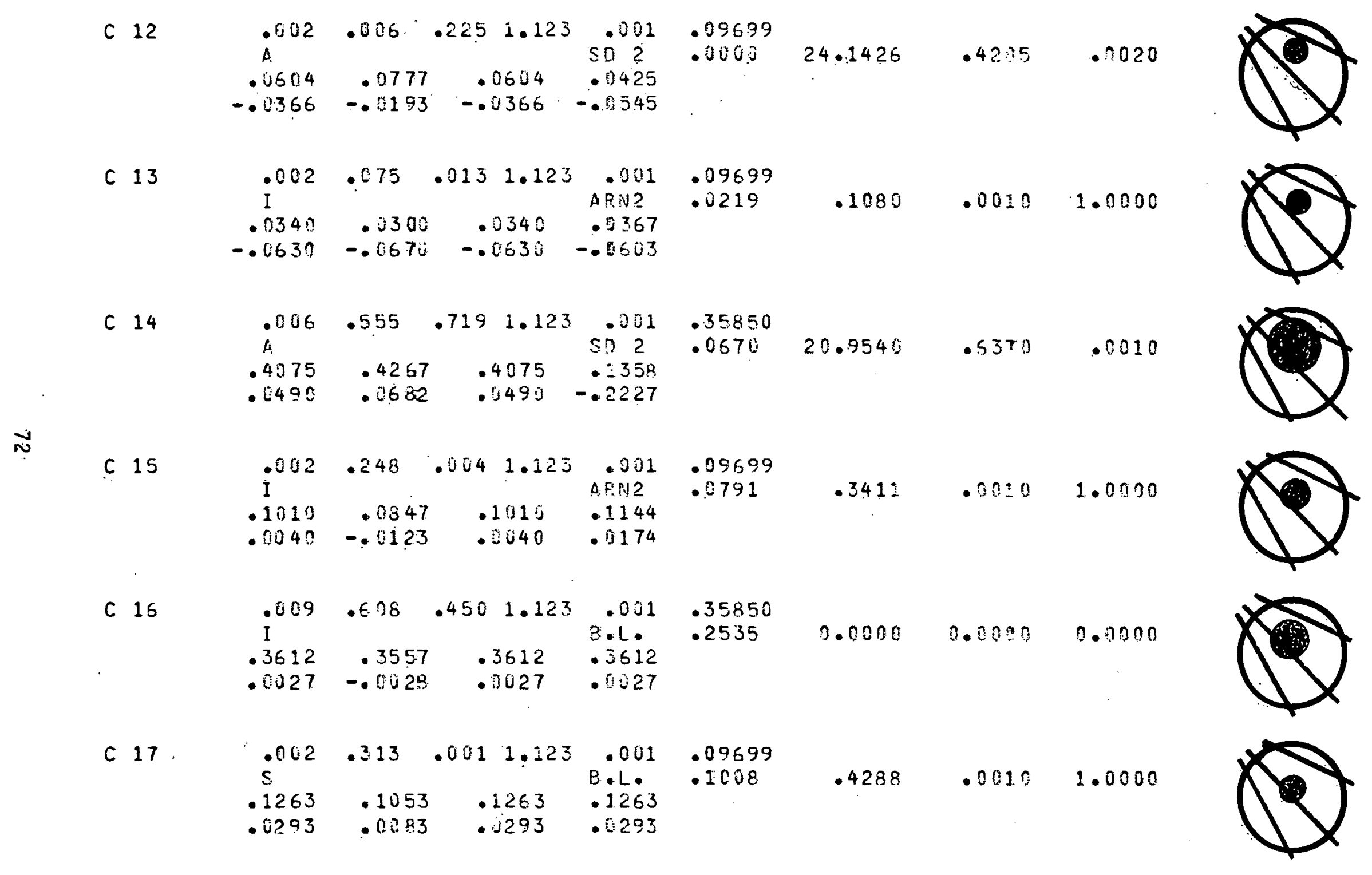


C 18

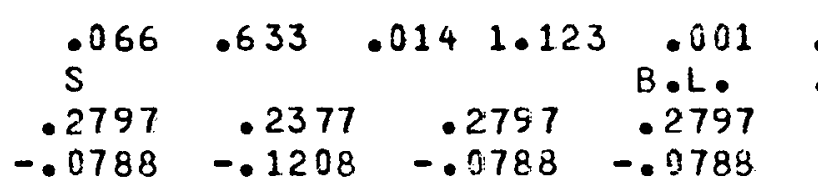

C 19

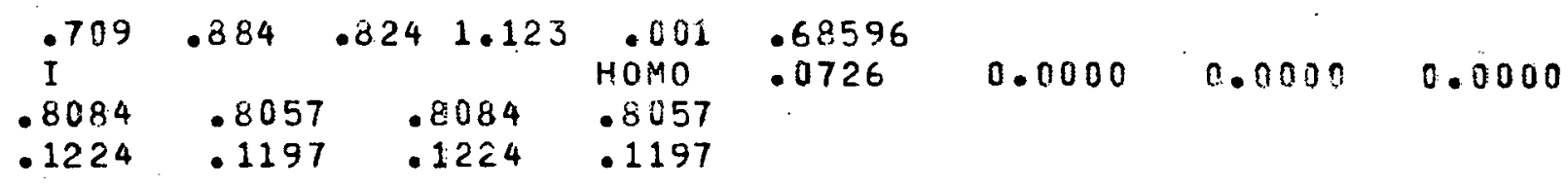

C 23

$\begin{array}{llllllll}.002 & .323 & .001 & 1.123 & .001 & .09699 & & \\ S & & & B .1 .0 & .1040 & .4425 & .0010 & 1.0000 \\ .1303 & .1087 & .1303 & .1303 & & & & \\ .0333 & .0117 & .0333 & .0333 & & & \end{array}$

$w$

C 24

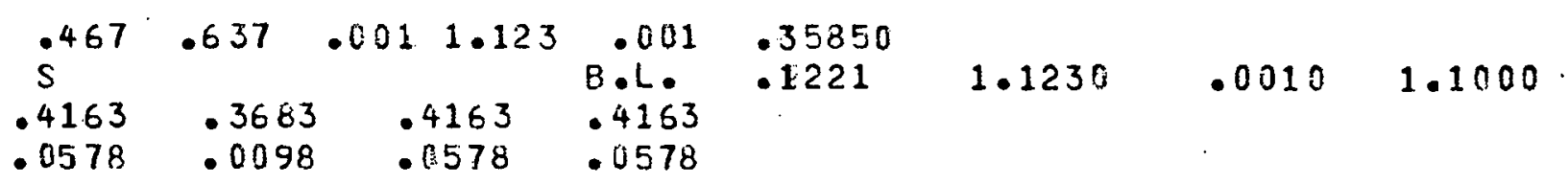

\begin{tabular}{|c|c|c|c|c|c|c|c|}
\hline $\begin{array}{l}.005 \\
.1113\end{array}$ & $\begin{array}{l}.273 \\
.0930\end{array}$ & $\begin{array}{c}.0011 .123 \\
.1113\end{array}$ & $\begin{array}{l}.001 \\
A R N 2 \\
.1252\end{array}$ & $\begin{array}{l}.09699 \\
.0865\end{array}$ & & .0010 & $1.000 n$ \\
\hline 0143 & -.0340 & .0143 & .0292 & & 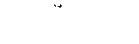 & & \\
\hline
\end{tabular}

C 25

$\begin{array}{llllllll}.854 & .884 & .014 & 1.123 & .001 & .68596 & & \\ S & & & 8.0 .0 & .2437 & 1.1230 & .0010 & 2.5000 \\ .6520 & .5840 & .6520 & .6520 & & & & \\ -.0340 & -.01020 & -.0340 & -.0340 & & & \end{array}$

C 26
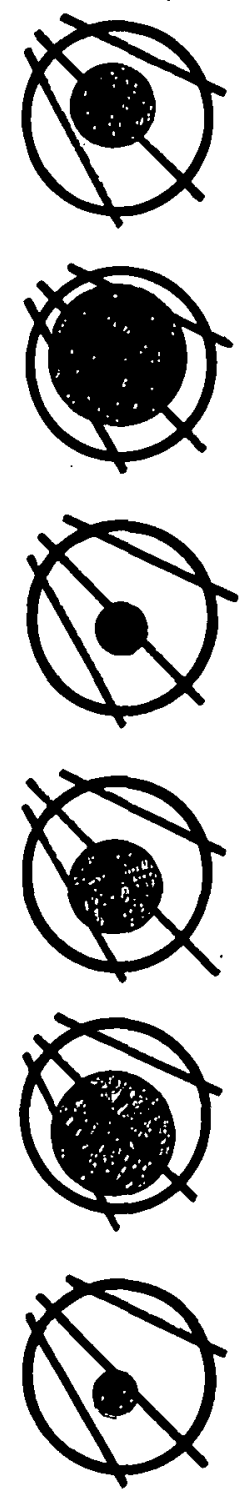


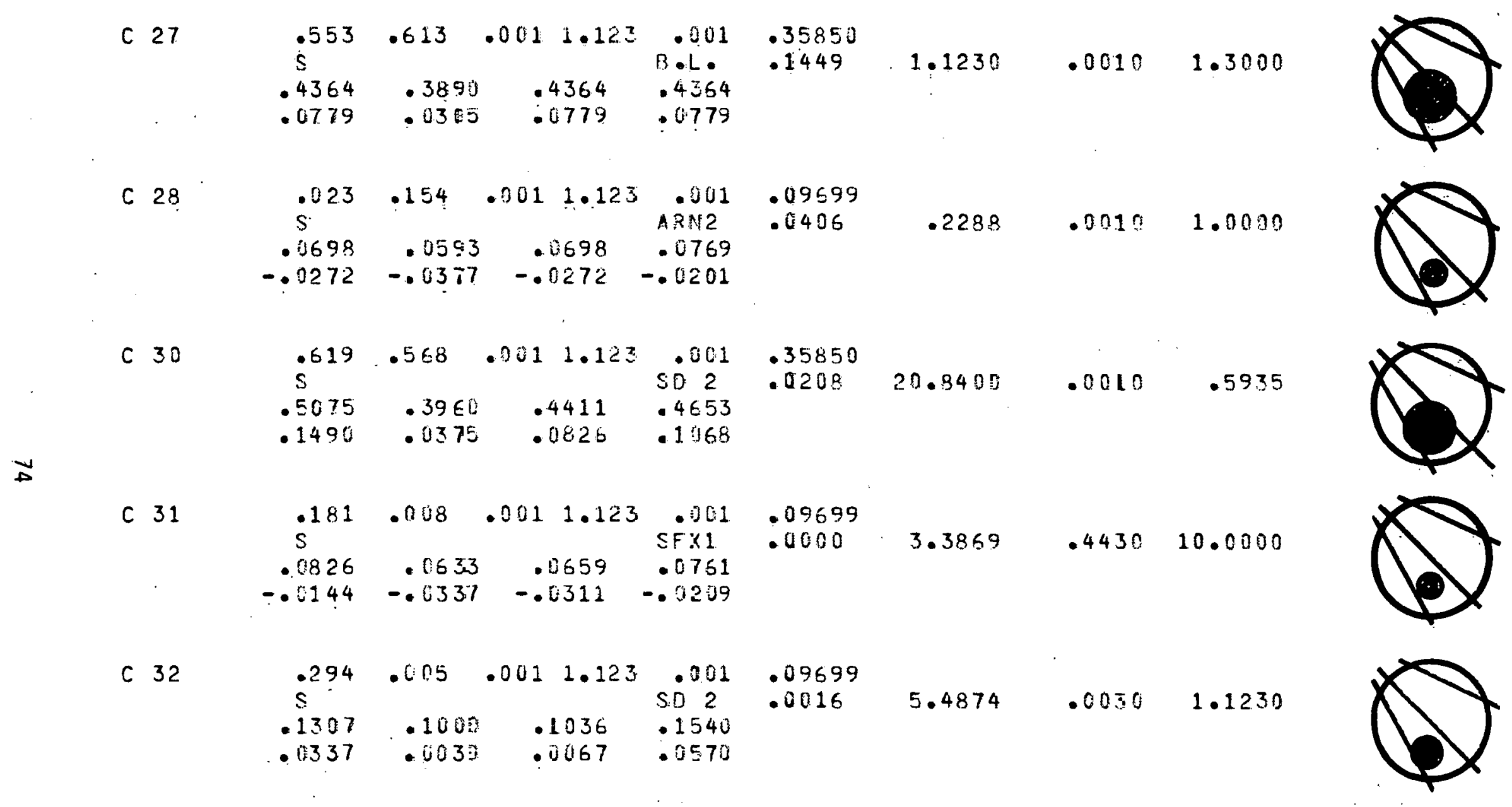


SIMULATED DATA

SD

\begin{tabular}{|c|c|c|c|c|c|c|c|}
\hline $\begin{array}{l}.147 \\
. s \\
.1162 \\
.0039\end{array}$ & $\begin{array}{l}.100 \\
.1157 \\
.0034\end{array}$ & $\begin{array}{r}.100 .900 \\
.1162 \\
.1039\end{array}$ & $\begin{array}{l}.100 \\
\text { SF X1 } \\
.1147 \\
.0024\end{array}$ & $\begin{array}{l}.11231 \\
.0013\end{array}$ & $\begin{array}{r}1.2500 \\
.9650\end{array}$ & $\begin{array}{l}-1000 \\
-2507\end{array}$ & $\begin{array}{r}.9000 \\
-11.0000\end{array}$ \\
\hline $\begin{array}{l}.252 \\
S \\
.1524 \\
.0159\end{array}$ & $\begin{array}{r}.100 \\
.1507 \\
.0177\end{array}$ & $\begin{array}{r}.100 .900 \\
.1524 \\
-.0159\end{array}$ & $\begin{array}{c}.100 \\
S F \times 1 \\
.1656 \\
-.0027\end{array}$ & $\begin{array}{l}.16832 \\
.0045\end{array}$ & $\begin{array}{l}4.2000 \\
4.0236\end{array}$ & $\begin{array}{l}.1000 \\
.6634\end{array}$ & $\begin{array}{r}.9900 \\
-5.0000\end{array}$ \\
\hline
\end{tabular}

SD

$\begin{array}{llllll}.289 & .133 & .100 & .900 & .100 & .19437 \\ S & & & S F \times 1 & .0015 \\ .1964 & .1740 & .1784 & .1938 & \\ .0020 & -.0204 & -.0160 & -.0606 & \end{array}$

\subsection{0}

4.9909

$.1000 \quad .9000$

$.5310-5.0000$

$.0020-.0204-.0160-.0006$

SD

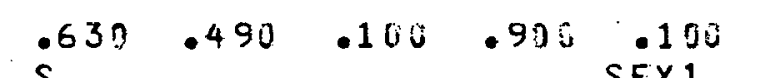

$$
\text { s } 6
$$

$$
.494
$$$$
.0032
$$

89

$49107 \quad 14.0000$ $.0302 \quad 13.3952$

SD

$\begin{array}{ccccccccc}.895 & .768 & .118 & .90 & .100 & .73189 & 21.0000 & .1000 & .9000 \\ S & & & & S F \times 1 & .0055 & 21.0016 & 1.2179 & -5.0000 \\ .7286 & .5937 & .6462 & .7319 & & & & & \\ -.0033 & -. .1382 & -.0857 & .0001 & & & & & \end{array}$


SO

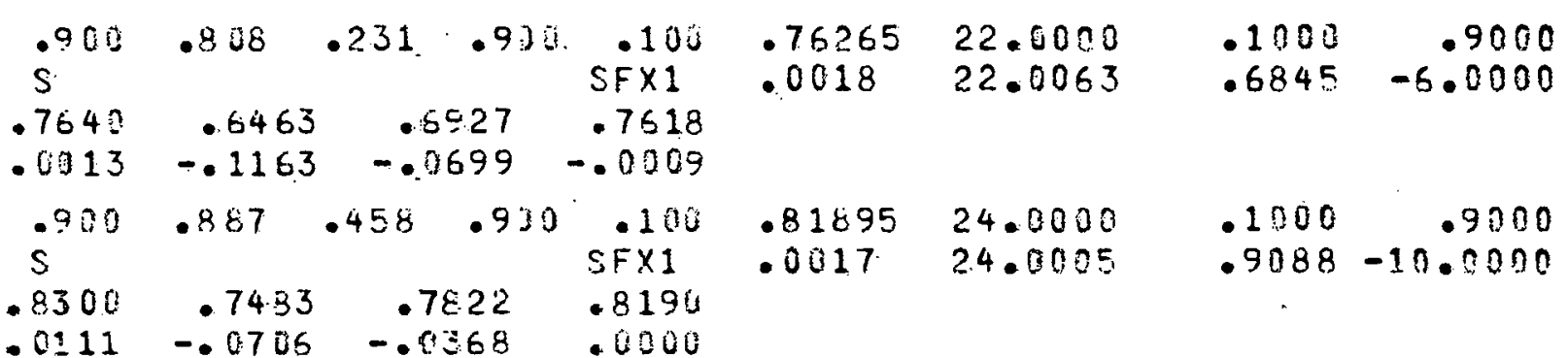

So

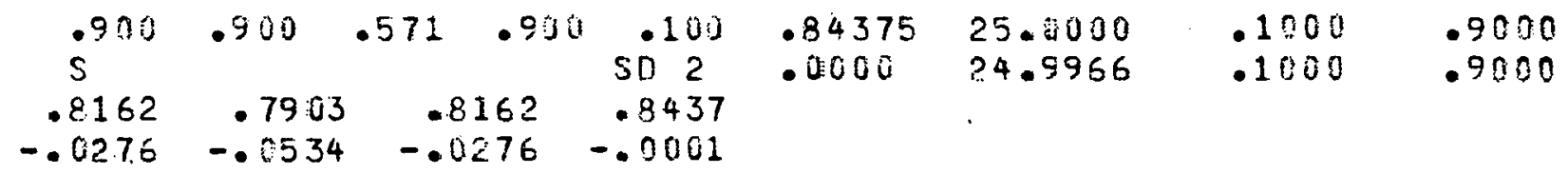

SD

$\begin{array}{ccccccccc}.900 & .990 & .798 & .900 & .100 & .88385 & 27.9000 & .1000 & .9000 \\ 5 & & & 502 & .0000 & 26.9999 & .1000 & .9000 \\ .8740 & .8660 & .8740 & .8839 & & & \end{array}$

SD

\begin{tabular}{|c|c|c|c|c|c|c|c|}
\hline$\dot{s}^{.324}$ & .300 & .300 .300 & $\begin{array}{l}.100 \\
\text { HOMO }\end{array}$ & $\begin{array}{l}.30615 \\
.0113\end{array}$ & $\begin{array}{l}1.2500 \\
0.2000\end{array}$ & $\begin{array}{r}.3000 \\
0.0090\end{array}$ & $\begin{array}{r}.7 .000 \\
0.0000\end{array}$ \\
\hline $\begin{array}{l}.3383 \\
.6321\end{array}$ & $\begin{array}{l}.3080 \\
.0018\end{array}$ & $\begin{array}{l}.3883 \\
.0421\end{array}$ & $\begin{array}{r}.3080 \\
.0018\end{array}$ & & & 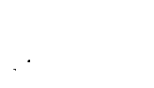 & \\
\hline
\end{tabular}

So:

\begin{tabular}{|c|c|c|c|c|c|c|c|c|}
\hline $\begin{aligned} & .136 \\
. & 1124 \\
. & 0332\end{aligned}$ & $\begin{array}{l}.100 \\
.1120 \\
.0028\end{array}$ & .100 & $\begin{array}{l}.910 \\
124 \\
0.2\end{array}$ & $\begin{array}{l}.100 \\
\text { HOMO } \\
.1120 \\
.0028\end{array}$ & $\begin{array}{l}.10923 \\
.0170\end{array}$ & $\begin{array}{l}1.3500 \\
3.3000\end{array}$ & $\begin{array}{r}.1000 \\
0.0000\end{array}$ & $\begin{array}{r}.7000 \\
0.0000\end{array}$ \\
\hline
\end{tabular}

SD

$\begin{array}{lcccccccc}.336 & .300 & .300 & .906 & .100 & .30923 & 1.2500 & .3000 & .9000 \\ 5 & & & .3040 & .0170 & 0.0000 & 0.0000 & 0.0000 \\ .3124 & .3120 & .3124 & .3120 & & & & \\ .0032 & .0028 & .0132 & .0028 & & & & \end{array}$


SD

\begin{tabular}{|c|c|c|c|c|c|c|}
\hline$\dot{s}^{900}$ & .900 & .739 .900 & $\begin{array}{l}.100 \\
S F \times 1\end{array}$ & $\begin{array}{l}.87424 \\
.0015\end{array}$ & $\begin{array}{l}26.0000 \\
26.5164\end{array}$ & $\begin{array}{rr}.3080 & .9000 \\
.4118 & -13.0000\end{array}$ \\
\hline $\begin{array}{l}.8590 \\
.0153\end{array}$ & $\begin{array}{r}.8463 \\
-.0279\end{array}$ & $\begin{array}{r}.8590 \\
-.0153\end{array}$ & $\begin{array}{r}.8709 \\
-.0033\end{array}$ & & & \\
\hline
\end{tabular}

SD

\begin{tabular}{|c|c|c|c|}
\hline $\begin{array}{l}.700 \\
s\end{array}$ & .700 & .539 .900 & $S \cdot 100$ \\
\hline $\begin{array}{l}.6590 \\
.0153\end{array}$ & $\begin{array}{r}.6463 \\
-.0279\end{array}$ & $\begin{array}{r}.6590 \\
-.0153\end{array}$ & $\begin{array}{r}.6734 \\
-.6009\end{array}$ \\
\hline
\end{tabular}

$\begin{array}{llll}.67424 & 25.0000 & .1000 & .7000 \\ .0168 & 27.2299 & .0193 & 3.0000\end{array}$

SD

\begin{tabular}{|c|c|c|c|}
\hline$\dot{s}^{700}$ & .730 & .592 .900 & $\begin{array}{l}.100 \\
A D P C\end{array}$ \\
\hline $\begin{array}{l}.6725 \\
.0103\end{array}$ & $\begin{array}{r}.6649 \\
-.0588\end{array}$ & $\begin{array}{r}.6725 \\
-.0103\end{array}$ & $\begin{array}{r}.6502 \\
-.0225\end{array}$ \\
\hline
\end{tabular}

\begin{tabular}{|c|c|c|c|}
\hline $\begin{array}{l}.68283 \\
.0115\end{array}$ & $\begin{array}{r}26.0000 \\
1.6320\end{array}$ & $\begin{array}{l}.3000 \\
.7911\end{array}$ & $\begin{array}{l}.7000 \\
.1000\end{array}$ \\
\hline
\end{tabular}

SD

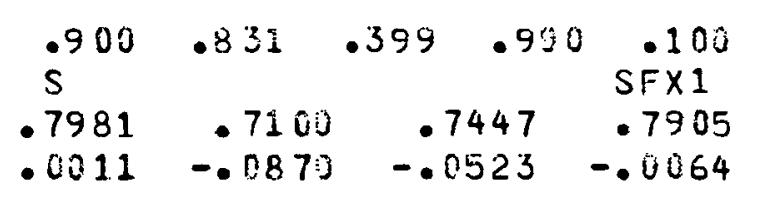

SO

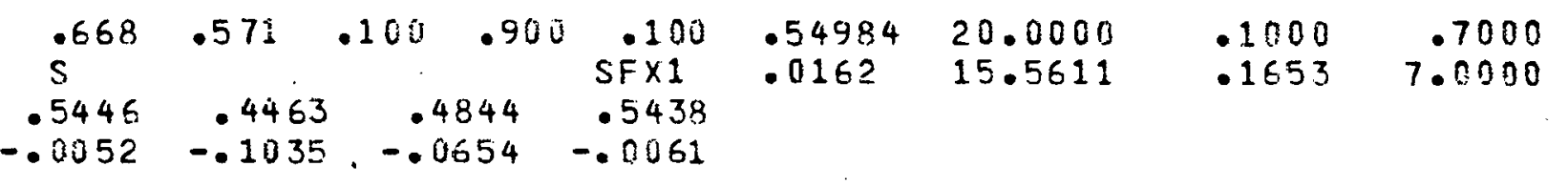




$\begin{array}{lcccccccc}.700 & .631^{\circ} & .199 & .900 & .100 & .59699 & 22.0000 & .1000 & .7000 \\ S & & & & S F \times 1 & .0174 & 17.3796 & .0727 & 4.0000 \\ .5981 & .5100 & .5447 & .5960 & & & & \\ .0011 & -.0870 & -.0523 & -.0010 & & & & \end{array}$

SD

$\begin{array}{lllllllll}.395 & .316 & .300 & .960 & .100 & .34718 & 5.0000 & .3000 & .7000 \\ 5 & & & \text { So } 2 & .0000 & 4.9689 & .3000 & .7038 \\ .3482 & .3370 & .3392 & .3472 & & & & \\ .0010 & -.0102 & -.0080 & .0000 & & & \end{array}$

SO

$.0010 \quad-.0102 \quad-.0080 \quad .0000$.

$\infty$

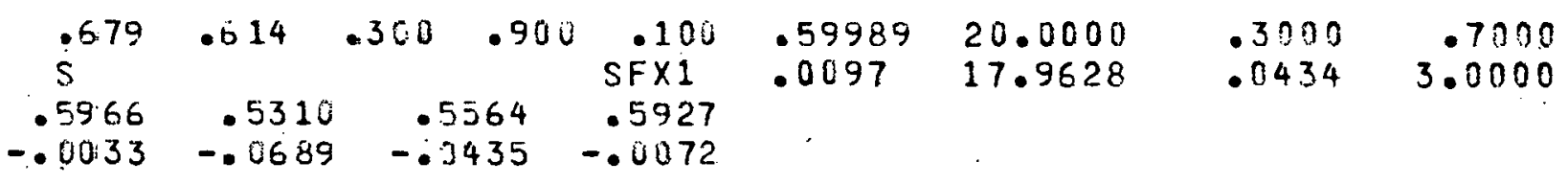

SD

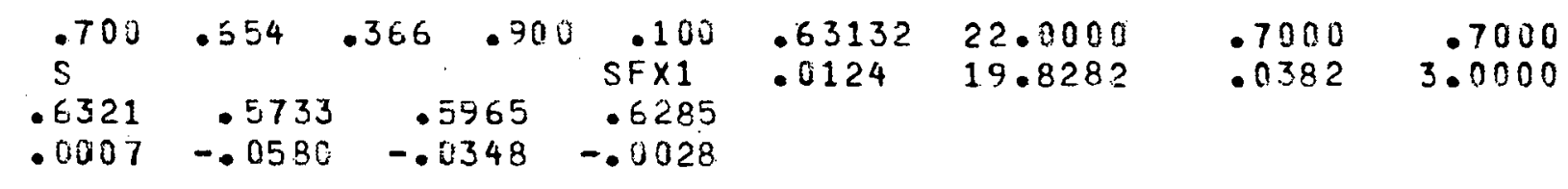

IṢD

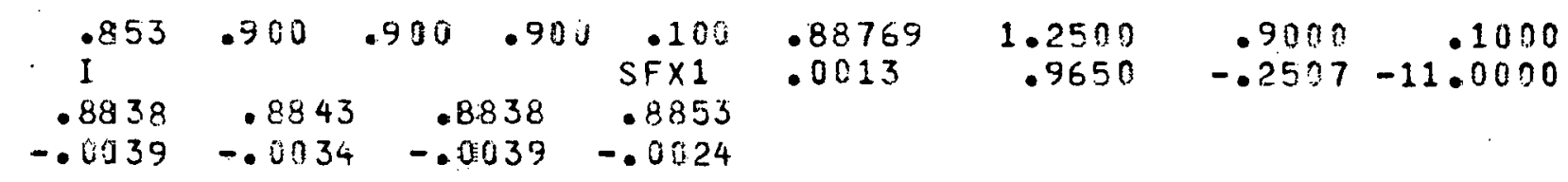

ISD

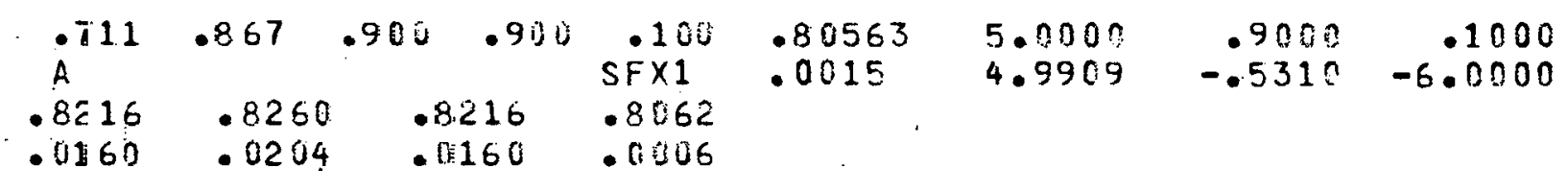




\begin{tabular}{|c|c|c|c|c|c|c|c|c|c|}
\hline ISD & $\begin{array}{l}.100 \\
.3073 \\
.0699\end{array}$ & $\begin{array}{r}.192 \\
.3537 \\
.1163\end{array}$ & $\begin{array}{r}.769 \\
. \\
.\end{array}$ & $\begin{array}{l}.900 \\
73 \\
99\end{array}$ & $\begin{array}{l}.100 \\
S F \times 1 \\
.2382 \\
.0009\end{array}$ & $\begin{array}{l}.23735 \\
.0018\end{array}$ & $\begin{array}{l}22.0000 \\
22.0063\end{array}$ & $\begin{array}{r}.9000 \\
-.6845\end{array}$ & $\begin{array}{r}.1000 \\
-6.0000\end{array}$ \\
\hline ISD & $\begin{array}{c}.100 \\
.1548 \\
.15204\end{array}$ & $\begin{array}{c}.100 \\
.1717 \\
.0373 \\
.\end{array}$ & $\begin{array}{r}.315 \\
.\end{array}$ & $\begin{array}{l}.900 \\
548 \\
264\end{array}$ & $\begin{array}{l}.103 \\
S F \times 1 \\
.1368 \\
.0024\end{array}$ & $\begin{array}{l}.13434 \\
.0006\end{array}$ & $\begin{array}{l}26.0000 \\
26.0006\end{array}$ & $\begin{array}{r}.9000 \\
-.5559\end{array}$ & $\begin{array}{r}.1000 \\
-9.0000\end{array}$ \\
\hline$A D$ & $\begin{array}{r}.109 \\
.1102 \\
-.0037\end{array}$ & $\begin{array}{r}.107 \\
.1110 \\
-.0030\end{array}$ & $\begin{array}{r}.117 \\
. \\
.1\end{array}$ & $\begin{array}{l}.900 \\
102 \\
37\end{array}$ & $\begin{array}{l}.100 \\
\text { HOMO } \\
.1110 \\
-.0030\end{array}$ & $\begin{array}{l}.11397 \\
.0043\end{array}$ & $\begin{array}{r}.1250 \\
0.000 ?\end{array}$ & $\begin{array}{r}.1000 \\
0.0000\end{array}$ & $\begin{array}{r}.9000 \\
0.0000\end{array}$ \\
\hline$A D$ & $\begin{array}{r}.128 \\
.1313 \\
-.0102\end{array}$ & $\begin{array}{r}.121 \\
.1337 \\
-.0079\end{array}$ & $\begin{array}{c}.152 \\
.\end{array}$ & $\begin{array}{l}.900 \\
313 \\
102\end{array}$ & $\begin{array}{l}.100 \\
\text { HOMO } \\
.1337 \\
-.0079\end{array}$ & $\begin{array}{l}.14155 \\
.0133\end{array}$ & $\begin{array}{r}.3750 \\
0.0000\end{array}$ & $\begin{array}{r}.1000 \\
0.0000\end{array}$ & $\begin{array}{r}.9000 \\
0.0000\end{array}$ \\
\hline$A D$ & $\begin{array}{r}.195 \\
.2049 \\
-.0293\end{array}$ & $\begin{array}{r}.170 \\
.2127 \\
-.0215\end{array}$ & $\begin{array}{r}.273 \\
.2\end{array}$ & $\begin{array}{l}.900 \\
049 \\
293\end{array}$ & $\begin{array}{r}.100 \\
A D P C \\
.2203 \\
-.0139\end{array}$ & $\begin{array}{l}.23420 \\
.0003\end{array}$ & $\begin{array}{l}1.2500 \\
1.2475\end{array}$ & $\begin{array}{c}.1000 \\
.1003 \\
.\end{array}$ & $\begin{array}{l}.9000 \\
.9000\end{array}$ \\
\hline$A D$ & $\begin{array}{r}.383 \\
.4142 \\
-.0515\end{array}$ & $\begin{array}{r}.310 \\
.4377 \\
-.0280\end{array}$ & $\begin{array}{c}.620 \\
.\end{array}$ & $\begin{array}{l}.900 \\
142 \\
515\end{array}$ & $\begin{array}{c}.100 \\
A R N 2 \\
.4200 \\
-.0457\end{array}$ & $\begin{array}{l}.46555 \\
.0179\end{array}$ & $\begin{array}{r}3.7500 \\
.1000\end{array}$ & $\begin{array}{l}.1000 \\
.9000\end{array}$ & $\begin{array}{r}.9000 \\
3.0000\end{array}$ \\
\hline
\end{tabular}




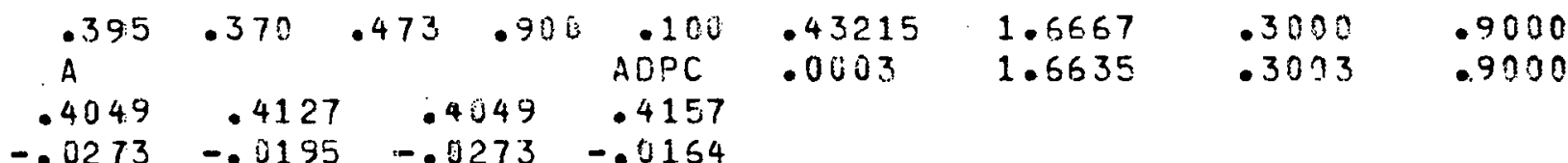

I $A D$

\begin{tabular}{|c|c|c|c|c|c|c|c|}
\hline$i^{-805}$ & .830 & .727 & $.91 j 0$ & $\begin{array}{l}.100 \\
A D P C\end{array}$ & $\begin{array}{l}.76580 \\
.0003\end{array}$ & $\begin{array}{l}1.2500 \\
1.2475\end{array}$ & $\begin{array}{r}.9000 \\
.8997\end{array}$ \\
\hline $\begin{array}{r}7951 \\
0293\end{array}$ & $\begin{array}{r}.787 \\
-721\end{array}$ & & $\begin{array}{l}51 \\
93\end{array}$ & $\begin{array}{r}.7797 \\
0139\end{array}$ & & & \\
\hline
\end{tabular}

IAD

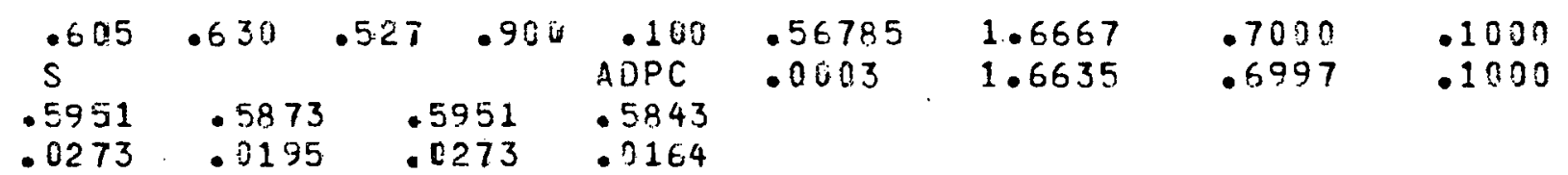

g

$A C$

$.658 \quad .500 \quad .781 \quad .906$

$$
\text { A. } 6261
$$

.6463 .06261

$.0139-.0072$

.100

ARN2

.63333

.0012

.1000

.9000

1.0000

$\therefore 0072$

.6340

$A C$

$.504 \quad .367 \quad .564 \quad .900$

.4950

$.5183 \quad .4950$

$.0183-.0050$ IRN?

.5000

.50000

.0003

.1000

.1003

.9000

.8998

2.0000

$-.0050$

- 0000

$A C$

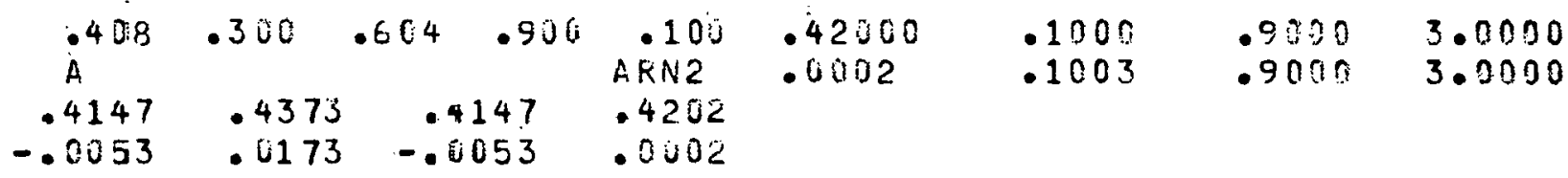


$A C$

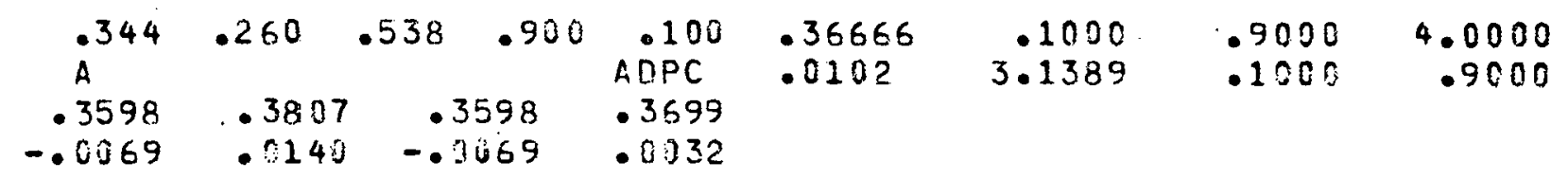

$A C$

$\begin{array}{rrrrrrrrr}.268 & .214 & .437 & .900 & .100 & .30000 & .1000 & .9000 & 6.0000 \\ A & & & .900 & A D C & .0135 & 2.3437 & .1000 & .9000 \\ .2894 & .3063 & .2894 & .3068 & & & & \end{array}$

$A C$

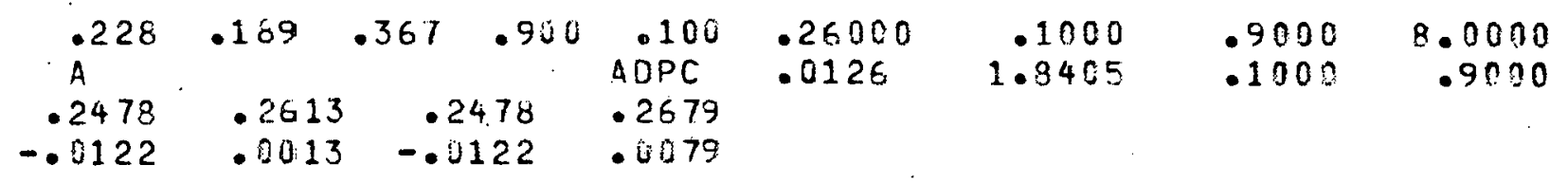

$\infty$

$\triangle C$

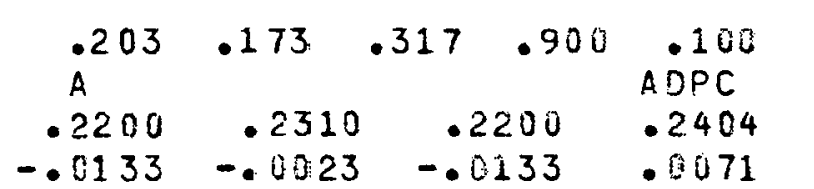

$\begin{array}{lrrr}.23333 & .1000 & .9000 & 10.0000 \\ .0103 & 1.4944 & .1000 & .9000\end{array}$

$A C$

$\begin{array}{rrrrrrrrr}.186 & .162 & .281 & .900 & .100 & .21429 & .1000 & .9000 & 12.0000 \\ A & & & & \text { ADPC } & .0082 & 1.2489 & .1000 & .9000 \\ . .2006 & .2097 & .2006 & .2202 & & & & \\ -.0137 & -.0046 & -.0137 & .0059 & & & \end{array}$

$A C$

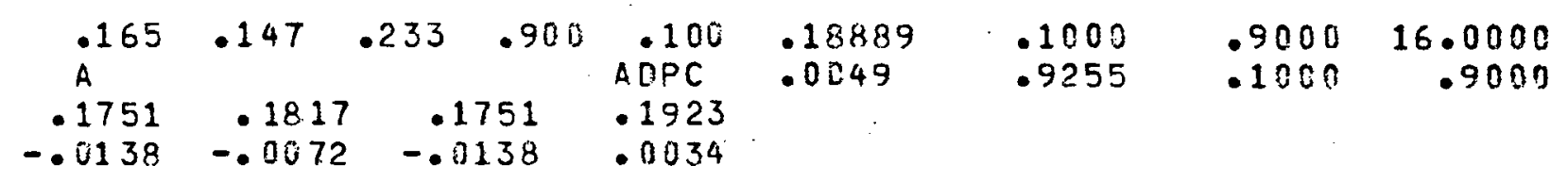


AC

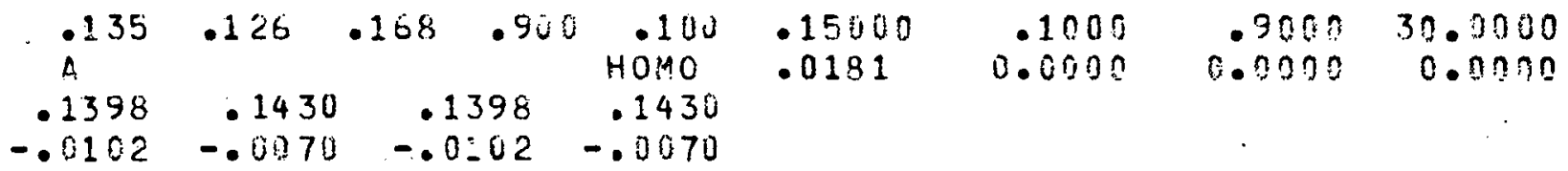

$A C$

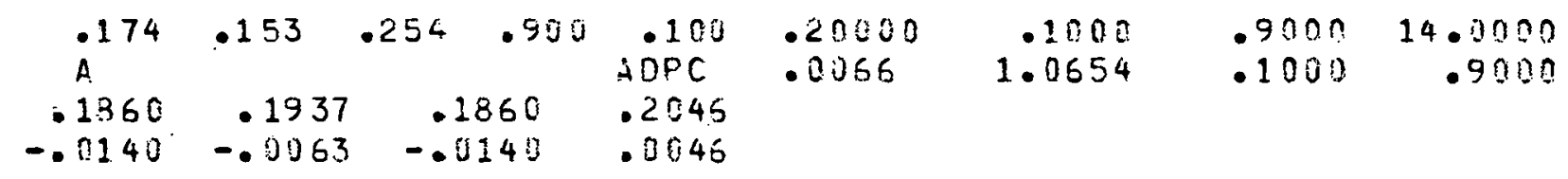

$A C A$

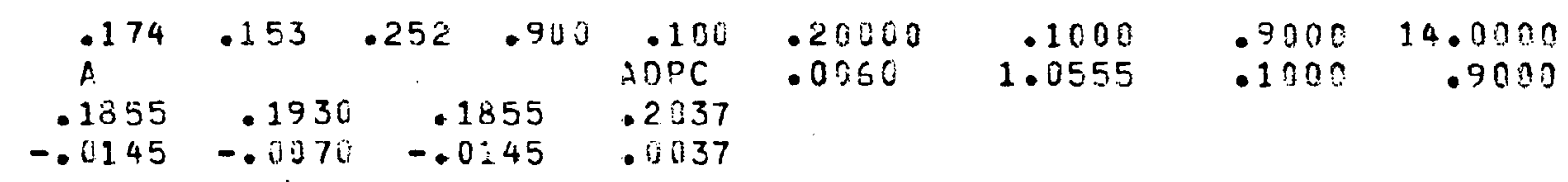

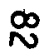

IAC

\begin{tabular}{|c|c|c|c|c|c|c|c|c|}
\hline $\begin{array}{l}.365 \\
.8502 \\
.0102\end{array}$ & $\begin{array}{l}.874 \\
.8570 \\
.0075\end{array}$ & $\begin{array}{r}.832 \\
.\end{array}$ & $\begin{array}{l}.900 \\
.02 \\
02\end{array}$ & $\begin{array}{l}.100 \\
\text { HOMO } \\
.8570 \\
.0070\end{array}$ & $\begin{array}{l}.85000 \\
.0181\end{array}$ & $\begin{array}{r}.9000 \\
0.0000\end{array}$ & $\begin{array}{r}1000 \\
0.0000\end{array}$ & $\begin{array}{r}30.0000 \\
0.0000\end{array}$ \\
\hline
\end{tabular}

IAC

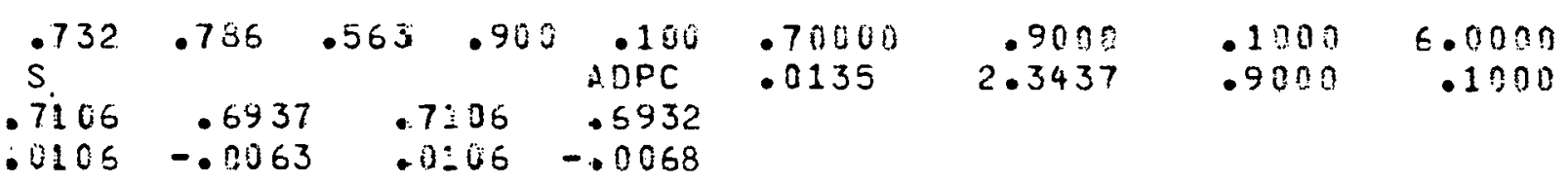

TSX

$\begin{array}{llllllll}.513 & .500 & .535 & .900 & .100 & .50000 & & \\ 4 & & & .090 & .0144 & 0.0000 & 0.0000 & 0.0000 \\ .5134 & .5160 & .5134 & .5160 & & & & \\ .0134 & .0163 & .0134 & .0160 & & & \end{array}$


TSX

$\begin{array}{llllllll}.540 & .600 & .519 & .900 & .100 & .60000 \\ S & & & A 0 P C & .0184 & 1.2496 & .6272 & .1000 \\ .5587 & .5530 & .5587 & .5479 & & & \\ -.0413 & -.0470 & -.0413 & -.0521 & \end{array}$

TSX

$\begin{array}{llllllll}.519 & .330 & .003 & .900 & .100 & .33000 & & \\ s & & & S F \times 1 & .0113 & 11.8571 & .2658 & -5.0000 \\ .3649 & .02840 & .3119 & .3544 & & & & \\ .0349 & -.03460 & -.0181 & .0244 & & & & \end{array}$

AN

\begin{tabular}{|c|c|c|c|c|c|c|c|}
\hline .695 & .500 & .8511 .000 & $\begin{array}{l}3.000 \\
\text { ARN2 }\end{array}$ & $\begin{array}{l}.66667 \\
.0003\end{array}$ & $\begin{array}{r}0.0000 \\
.0009\end{array}$ & $\begin{array}{r}1.0000 \\
.9996\end{array}$ & $\begin{array}{l}1.0000 \\
1.0000\end{array}$ \\
\hline $\begin{array}{l}.6567 \\
.0100\end{array}$ & $\begin{array}{l}.5824 \\
.0153\end{array}$ & $\begin{array}{r}.6567 \\
-.0100\end{array}$ & $\begin{array}{r}.6667 \\
-.0000\end{array}$ & & & & \\
\hline
\end{tabular}

$\stackrel{\infty}{\omega}$

AN

.589
.5640
-.0074

$.400 \quad .7881 .0000 .000$

0.0000

1.0000

1.5000

$-.0074$

.5923

ARN2

0.0000

1.000

1.5000

AN

\begin{tabular}{|c|c|c|c|}
\hline .505 & .333 & .7301 .000 & $\begin{array}{l}0.000 \\
\text { ARN2 }\end{array}$ \\
\hline 4935 & $\begin{array}{l}-5227 \\
-527\end{array}$ & $\begin{array}{r}.4935 \\
-\quad 0065\end{array}$ & .4999 \\
\hline
\end{tabular}

.50000

.0003

0.0000

0.0003

1.0000

.9998

2.0000

$\begin{array}{lll}-.0065 \quad .0227 & -.0065 \quad-.0001\end{array}$

AN

$\begin{array}{ccccccccc}.438 & .286 & .677 & 1.000 & 0.000 & .44444 & 0.0000 & 1.0000 & 2.5000 \\ \text { A } & & & \text { ARN2 } & .0002 & .0006 & .9989 & 2.5000 \\ .4380 & .4670 & .4380 & .0443 & & & & \\ -.0064 & .0226 & -.0064 & -.0002 & & & & & \end{array}$


AN

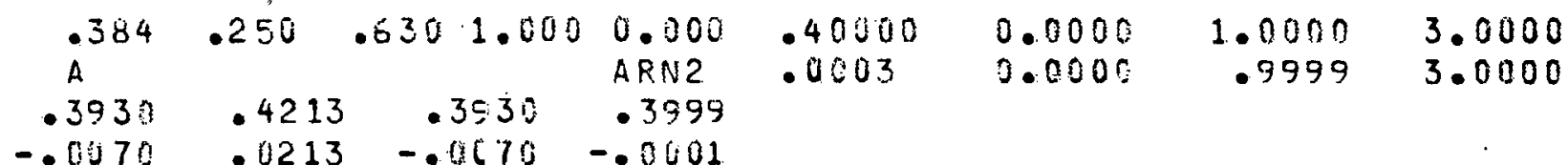

AN

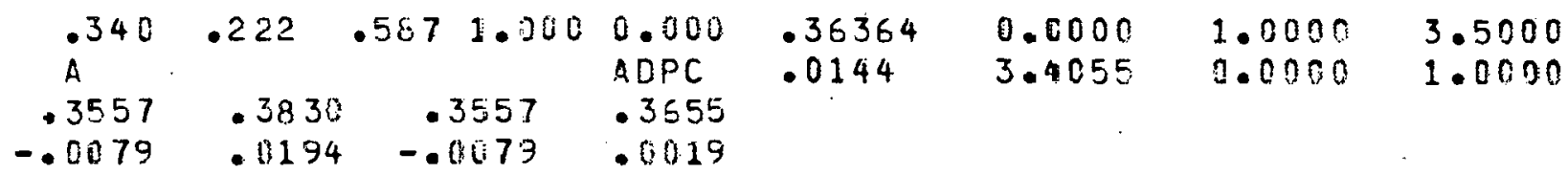

AN

\begin{tabular}{|c|c|c|c|c|c|c|c|}
\hline$\dot{A}^{.304}$ & .200 & $.54 \pi 1.000$ & $\begin{array}{l}0.000 \\
A D P C\end{array}$ & $\begin{array}{l}.33333 \\
.0125\end{array}$ & $\begin{array}{l}0.0000 \\
3.1348\end{array}$ & $\begin{array}{l}1.0000 \\
c .0000\end{array}$ & $\begin{array}{l}4.0000 \\
1.0000\end{array}$ \\
\hline $\begin{array}{l}.3243 \\
.6090\end{array}$ & $\begin{array}{l}.3503 \\
.0170\end{array}$ & $\begin{array}{r}.3243 \\
-.0490\end{array}$ & $\begin{array}{l}.3369 \\
.0036\end{array}$ & & & & \\
\hline
\end{tabular}

$\stackrel{\infty}{\infty}$

AN

$\begin{array}{ccccccccc}.253 & .167 & .485 & 1.500 & 0.000 & .28571 & 0.0000 & 1.0000 & 5.0000 \\ 0 & & & \text { A.DPC } & .0161 & 2.7273 & 0.0000 & 1.0000 \\ .2777 & .3017 & .2777 & .2959 & & & \end{array}$

AN

\begin{tabular}{|c|c|c|c|c|c|c|c|}
\hline$i^{.210}$ & .143 & $.42 z 1.000$ & $\begin{array}{l}0.000 \\
A D P C\end{array}$ & $\begin{array}{l}.25000 \\
.0169\end{array}$ & $\begin{array}{l}0.7000 \\
2.3475\end{array}$ & $\begin{array}{l}1.0000 \\
0.0000\end{array}$ & $\begin{array}{l}6.0000 \\
1.0000\end{array}$ \\
\hline $\begin{array}{r}.2372 \\
.0128\end{array}$ & $\begin{array}{r}.2583 \\
.0083\end{array}$ & $\begin{array}{r}.2372 \\
-.0128\end{array}$ & $\begin{array}{l}.2589 \\
.0089\end{array}$ & & & & \\
\hline
\end{tabular}

AN

$\begin{array}{ccccccccc}.159 & .111 & .334 & 1.000 & 0.000 & .20000 & 0.0000 & 2.0000 & 8.0000 \\ A & & & A 0 P C & .0162 & 1.3390 & 0.0000 & 1.0000 \\ .1344 & .2013 & .1844 & .2098 & & & & & \\ -.1156 & .0113 & -.0156 & .0098 & & & & \end{array}$


$A N$

$\begin{array}{ccccccccc}.128 & .091 & .272 & 1.000 & 0.000 & .16667 & 0.0000 & 1.0000 & 10.0000 \\ A & & & \text { ADPC } & .0135 & 1.4954 & 0.0000 & 1.0000 \\ .1499 & .1637 & .1499 & .1756 & & & & \end{array}$

AN

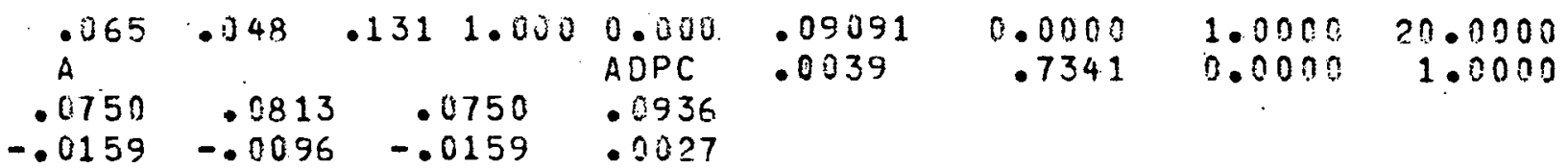

AN

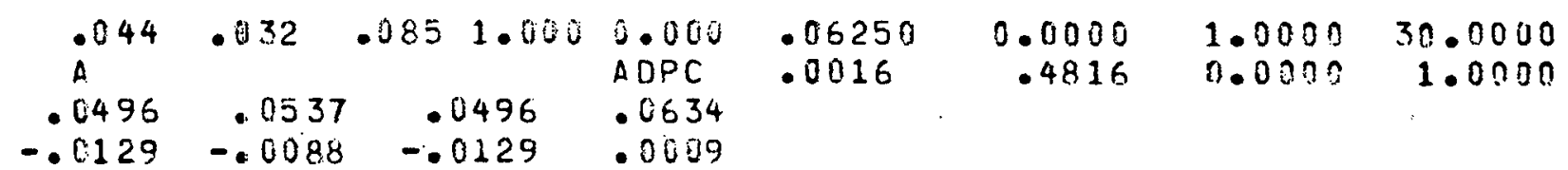

옹

$A D$

$\begin{array}{cccccccc}.816 & .4681 .000 & 1.000 & 0.000 & .71669 & 5.6550 & 0.0000 & 1.0000 \\ A & & & 3.06 & .1123 & 0.0000 & 1.0000 & 1.0000 \\ .7236 & .7613 & .7236 & .7236 & & & & \\ .0069 & .0446 & .0069 & .0069 & & & \end{array}$

$A D$

\begin{tabular}{|c|c|c|c|c|c|c|c|c|}
\hline $\begin{array}{l}.495 \\
.4580 \\
.0054\end{array}$ & $\begin{array}{r}.331 \\
.608 \\
.056\end{array}$ & $\begin{array}{l}1.000 \\
1 \\
1\end{array}$ & $\begin{array}{l}1.000 \\
.5580 \\
0.054\end{array}$ & $\begin{array}{l}0.000 \\
\text { B.L. } \\
.5580 \\
.0054\end{array}$ & $\begin{array}{l}.55261 \\
.1399\end{array}$ & $\begin{array}{l}4.7190 \\
0.0000\end{array}$ & $\begin{array}{l}0.0000 \\
1.0000\end{array}$ & $\begin{array}{l}1.0000 \\
1.5000\end{array}$ \\
\hline
\end{tabular}

$A D$

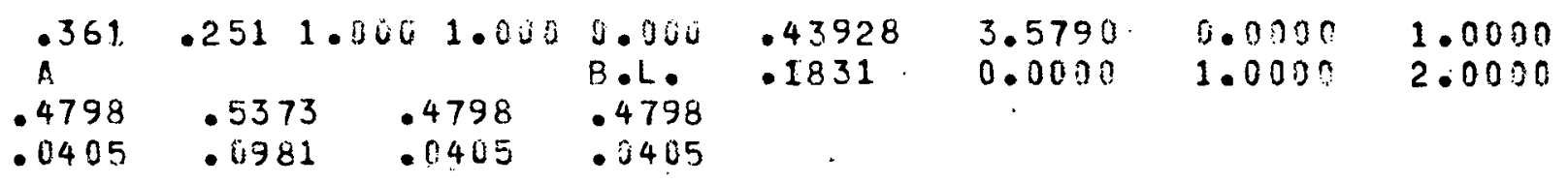


产

$A D$

$$
\begin{array}{rrrrr}
.216 & .155 & .45 T 1.000 & 0.000 \\
A & & & & \\
\text { ARN2 } & \\
.2530 & .2763 & .2530 & .2675 \\
-.0328 & -.0098 & -.0328 & -.0182
\end{array}
$$

$A D$

\begin{tabular}{|c|c|c|c|}
\hline$i^{141}$ & .102 & .2781 .000 & $\begin{array}{l}0.000 \\
A D P C\end{array}$ \\
\hline $\begin{array}{r}.1603 \\
-.0339\end{array}$ & $\begin{array}{r}.1737 \\
-.0205\end{array}$ & $\begin{array}{r}.1303 \\
-.0335\end{array}$ & $\begin{array}{r}.1826 \\
-.0116\end{array}$ \\
\hline
\end{tabular}

$A D$
$A D$

$A D$

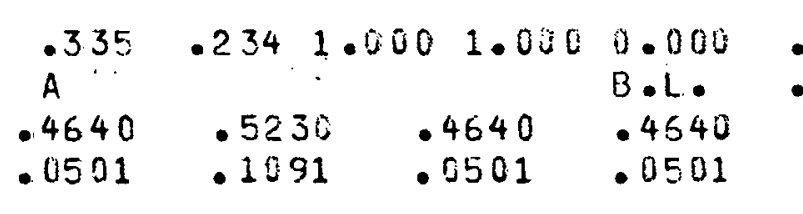

$A D$

\begin{tabular}{|c|c|c|c|}
\hline$i^{268}$ & .150 & .6141 .030 & $\begin{array}{l}5.000 \\
\text { ADPC }\end{array}$ \\
\hline $\begin{array}{r}3249 \\
0298\end{array}$ & - 3573 & $\begin{array}{r}.3449 \\
-0198\end{array}$ & .3548 \\
\hline
\end{tabular}
$.0427 \quad 3.31557$
3.4478

0.0000 0.0000

1.0000 1.0000

$\begin{array}{llll}.35666 & 2.9100 & 0.0000 & 1.0000\end{array}$ 1.00003 .5000

577

$28577 \quad 2.2070$ .0195 . 0.0000

0.0003 .8026

1.0000 4.0030 .0073

1.4580 1.5647

0.0030 0.0000

1.0000 1.0000

$\begin{array}{llll}.15943 & 1.1850 & 0.0000 & 1.0000 \\ .0045 & 1.2510 & 0.0000 & 1.0000\end{array}$




$\begin{array}{ccccc}.080 & .059 & .153 & 1.000 & 0.000 \\ A & & & & A D P C \\ .0902 & .0973 & .0902 & .1092 \\ -.0241 & -.0170 & -.0241 & -.0051\end{array}$

\section{.11430}

.0022

.8390

.8709

0.0000

0.0900

1.0000

$\begin{array}{lllll}.0041 & -.0170 & -.0241 & -.0351\end{array}$

$A D$
.07624

.0007

.5540

.5675

0.0000

0.0000

1.0000

1.0000

$\begin{array}{llll}.0591 & .0637 .0591 .0738\end{array}$

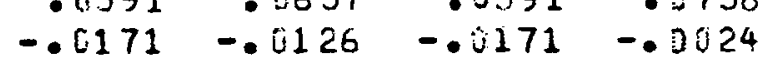




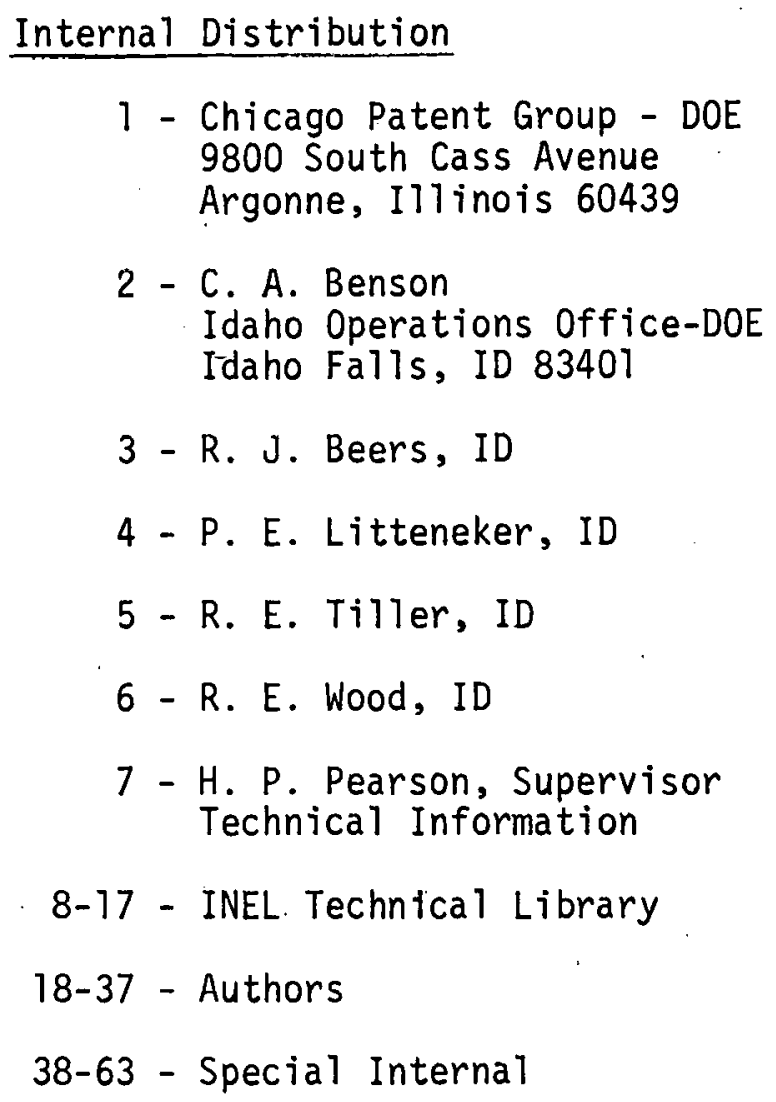

External Distribution

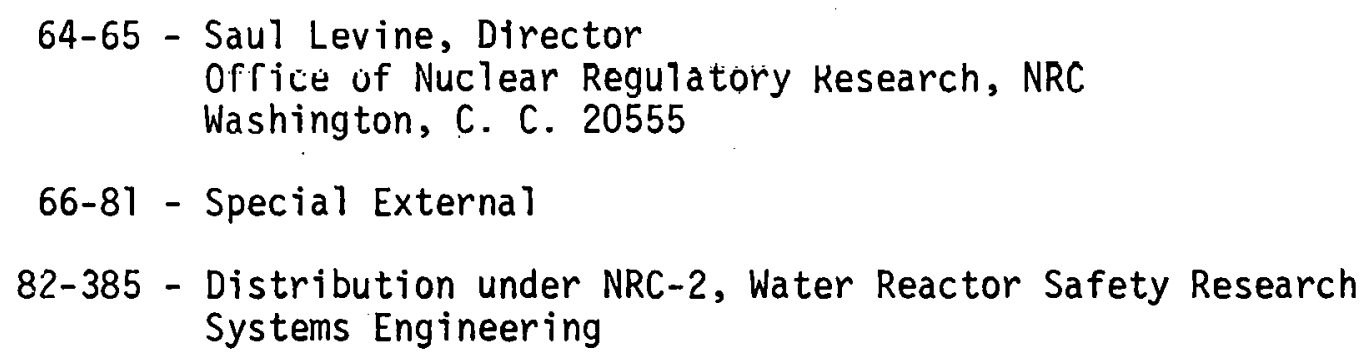

